\title{
Color Differences Highlight Concomitant Polymorphism of Chalcones
}

Charlie L. Hall ${ }^{1}$, Rui Guo ${ }^{2}$, Jason Potticary ${ }^{1}$, Matthew Cremeens ${ }^{3}$, Stephen D. Warren ${ }^{3}$, Iryna Andrusenko ${ }^{4}$, Mauro Gemmi ${ }^{4}$, Martijn A. Zwijnenburg ${ }^{2}$, Hazel A. Sparkes ${ }^{1}$, Natalie E. Pridmore ${ }^{1}$, Sarah L. Price ${ }^{2}$, Simon R. Hall ${ }^{1 *}$

1 University of Bristol, School of Chemistry, Cantock's Close, Bristol BS8 1TS, U.K.

2 Department of Chemistry, University College London, 20 Gordon Street, London WC1H OAJ, U.K.

3 Gonzaga University, 502 E. Boone Avenue, Spokane, WA 99258, United States.

4 Center for Nanotechnology Innovation@NEST, Istituto Italiano di Tecnologia, Piazza San Silvestro 12, Pisa, Italy.

\section{Table of Contents}

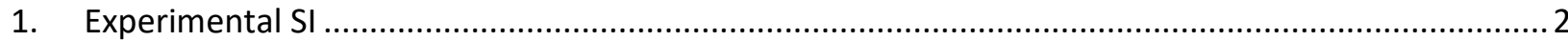

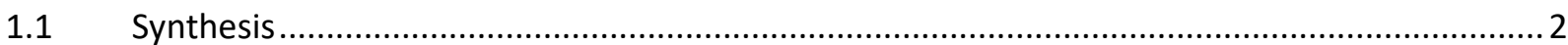

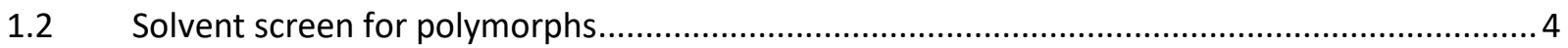

1.2.1 Crystallization within a static magnetic field .............................................................. 6

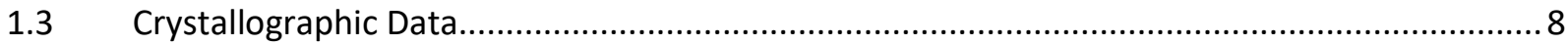

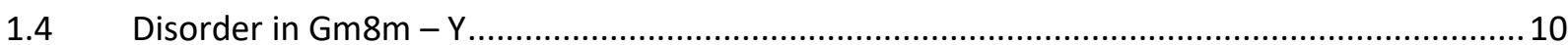

$1.5 \quad$ Low Temperature Powder Diffraction Data ...................................................................... 12

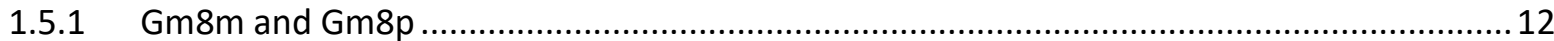

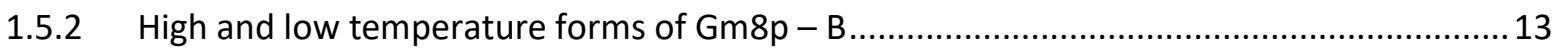

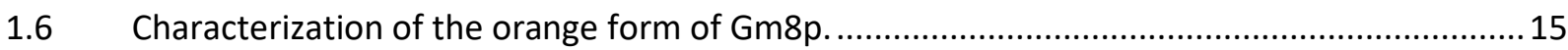

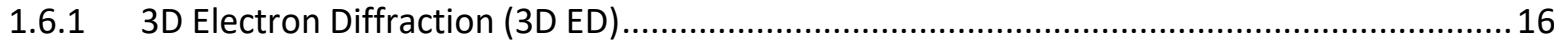

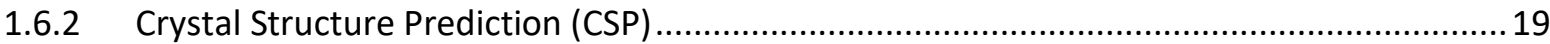

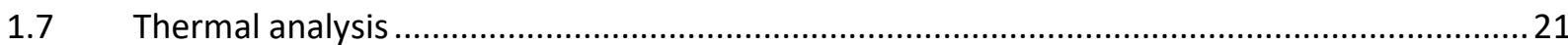

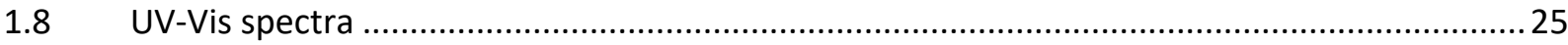

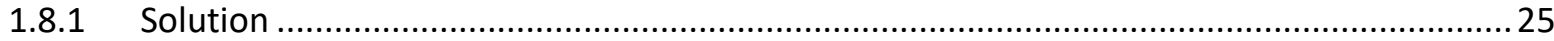

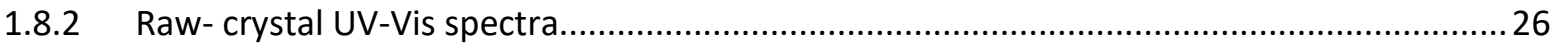

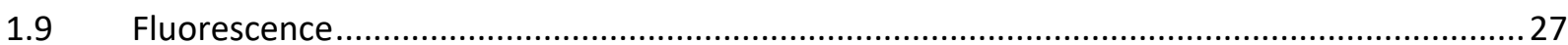

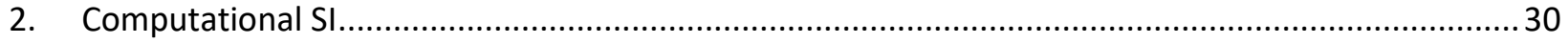

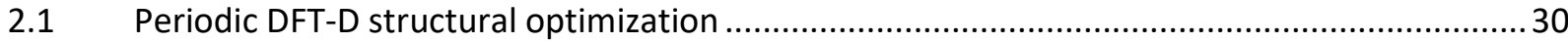

2.2 Periodic DFT-D relative energies using various dispersion corrections ..................................30 
2.3 Phonon dispersion and free energy calculations

2.4 Example of electronic band structure $(\mathrm{Gm} 8 \mathrm{~m}-\mathrm{Y})$ as calculated by periodic PBE calculations 33

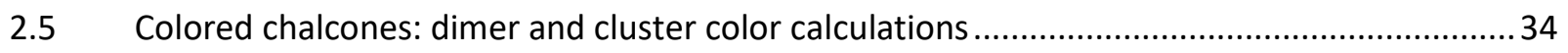

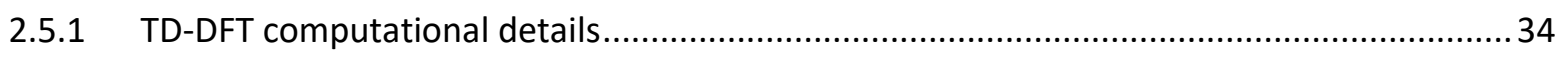

2.5.2 TD-DFT calculations of UV-Vis spectra of monomers in crystals .......................................34

2.5.3 TD-DFT calculations of UV-Vis spectra of unique dimer motifs in crystals .......................... 40

2.5.4 Cumulative effect on UV-Vis spectra of stacks of dimers ..............................................61

2.6 Calculation of diamagnetic susceptibility tensors .......................................................... 71

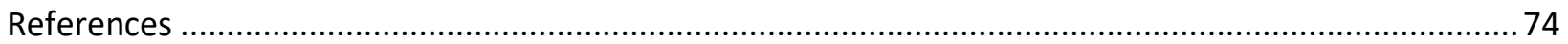

\section{Experimental SI}

\subsection{Synthesis}

Gm8m ((E)-1-[3-(dimethylamino)phenyl]-3-(3-nitrophenyl)prop-2-en-1-one or 3'-dimethylamino-3nitrochalcone):

3-Nitrobenzaldehyde (3 mmol) and 3'-dimethylaminoacetophenone ( $3 \mathrm{mmol}$ ) were each dissolved in $95 \%$ ethanol ( $1 \mathrm{~mL}$ ). Each solution or mixture was cooled on ice for 3-5 minutes. To the acetophenone mixture, $0.30 \mathrm{~mL}$ of $50 \% \mathrm{NaOH}$ (aq) was added. While the acetophenone/base mixture was vigorously stirred, the aldehyde mixture was added vigorously mixed for another 30 minutes. The reaction was quenched with $10 \mathrm{~mL}$ of ice water. Solids were collected by vacuum filtration and washed with cold water. Chalcones were recrystallized with methanol or ethanol. ${ }^{1} \mathrm{H} \mathrm{NMR}(400 \mathrm{MHz}$, chloroform-d) shifts are in ppm and were referenced to TMS: $8.48(\mathrm{t}, J=2.1 \mathrm{~Hz}, 1 \mathrm{H}), 8.24$ (ddd, $J=8.2,2.1,1.0 \mathrm{~Hz}, 1 \mathrm{H}), 7.91(\mathrm{~d}, J=7.7 \mathrm{~Hz}, 1 \mathrm{H})$, $7.80(\mathrm{~d}, J=15.8 \mathrm{~Hz}, 1 \mathrm{H}), 7.68-7.55(\mathrm{~m}, 2 \mathrm{H}), 7.45-7.28(\mathrm{~m}, 3 \mathrm{H}), 6.97(\mathrm{dt}, J=7.5,2.3 \mathrm{~Hz}, 1 \mathrm{H}), 3.03(\mathrm{~s}, 6 \mathrm{H})$. ${ }^{13} \mathrm{C} \mathrm{NMR}\left(100 \mathrm{MHz}\right.$, chloroform- $d$ ) shifts are in ppm and were referenced to $\mathrm{CDCl}_{3}: 190.39,150.86,148.76$, $141.16,138.42$, 136.91, 134.29, 130.06, 129.34, 125.23, 124.56, 122.48, 117.33, 116.91, 111.55, and 40.57.<smiles>CC(=O)c1cccc(N(C)C)c1</smiles>

Scheme 1 The aldol condensation reaction between 3-nitrobenzaldehyde and 3'-dimethylaminoacetophenone to produce Gm8m. 
Gm8p ((E)-1-[3-(dimethylamino)phenyl]-3-(4-nitrophenyl)prop-2-en-1-one or 3'dimethylamino-4nitrochalcone):

4-Nitrobenzaldehyde ( $3 \mathrm{mmol}$ ) and 3 '-dimethylaminoacetophenone ( $3 \mathrm{mmol}$ ) were each dissolved in $95 \%$ ethanol ( $1 \mathrm{~mL}$ ). Each solution or mixture was cooled on ice for 3-5 minutes. To the acetophenone mixture, $0.30 \mathrm{~mL}$ of $50 \% \mathrm{NaOH}(\mathrm{aq})$ was added. While the acetophenone/base mixture was vigorously stirred, the aldehyde mixture was added vigorously mixed for another 30 minutes. The reaction was quenched with $10 \mathrm{~mL}$ of ice water. Solids were collected by vacuum filtration and washed with cold water. Chalcones were recrystallized with methanol or ethanol. ${ }^{1} \mathrm{H} N M R(400 \mathrm{MHz}$, chloroform- $d)$ are in ppm and were referenced to TMS: $8.26(\mathrm{~d}, J=8.8 \mathrm{~Hz}, 2 \mathrm{H}), 7.79(\mathrm{~d}, J=15.7 \mathrm{~Hz}, 1 \mathrm{H}), 7.77(\mathrm{~d}, J=8.8 \mathrm{~Hz}, 2 \mathrm{H}), 7.63(\mathrm{~d}, J=$ $15.7 \mathrm{~Hz}, 1 \mathrm{H}), 7.42-7.22(\mathrm{~m}, 3 \mathrm{H}), 6.97$ (ddd, $J=7.9,2.8,1.5 \mathrm{~Hz}, 1 \mathrm{H}), 3.03(\mathrm{~s}, 6 \mathrm{H}) .{ }^{13} \mathrm{C} \mathrm{NMR}(100 \mathrm{MHz}$, chloroform- $d$ ) shifts are in ppm and were referenced to $\mathrm{CDCl}_{3}$ : 190.40, 150.90, 148.52, 141.36, 141.05, $138.40,129.37,128.98,126.38,124.27,117.40,116.89,111.56$, and 40.58 .<smiles>CC(=O)c1cccc(N(C)C)c1</smiles>

Scheme 2 The aldol condensation reaction between 4-nitrobenzaldehyde and 3'-dimethylaminoacetophenone to produce Gm8p.

NMR data was collected with a Brooker 400 model using TopSpin software. The data was plotted and analyzed using MesReNova.
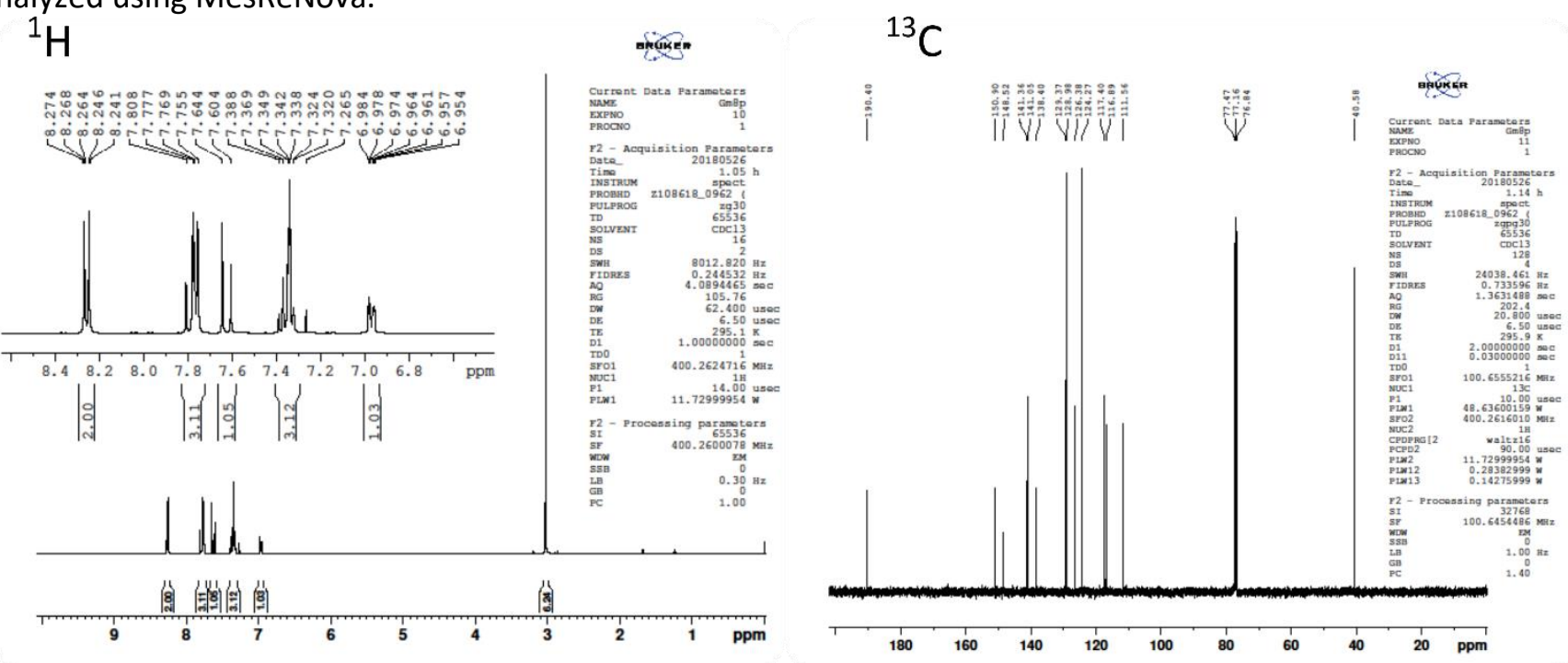

Figure $1^{1} \mathrm{H} \&{ }^{13} \mathrm{C}$ NMR of a $40 \mathrm{mg} \cdot \mathrm{mL}^{-1}$ solution of $\mathrm{Gm} 8 \mathrm{~m}$ in $\mathrm{CDCl}_{3}$. 

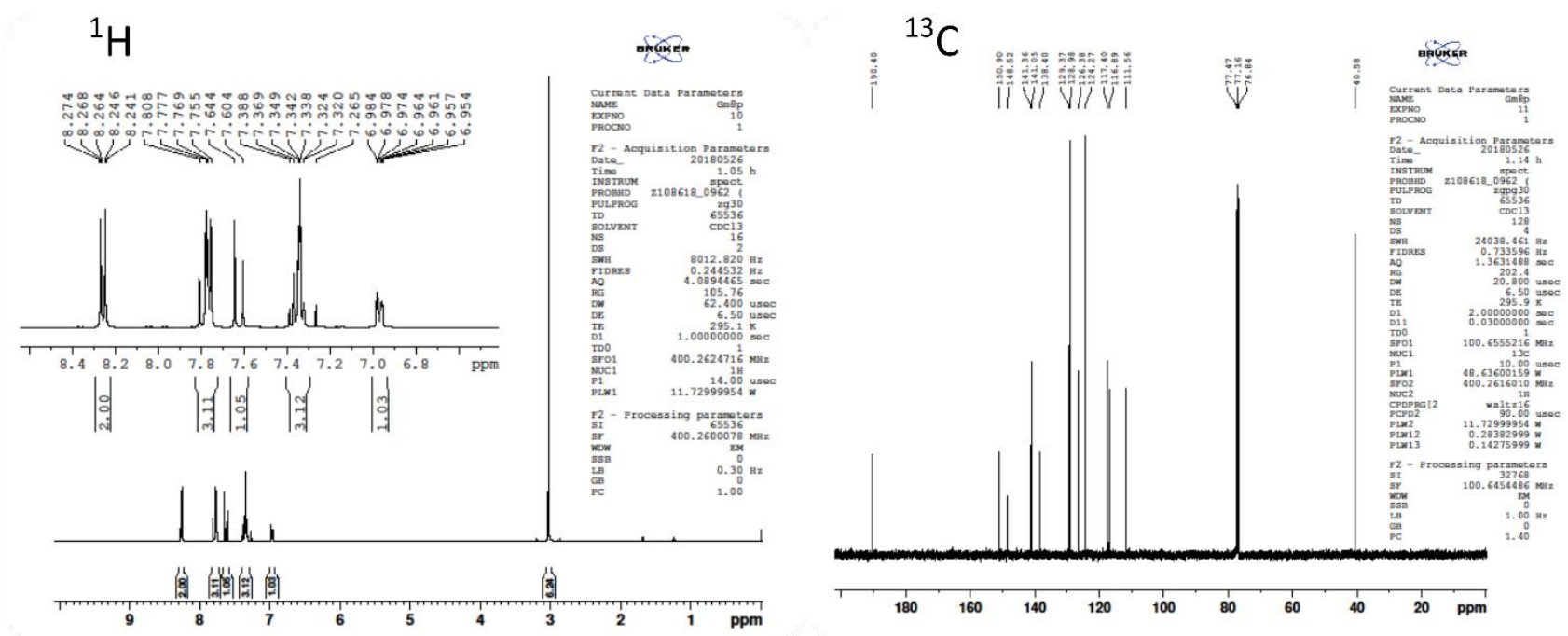

Figure $2^{1} \mathrm{H} \&{ }^{13} \mathrm{C} N M R$ of a $40 \mathrm{mg} \cdot \mathrm{mL}^{-1}$ solution of $\mathrm{Gm} 8 \mathrm{p}$ in $\mathrm{CDCl}_{3}$.

\subsection{Solvent screen for polymorphs}

Crystallization was carried out via evaporation of different solvents. Each crystallization vessel was covered with parafilm with a needle hole. Each solution was weighed out and filtered into clean crystallization vessels using $0.2 \mu \mathrm{m}$ PTFE filters. Solutions were left at room temperature to evaporate. Table 1-Table 6 show the results of the systematic solvent screen. Colors in table represent the polymorphs produced to make trends easier to see. Polymorphs were assigned by color and morphology, and crystals of distinct morphologies were characterized by their x-ray diffraction pattern.

Three different crystallization vessels were assessed: test tubes $-10 \mathrm{~mm}$ diameter $\times 50 \mathrm{~mm}$ height; vials $-10 \mathrm{~mm}$ diameter $\times 50 \mathrm{~mm}$ height (flat bottom); petri dish $-100 \mathrm{~mm}$ diameter $\times 10 \mathrm{~mm}$ height.

For the red polymorph of Gm8p there are 3 distinct morphologies (SI Figure 3):

- $R(N)$ - Needles formed

- $R(P)-A$ polycrystalline powder is formed of sizes $<10$ microns

- $\mathrm{R}-\mathrm{A}$ block-like crystal is formed

Any amorphous results are denoted 'Am'. Gm8p gave a $3^{\text {rd }}$ polymorph, denoted 3, which is orange and could not grow to single crystals suitable for SXRD or a highly crystalline powder pattern. The limited characterization of this polymorph is in SI 1.6. 


\begin{tabular}{|l|l|l|l|l|}
\hline Gm8m & \multicolumn{2}{|l|}{ Test Tube } & \multicolumn{2}{l|}{} \\
\hline Concentration & \multicolumn{2}{|l|}{$5 \mathrm{mg} \cdot \mathrm{mL}^{-1}$} & \multicolumn{2}{l|}{$10{\mathrm{mg} \cdot \mathrm{mL}^{-1}}^{-1}$} \\
\hline Methanol & $\mathrm{Y}$ & $\mathrm{Y}$ & & \\
\hline Ethanol & $\mathrm{Y}$ & $\mathrm{Y}$ & & \\
\hline Chloroform & $\mathrm{O} / \mathrm{Y}$ & $\mathrm{O} / \mathrm{Y}$ & $\mathrm{O} / \mathrm{Y}$ & $\mathrm{O} / \mathrm{Y}$ \\
\hline Toluene & $\mathrm{Am}$ & $\mathrm{Am}$ & $\mathrm{Am}$ & $\mathrm{Am}$ \\
\hline Ethyl Acetate & $\mathrm{O}$ & $\mathrm{O} / \mathrm{Y}$ & $\mathrm{O}$ & $\mathrm{O}$ \\
\hline Tetrahydrofuran & $\mathrm{O}$ & $\mathrm{O}$ & $\mathrm{O} / \mathrm{Y}$ & $\mathrm{O} / \mathrm{Y}$ \\
\hline Acetone & $\mathrm{O}$ & $\mathrm{O}$ & $\mathrm{Y}$ & $\mathrm{Y}$ \\
\hline
\end{tabular}

Table 1 Results for the solvent screen of $\mathrm{Gm8m}$ recrystallized in a variety of solvents via evaporation in test tubes.

\begin{tabular}{|l|l|l|l|l|}
\hline Gm8m & \multicolumn{2}{|l|}{ Vial } & \multicolumn{2}{l|}{} \\
\hline Concentration & \multicolumn{2}{|l|}{$5{\mathrm{mg} \cdot \mathrm{mL}^{-1}}^{2} 10{\mathrm{mg} \cdot \mathrm{mL}^{-1}}^{-1}$} & \multicolumn{2}{l|}{} \\
\hline Methanol & $\mathrm{O} / \mathrm{Y}$ & $\mathrm{O} / \mathrm{Y}$ & & \\
\hline Ethanol & $\mathrm{O} / \mathrm{Y}$ & $\mathrm{O} / \mathrm{Y}$ & & \\
\hline Chloroform & $\mathrm{O} / \mathrm{Y}$ & $\mathrm{O} / \mathrm{Y}$ & $\mathrm{O} / \mathrm{Y}$ & $\mathrm{O} / \mathrm{Y}$ \\
\hline Toluene & $\mathrm{O}$ & $\mathrm{O}$ & $\mathrm{O}$ & $\mathrm{O}$ \\
\hline Ethyl Acetate & $\mathrm{O}$ & $\mathrm{O}$ & $\mathrm{O}$ & $\mathrm{O}$ \\
\hline Tetrahydrofuran & $\mathrm{O}$ & $\mathrm{O}$ & $\mathrm{O}$ & $\mathrm{O}$ \\
\hline Acetone & $\mathrm{O}$ & $\mathrm{O}$ & $\mathrm{Y}$ & $\mathrm{Y}$ \\
\hline
\end{tabular}

Table 2 Results for the solvent screen of $\mathrm{Gm} 8 \mathrm{~m}$ recrystallized in a variety of solvents via evaporation in vials.

\begin{tabular}{|l|l|l|l|l|}
\hline Gm8p & \multicolumn{2}{|l|}{ Test Tube } & \multicolumn{2}{l|}{} \\
\hline Concentration & \multicolumn{2}{|l|}{5 mg.mL } & \multicolumn{2}{l|}{$10{\mathrm{mg} \cdot \mathrm{mL}^{-1}}^{-1}$} \\
\hline Methanol & $\mathrm{R}(\mathrm{N})$ & $\mathrm{R}(\mathrm{N})$ & & \\
\hline Ethanol & & & & \\
\hline Chloroform & $\mathrm{R}(\mathrm{P})$ & $\mathrm{R}(\mathrm{P})$ & $\mathrm{R}(\mathrm{P})$ & $\mathrm{R}(\mathrm{P})$ \\
\hline Toluene & $\mathrm{R}(\mathrm{N})$ & $\mathrm{R}(\mathrm{N})$ & $\mathrm{R}(\mathrm{N})$ & $\mathrm{R}(\mathrm{N})$ \\
\hline Ethyl Acetate & 3 & $\mathrm{R}(\mathrm{P})$ & 3 & 3 \\
\hline Tetrahydrofuran & $\mathrm{R}$ & $\mathrm{R}$ & $\mathrm{R}$ & $\mathrm{R}$ \\
\hline Acetone & 3 & 3 & $\mathrm{R}(\mathrm{N})$ & $\mathrm{R}(\mathrm{N})$ \\
\hline
\end{tabular}

Table 3 Results for the solvent screen on Gm8p recrystallized in a variety of solvents via evaporation in test tubes. 


\begin{tabular}{|l|l|l|l|l|}
\hline Gm8p & \multicolumn{2}{|l|}{ Vial } & \multicolumn{2}{l|}{} \\
\hline Concentration & \multicolumn{2}{|l|}{5 mg.mL } & \multicolumn{2}{l|}{$10 \mathrm{mg}^{-1} \mathrm{~mL}^{-1}$} \\
\hline Methanol & $\mathrm{R}(\mathrm{P})$ & $\mathrm{R}(\mathrm{N})$ & & \\
\hline Ethanol & & & & \\
\hline Chloroform & $\mathrm{R}(\mathrm{P})$ & $\mathrm{R}(\mathrm{P})$ & $\mathrm{R}(\mathrm{P})$ & $\mathrm{R}(\mathrm{P})$ \\
\hline Toluene & $\mathrm{R}(\mathrm{N})$ & $\mathrm{R}(\mathrm{N})$ & $\mathrm{R} / \mathrm{B}$ & $\mathrm{R} / \mathrm{B}$ \\
\hline Ethyl Acetate & $\mathrm{R}(\mathrm{N})$ & $\mathrm{R}(\mathrm{N})$ & $\mathrm{R}(\mathrm{N})$ & $\mathrm{R}(\mathrm{N})$ \\
\hline Tetrahydrofuran & 3 & 3 & $R$ & $R$ \\
\hline Acetone & 3 & $\mathrm{R}(\mathrm{N})$ & $\mathrm{R}(\mathrm{N})$ & $\mathrm{R}(\mathrm{N})$ \\
\hline
\end{tabular}

Table 4 Results for the solvent screen on Gm8p recrystallized in a variety of solvents via evaporation in vials.

\begin{tabular}{|l|l|l|l|l|l|l|l|l|l|}
\hline Gm8m & \multicolumn{4}{|l|}{ Patri Dish } & \multicolumn{4}{|l|}{$10 \mathrm{mg}^{-1} \mathrm{~mL}^{-1}$} & \multicolumn{4}{|l|}{} \\
\hline Acetone & $\mathrm{Y} / \mathrm{O}$ & $\mathrm{Y} / \mathrm{O}$ & $\mathrm{Y} / \mathrm{O}$ & $\mathrm{Y}$ & $\mathrm{Y}$ & $\mathrm{Y} / \mathrm{O}$ & $\mathrm{Y}$ & $\mathrm{O}$ & $\mathrm{Y} / \mathrm{O}$ \\
\hline
\end{tabular}

Table 5 Results for the crystallization of $\mathrm{Gm} 8 \mathrm{~m}$ via evaporation from acetone in petri dishes.

\begin{tabular}{|c|c|c|c|c|c|c|c|c|c|}
\hline Gm8p & \multicolumn{3}{|c|}{ Patri Dish } & \multicolumn{3}{|c|}{$10 \mathrm{mg} \cdot \mathrm{mL}^{-1}$} & & & \\
\hline Acetone & B & $R / B$ & $\mathrm{R} / \mathrm{B}$ & B & B & $R / B$ & B & B & B \\
\hline
\end{tabular}

Table 6 Results for the crystallization of Gm8p via evaporation from ethanol in petri dishes.

a)

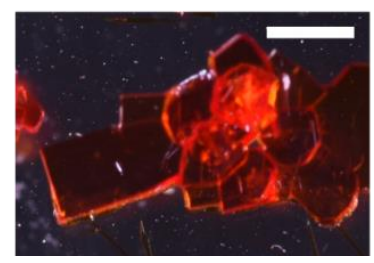

b)

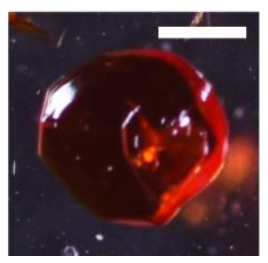

c)

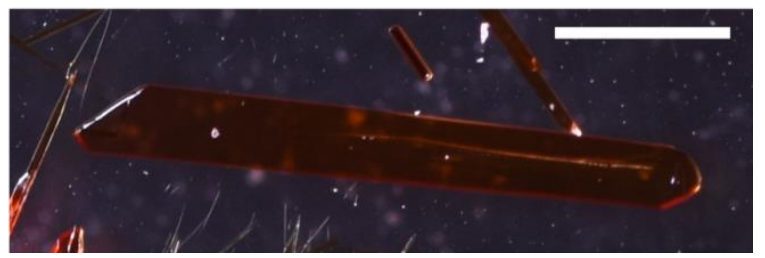

Figure 3 Morphologies of Gm8p - R a) Plate-like morphology b) Block-like morphology c) Needle morphology. Scale bars represent $1 \mathrm{~mm}$.

\subsubsection{Crystallization within a static magnetic field}

\section{Evaporative crystallization of Gm8m}

A series of evaporative experiments were carried out using either ethanol or acetone as a solvent, with applied static fields between 0-2.7 T. $1 \mathrm{~mL}$ of $5 \mathrm{mg} \cdot \mathrm{mL}^{-1}$ solution was evaporated over 24 hours from $1 \mathrm{~cm}$ diameter test tubes. From ethanol there was no indication of a change in the crystal growth via evaporation with increasing field.

\section{Cooling growth of Gm8m}

A series of experiments were carried out to grow crystals of $\mathrm{Gm} 8 \mathrm{~m}$ and $\mathrm{Gm} 8 \mathrm{p}$ via slow cooling of a 9 $\mathrm{mg} \cdot \mathrm{mL}^{-1}$ ethanol solution from $65^{\circ} \mathrm{C}$ to $0^{\circ} \mathrm{C}$. Initially a sealed system was used to cool the system, utilizing a copper block cooled via water pumped from a heat bath. However, the production of a supersaturation 
in this manner did not lead to crystallization, even after being left for time periods up to a week. To allow greater supersaturations, the cooled samples in the magnetic field were allowed to evaporate while still in the field, until small crystals started to appear. Growth in the manner allowed crystals to form over a period of 2-3 days.

Growth with applied fields varying from 0-2 T did not show any change in the polymorph produced. In general under all applied magnetic fields, Gm8m - O formed from experiments. In Gm8p, the red polymorph was always seen in the needle-like morphology.

\begin{tabular}{|c|c|c|c|c|c|c|}
\hline $\begin{array}{l}\text { Magnetic } \\
\text { Field / T }\end{array}$ & Run 1 & Run 2 & Run 3 & Run 4 & Run 5 & Run 6 \\
\hline 0 & $\mathrm{Gm} 8 \mathrm{~m}-\mathrm{O}$ & $\mathrm{Gm} 8 \mathrm{~m}-\mathrm{O}$ & $\mathrm{Gm} 8 \mathrm{~m}-\mathrm{O}$ & $\mathrm{Gm} 8 \mathrm{~m}-\mathrm{O}$ & $\mathrm{Gm} 8 \mathrm{~m}-\mathrm{O}$ & $\mathrm{Gm} 8 \mathrm{~m}-\mathrm{C}$ \\
\hline 0.5 & $\mathrm{Gm} 8 \mathrm{~m}-\mathrm{O}$ & $\mathrm{Gm} 8 \mathrm{~m}-\mathrm{O}$ & $\mathrm{Gm} 8 \mathrm{~m}-\mathrm{O}$ & $\mathrm{Gm} 8 \mathrm{~m}-\mathrm{O}$ & & \\
\hline 1 & $\mathrm{Gm} 8 \mathrm{~m}-\mathrm{O}$ & $\mathrm{Gm} 8 \mathrm{~m}-\mathrm{O}$ & $\mathrm{Gm} 8 \mathrm{~m}-\mathrm{O}$ & $\mathrm{Gm} 8 \mathrm{~m}-\mathrm{O}$ & & \\
\hline 1.5 & $\mathrm{Gm} 8 \mathrm{~m}-\mathrm{O}$ & $\mathrm{Gm} 8 \mathrm{~m}-\mathrm{O}$ & $\mathrm{Gm} 8 \mathrm{~m}-\mathrm{O}$ & $\mathrm{Gm} 8 \mathrm{~m}-\mathrm{O}$ & & \\
\hline 1.6 & $G m 8 m-Y$ & $\mathrm{Gm} 8 \mathrm{~m}-\mathrm{Y}$ & $\mathrm{Gm} 8 \mathrm{~m}-\mathrm{O}$ & $\mathrm{Gm} 8 \mathrm{~m}-\mathrm{O}$ & $\mathrm{Gm} 8 \mathrm{~m}-\mathrm{O}$ & $\mathrm{Gm} 8 \mathrm{~m}-\mathrm{C}$ \\
\hline
\end{tabular}

Table 7 Summary of magnetic field cooling experiments run on $\mathrm{Gm} 8 \mathrm{~m}$ at applied fields between 0-1.6 $\mathrm{T}$.

\begin{tabular}{|l|l|l|l|l|l|l|}
\hline $\begin{array}{l}\text { Magnetic } \\
\text { Field / T }\end{array}$ & Run 1 & Run 2 & Run 3 & Run 4 & Run 5 & Run 6 \\
\hline 0 & Gm8p-R & Gm8p-R & Gm8p-R & Gm8p-R & Gm8p-R & Gm8p-R \\
\hline 0.5 & Gm8p-R & Gm8p-R & & & & \\
\hline 1 & Gm8p-R & Gm8p-R & & & & \\
\hline 1.5 & Gm8p-R & Gm8p-R & & & & \\
\hline 1.6 & Gm8p-R & Gm8p-R & & & & \\
\hline
\end{tabular}

Table 8 Summary of magnetic field cooling experiments run on $\mathrm{Gm} 8 \mathrm{p}$ at applied fields between 0-1.6T. 


\subsection{Crystallographic Data}

\begin{tabular}{|c|c|c|c|c|}
\hline Identification code & Gm8m - Y & Gm8m - 0 & Gm8p-B & Gm8p-R \\
\hline CCDC Identifier & 1983905 & 1983906 & 1983902 & 1983910 \\
\hline Empirical formula & $\mathrm{C}_{17} \mathrm{H}_{16} \mathrm{~N}_{2} \mathrm{O}_{3}$ & $\mathrm{C}_{17} \mathrm{H}_{16} \mathrm{~N}_{2} \mathrm{O}_{3}$ & $\mathrm{C}_{17} \mathrm{H}_{16} \mathrm{~N}_{2} \mathrm{O}_{3}$ & $\mathrm{C}_{17} \mathrm{H}_{16} \mathrm{~N}_{2} \mathrm{O}_{3}$ \\
\hline Formula weight & 296.32 & 296.32 & 296.32 & 296.32 \\
\hline Temperature/K & $100(2)$ & $100(2)$ & $100(2)$ & $100(2)$ \\
\hline Crystal system & monoclinic & triclinic & monoclinic & monoclinic \\
\hline Space group & $P 2_{1} / c$ & $P-1$ & $P 2_{1} / c$ & $P 2_{1} / n$ \\
\hline$a / \AA ̊$ & $12.5686(6)$ & $8.3376(3)$ & $7.8173(5)$ & $8.3419(2)$ \\
\hline b/Å & $6.2878(4)$ & $9.4304(3)$ & $13.4524(8)$ & $8.0686(2)$ \\
\hline$c / \AA ̊$ & $18.1107(10)$ & $10.0957(3)$ & $13.7886(7)$ & $21.6440(5)$ \\
\hline$\alpha /^{\circ}$ & 90 & $102.249(2)$ & 90 & 90 \\
\hline$\beta /^{\circ}$ & $92.988(4)$ & $102.697(2)$ & $97.479(4)$ & $91.1060(15)$ \\
\hline$\gamma / /^{\circ}$ & 90 & $104.847(2)$ & 90 & 90 \\
\hline Volume/ $/ \AA^{3}$ & $1429.32(14)$ & $717.55(4)$ & 1437.69(15) & $1456.53(6)$ \\
\hline $\mathrm{Z}$ & 4 & 2 & 4 & 4 \\
\hline$\rho_{\text {calc }} \mathrm{g} / \mathrm{cm}^{3}$ & 1.377 & 1.371 & 1.369 & 1.351 \\
\hline$\mu / \mathrm{mm}^{-1}$ & 0.096 & 0.095 & 0.095 & 0.094 \\
\hline$F(000)$ & 624 & 312 & 624 & 624 \\
\hline Crystal size $/ \mathrm{mm}^{3}$ & $\begin{array}{l}0.716 \times 0.257 \times 0.15 \\
7\end{array}$ & $\begin{array}{l}0.624 \times 0.434 \times 0.42 \\
8\end{array}$ & $0.44 \times 0.263 \times 0.19$ & $\begin{array}{l}0.354 \times 0.296 \times 0.14 \\
4\end{array}$ \\
\hline Radiation & $\begin{array}{l}\text { MoKa } \\
(\lambda=0.71073)\end{array}$ & $\begin{array}{l}\text { MoK } \alpha \\
(\lambda=0.71073)\end{array}$ & $\begin{array}{l}\text { MoK } \alpha \\
(\lambda=0.71073)\end{array}$ & $\begin{array}{l}\text { MoK } \alpha \\
(\lambda=0.71073)\end{array}$ \\
\hline $2 \theta$ range for data collection $/^{\circ}$ & 3.244 to 50.7 & 4.314 to 54.194 & 4.248 to 55.918 & 3.764 to 54.276 \\
\hline Index ranges & $\begin{array}{l}-15 \leq h \leq 15 \\
-7 \leq k \leq 7 \\
-21 \leq 1 \leq 21\end{array}$ & $\begin{array}{l}-10 \leq h \leq 10 \\
-12 \leq k \leq 10 \\
-12 \leq l \leq 12\end{array}$ & $\begin{array}{l}-10 \leq h \leq 10 \\
-17 \leq k \leq 9 \\
-18 \leq 1 \leq 18\end{array}$ & $\begin{array}{l}-10 \leq h \leq 10 \\
-10 \leq k \leq 10 \\
-27 \leq l \leq 27\end{array}$ \\
\hline Reflections collected & 13926 & 14156 & 12921 & 11935 \\
\hline $\mathbf{R}_{\text {int }} / \mathbf{R}_{\text {sigma }}$ & $0.0547 / 0.0385$ & $0.0212 / 0.0179$ & $0.0410 / 0.0388$ & $0.0362 / 0.0345$ \\
\hline Data/restraints/parameters & $2616 / 72 / 229$ & $3163 / 0 / 201$ & $3457 / 0 / 201$ & $3226 / 0 / 201$ \\
\hline Goodness-of-fit on $\mathrm{F}^{2}$ & 1.009 & 1.038 & 1.038 & 1.037 \\
\hline Final $R$ indexes [I>=2 $\sigma(I)]$ & $\begin{array}{l}R_{1}=0.0403 \\
W R_{2}=0.0885\end{array}$ & $\begin{array}{l}R_{1}=0.0349 \\
W R_{2}=0.0923\end{array}$ & $\begin{array}{l}R_{1}=0.0421 \\
w R_{2}=0.0965\end{array}$ & $\begin{array}{l}R_{1}=0.0418 \\
W R_{2}=0.0952\end{array}$ \\
\hline Final $\mathbf{R}$ indexes [all data] & $\begin{array}{l}R_{1}=0.0690 \\
w R_{2}=0.1029\end{array}$ & $\begin{array}{l}R_{1}=0.0430 \\
W R_{2}=0.0978\end{array}$ & $\begin{array}{l}R_{1}=0.0624 \\
W R_{2}=0.1067\end{array}$ & $\begin{array}{l}R_{1}=0.0584 \\
W R_{2}=0.1044\end{array}$ \\
\hline Largest diff. peak/hole / e $\AA^{-3}$ & $0.18 /-0.25$ & $0.36 /-0.26$ & $0.28 /-0.24$ & $0.26 /-0.20$ \\
\hline
\end{tabular}

Table 9 Crystallographic data for the structural solution of Gm8m - Y, Gm8m - 0, Gm8p - R and Gm8p - B via single crystal Xray diffraction. 

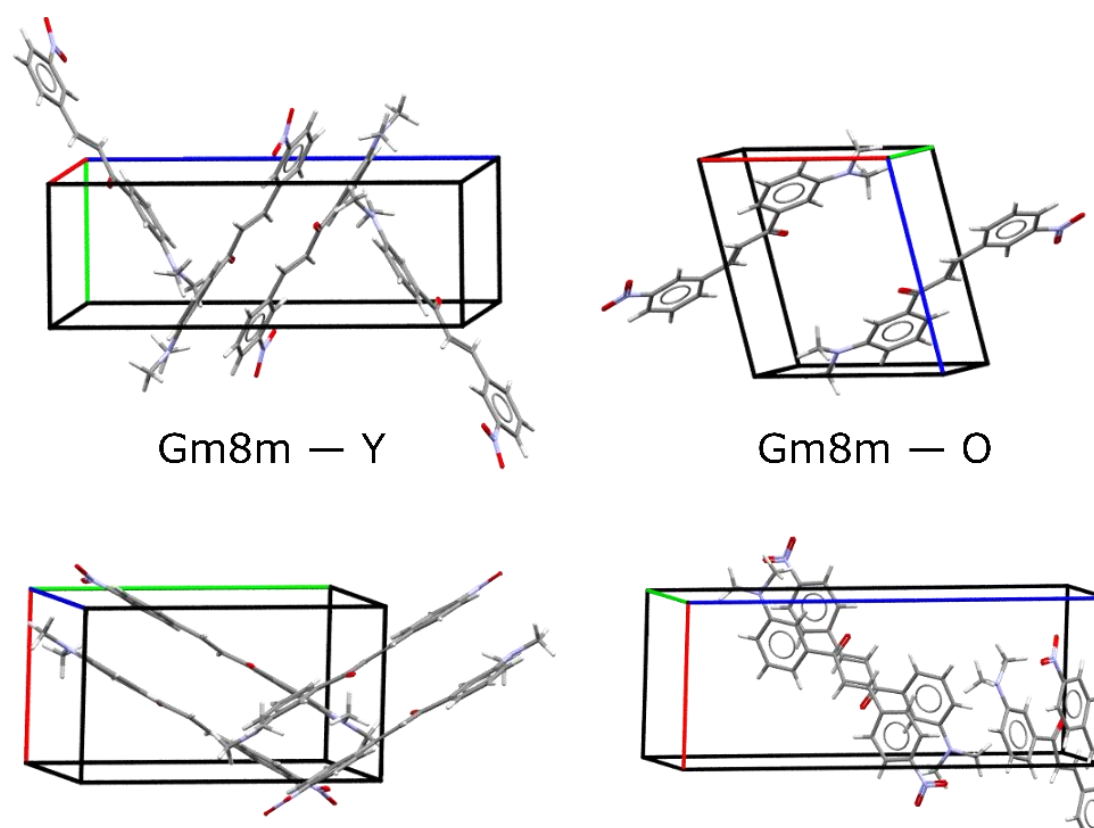

$$
\mathrm{Gm} 8 \mathrm{p}-\mathrm{B}
$$

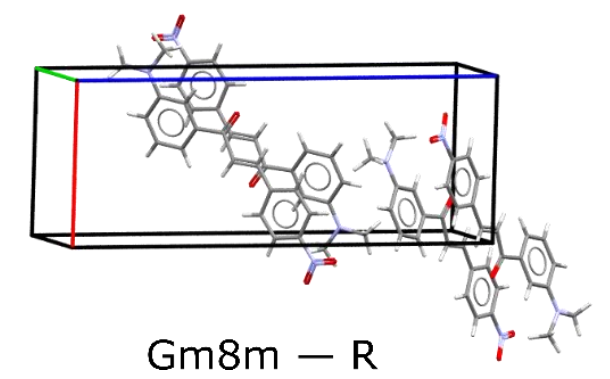

Figure 4 Unit cells of crystal structures of Gm8m - Y, Gm8m - 0, Gm8p - B and Gm8p - B solved via single crystal x-ray diffraction.

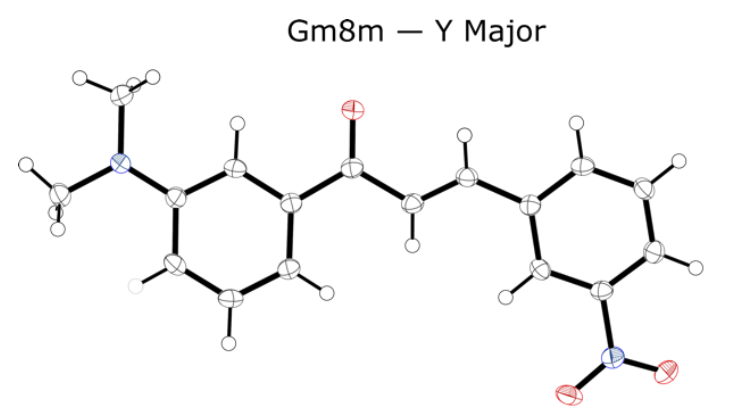

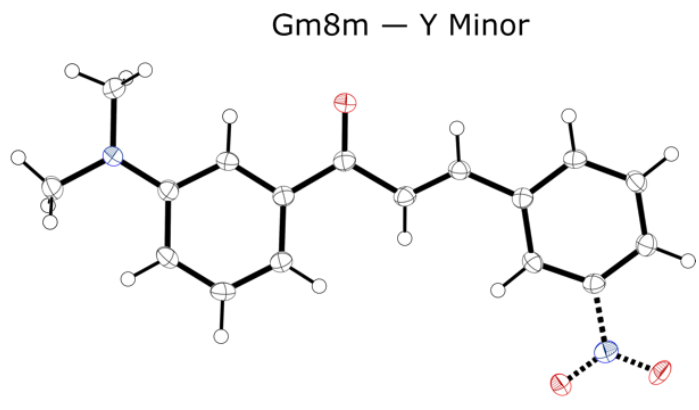

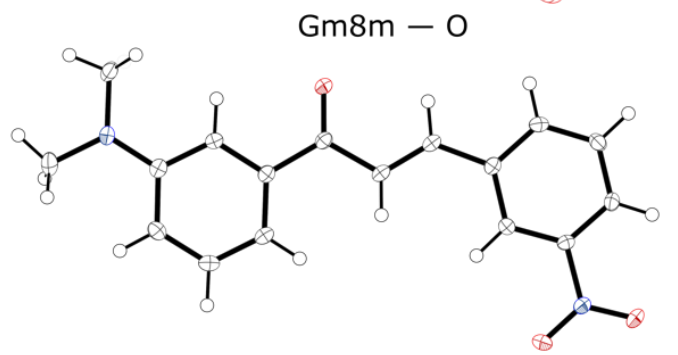

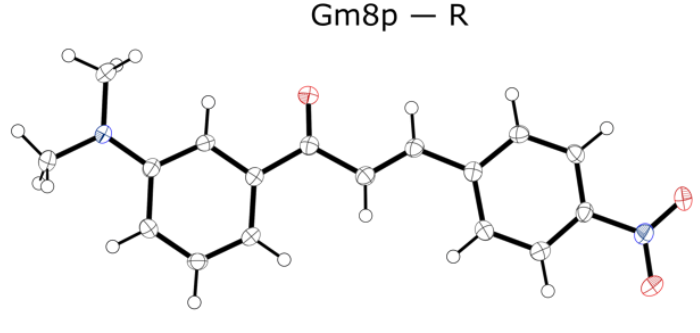

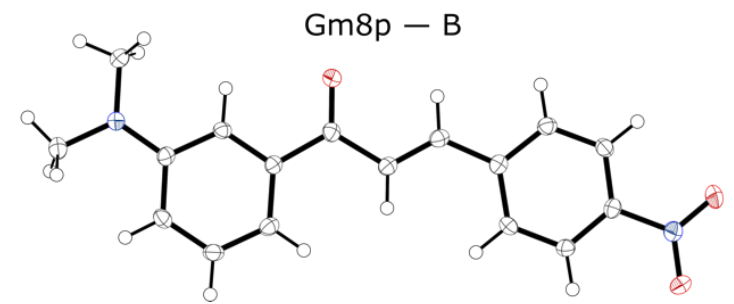

Figure 5 ORTEP diagrams for crystal structures of Gm8m - Y, Gm8m - O, Gm8p - R and Gm8p - B solved via single crystal x-ray diffraction. Thermal ellipsoids are plotted with a probability level of $50 \%$. 


\subsection{Disorder in Gm8m - Y}

The disorder in $\mathrm{Gm} 8 \mathrm{~m}$ - Y was characterized as dynamic by taking single crystal x-ray diffraction data at different temperatures. The same crystal was used for each run. Table 10 shows the occupancies for the major and minor components of the $\mathrm{NO}_{2}$ group. As the temperature is reduced the occupancy of the major component increases, indicating that the disorder is dynamic. Thermal ellipsoid plots for each temperature are shown in Figure 6. Crystallographic data for structures used to calculate disorder is shown in Table 11. Figure 7 shows the trend in crystallographic parameters of $\mathrm{Gm} 8 \mathrm{~m}-\mathrm{Y}$ as the temperature is changed. As the sample is cooled both the $a$ - and $c$-axis contract, whereas the $b$-axis gets longer. This apparent negative thermal expansion is due to the change in the angle between the molecular planes, which is reflected by the change in cell angle $b$.

\begin{tabular}{|l|l|l|}
\hline Temperature / K & Major & Minor \\
\hline $\mathbf{2 5 0}$ & $0.668(11)$ & $0.332(11)$ \\
\hline $\mathbf{2 0 0}$ & $0.721(11)$ & $0.279(11)$ \\
\hline $\mathbf{1 5 0}$ & $0.786(11)$ & $0.214(11)$ \\
\hline $\mathbf{1 0 0}$ & $0.862(11)$ & $0.138(11)$ \\
\hline
\end{tabular}

Table 10 Major and minor occupancies for the disordered $\mathrm{NO}_{2}$ group in $\mathrm{Gm} 8 \mathrm{~m}-\mathrm{Y}$ at different temperatures.
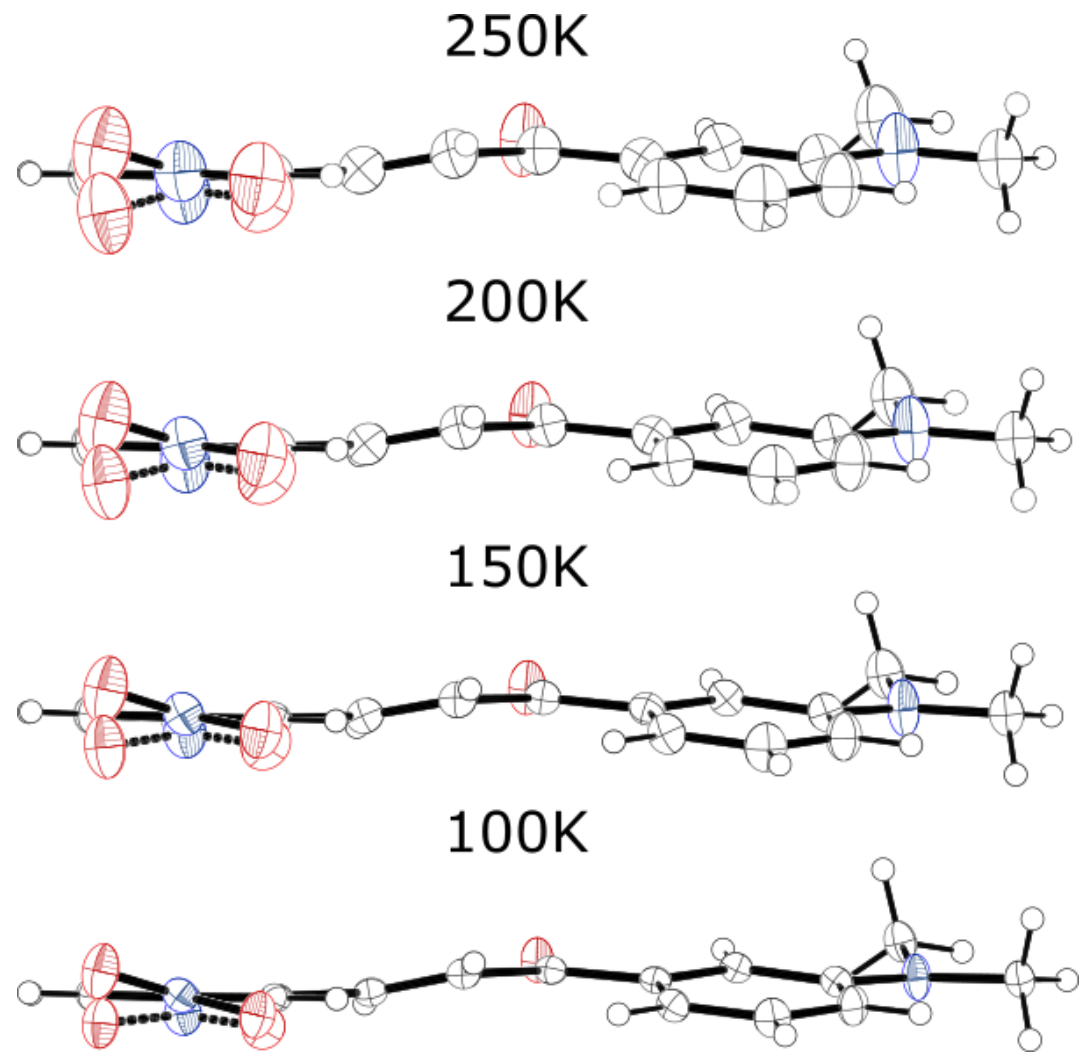

Figure 6 Thermal ellipsoids of $\mathrm{Gm8m}-\mathrm{Y}$ crystal structures solved at temperatures between 100-250 K. Thermal ellipsoids are plotted with a probability level of $50 \%$. 


\begin{tabular}{|c|c|c|c|c|}
\hline Identification code & Gm8m - Y 250K & Gm8m - Y 200K & Gm8m - Y 150K & Gm8m - Y 100K \\
\hline CCDC Identifier & 1983909 & 1983903 & 1983907 & 1983901 \\
\hline Empirical formula & $\mathrm{C}_{17} \mathrm{H}_{16} \mathrm{~N}_{2} \mathrm{O}_{3}$ & $\mathrm{C}_{17} \mathrm{H}_{16} \mathrm{~N}_{2} \mathrm{O}_{3}$ & $\mathrm{C}_{17} \mathrm{H}_{16} \mathrm{~N}_{2} \mathrm{O}_{3}$ & $\mathrm{C}_{17} \mathrm{H}_{16} \mathrm{~N}_{2} \mathrm{O}_{3}$ \\
\hline Formula weight & 296.32 & 296.32 & 296.32 & 296.32 \\
\hline Temperature/K & $250(2)$ & $200(2)$ & $150(2)$ & $100(2)$ \\
\hline Crystal system & monoclinic & monoclinic & monoclinic & monoclinic \\
\hline Space group & $P 2_{1} / c$ & $P 2_{1} / c$ & $P 2_{1} / c$ & $P 2_{1} / c$ \\
\hline$a / \AA ̊$ & $12.5891(3)$ & $12.5782(3)$ & $12.5711(3)$ & $12.5617(3)$ \\
\hline b/Å & $6.2668(2)$ & $6.2852(2)$ & $6.2942(2)$ & $6.3072(2)$ \\
\hline$c / \AA ̊ \AA$ & $18.6610(4)$ & $18.4322(4)$ & $18.2325(4)$ & $18.0352(4)$ \\
\hline$\alpha /^{\circ}$ & 90 & 90 & 90 & 90 \\
\hline$\beta /^{\circ}$ & $92.8145(17)$ & 92.9393(17) & $92.9811(17)$ & $92.9741(17)$ \\
\hline$\gamma /{ }^{\circ}$ & 90 & 90 & 90 & 90 \\
\hline Volume/Å ${ }^{3}$ & $1470.45(7)$ & $1455.27(7)$ & $1440.69(7)$ & $1426.99(6)$ \\
\hline $\mathbf{Z}$ & 4 & 4 & 4 & 4 \\
\hline$\rho_{\text {calc }} / \mathrm{cm}^{3}$ & 1.338 & 1.352 & 1.366 & 1.379 \\
\hline$\mu / \mathrm{mm}^{-1}$ & 0.093 & 0.094 & 0.095 & 0.096 \\
\hline$F(000)$ & 624 & 624 & 624 & 624 \\
\hline Crystal size $/ \mathrm{mm}^{3}$ & $0.478 \times 0.254 \times 0.15$ & $0.478 \times 0.254 \times 0.15$ & $0.478 \times 0.254 \times 0.15$ & $0.478 \times 0.254 \times 0.15$ \\
\hline Radiation & $\begin{array}{l}\text { MoK } \alpha \\
(\lambda=0.71073)\end{array}$ & $\begin{array}{l}\text { MoKa } \\
(\lambda=0.71073)\end{array}$ & $\begin{array}{l}\text { MoK } \alpha \\
(\lambda=0.71073)\end{array}$ & $\begin{array}{l}\text { MoK } \alpha \\
(\lambda=0.71073)\end{array}$ \\
\hline $2 \theta$ range for data collection $/^{\circ}$ & 3.24 to 55.1 & 3.242 to 54.964 & 4.474 to 55.136 & 3.246 to 54.202 \\
\hline Index ranges & $\begin{array}{l}-14 \leq h \leq 16 \\
-8 \leq k \leq 8 \\
-24 \leq I \leq 24\end{array}$ & $\begin{array}{l}-16 \leq h \leq 13 \\
-8 \leq k \leq 8 \\
-23 \leq 1 \leq 23\end{array}$ & $\begin{array}{l}-16 \leq h \leq 13 \\
-8 \leq k \leq 8 \\
-23 \leq 1 \leq 23\end{array}$ & $\begin{array}{l}-16 \leq h \leq 13 \\
-8 \leq k \leq 8 \\
-22 \leq 1 \leq 23\end{array}$ \\
\hline Reflections collected & 12460 & 12233 & 12077 & 11360 \\
\hline$R_{\text {int }} / R_{\text {sigma }}$ & $0.0286 / 0.0277$ & $0.0276 / 0.0269$ & $0.0743 / 0.0573$ & $0.0751 / 0.0563$ \\
\hline Data/restraints/parameters & $3399 / 72 / 229$ & $3343 / 72 / 229$ & $3337 / 72 / 229$ & $3140 / 72 / 229$ \\
\hline Goodness-of-fit on $F^{2}$ & 1.023 & 1.032 & 0.971 & 1.005 \\
\hline Final $R$ indexes [I>=2 $\sigma(I)]$ & $\begin{array}{l}R_{1}=0.0438 \\
W R_{2}=0.1064\end{array}$ & $\begin{array}{l}R_{1}=0.0418 \\
W R_{2}=0.1013\end{array}$ & $\begin{array}{l}R_{1}=0.0387 \\
w R_{2}=0.0962\end{array}$ & $\begin{array}{l}R_{1}=0.0372 \\
w R_{2}=0.0930\end{array}$ \\
\hline Final $R$ indexes [all data] & $\begin{array}{l}R_{1}=0.0735 \\
W R_{2}=0.1220\end{array}$ & $\begin{array}{l}R_{1}=0.0646 \\
w R_{2}=0.1126\end{array}$ & $\begin{array}{l}R_{1}=0.0618 \\
w R_{2}=0.1041\end{array}$ & $\begin{array}{l}R_{1}=0.0535 \\
w R_{2}=0.1009\end{array}$ \\
\hline Largest diff. peak/hole / e $\AA^{-3}$ & $0.20 /-0.19$ & $0.20 /-0.18$ & $0.27 /-0.21$ & $0.32 /-0.23$ \\
\hline
\end{tabular}

Table 11 Crystallographic data for single crystal x-ray diffraction of $\mathrm{Gm8m}-\mathrm{Y}$ at different temperatures. 

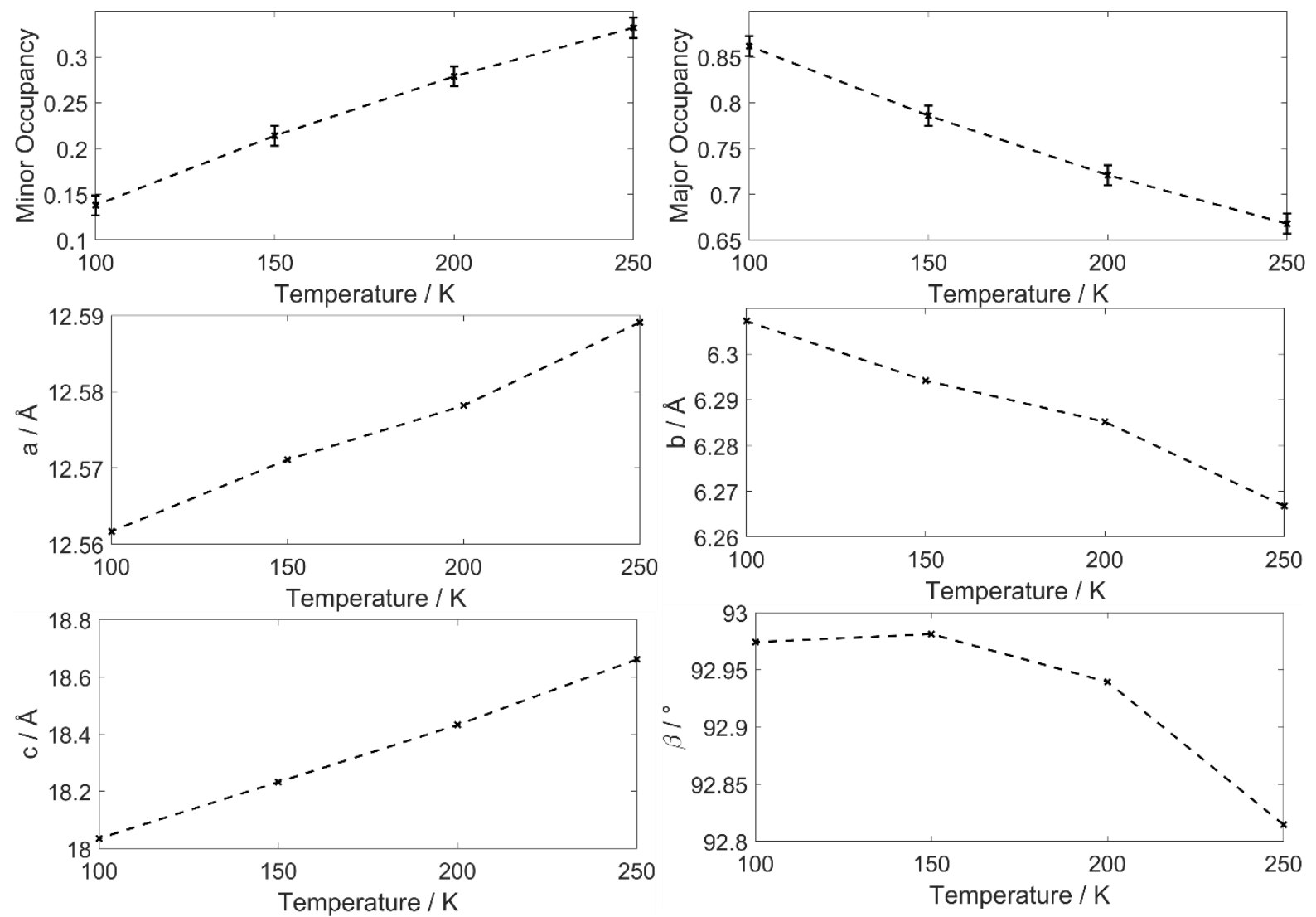

Figure 7 Graphs showing the change of crystallographic parameters of Gm8m - Y with varying temperature from single crystal $\mathrm{x}$-ray diffraction data.

\subsection{Low Temperature Powder Diffraction Data}

\subsubsection{Gm8m and Gm8p}

Low temperature powder diffraction data was collected using a D8 advance powder diffractometer with a Phenix sample stage. Samples were crushed and placed on low-background silicon holders. Powders were cooled from $300 \mathrm{~K}$ to $12 \mathrm{~K}$, followed by heating back to $300 \mathrm{~K}$. Diffraction patterns were taken at $12 \mathrm{~K}$, $300 \mathrm{~K}$ and periodically during the heating and cooling cycles. As diffraction patterns were taking during the temperature ramping stage, exact temperatures of the periodic measurements are not available. Diffraction patterns were collected in the range 5-40 $2 \theta$ with a ramp rate of $0.75^{\circ}$. $\mathrm{min}^{-1}$. Crystallographic parameters were analyzed using Rietveld analysis using the Profex software. ${ }^{1}$ Table 12 to Table 14 summarize the crystallographic data acquired from Rietveld analysis of powder patterns of crystals of $\mathrm{Gm} 8 \mathrm{~m}-\mathrm{Y}, \mathrm{Gm} 8 \mathrm{~m}-\mathrm{O}$ and $\mathrm{Gm} 8 \mathrm{p}-\mathrm{R}$. 


\begin{tabular}{|c|c|c|c|}
\hline Identification code & $G m 8 m-Y$ & $\mathrm{Gm} 8 \mathrm{~m}-0$ & $G m 8 p-R$ \\
\hline Temperature/K & 300 & 300 & 300 \\
\hline $\mathrm{a} / \AA ̊$ & 12.6332(12) & $8.3370(9)$ & $8.386(2)$ \\
\hline b/Å & $6.2561(8)$ & $9.5613(9)$ & $8.1743(5)$ \\
\hline$c / \AA ̊$ & $18.942(2)$ & $10.3919(8)$ & $22.013(2)$ \\
\hline$\alpha /^{\circ}$ & 90 & $103.544(5)$ & 90 \\
\hline$\beta /^{\circ}$ & $92.647(6)$ & $103.003(8)$ & $91.751(13)$ \\
\hline$\gamma /{ }^{\circ}$ & 90 & $104.395(7)$ & 90 \\
\hline
\end{tabular}

Table 12 Crystallographic parameters acquired from Rietveld refinement of x-ray powder patterns of $\mathrm{Gm} 8 \mathrm{~m}-\mathrm{Y}, \mathrm{Gm} 8 \mathrm{~m}-0$ and Gm8p - R at 300K.

\begin{tabular}{|c|c|c|c|}
\hline Identification code & $G m 8 m-Y$ & Gm8m-0 & Gm8p-R \\
\hline Temperature/K & 12 & 12 & 12 \\
\hline$a / \AA$ & $12.5644(14)$ & $8.341(11)$ & $8.3232(14)$ \\
\hline b/Å & $6.3401(12)$ & $9.415(12)$ & $8.0437(6)$ \\
\hline c/Å & $17.882(2)$ & $10.059(9)$ & 21.583(3) \\
\hline$\alpha /^{\circ}$ & 90 & $102.056(6)$ & 90 \\
\hline$\beta /^{\circ}$ & $92.910(7)$ & $102.46(11)$ & $91.010(9)$ \\
\hline$\gamma /^{\circ}$ & 90 & $105.018(8)$ & 90 \\
\hline
\end{tabular}

Table 13 Crystallographic parameters acquired from Rietveld refinement of x-ray powder patterns of $\mathrm{Gm} 8 \mathrm{~m}-\mathrm{Y}, \mathrm{Gm} 8 \mathrm{~m}-\mathrm{O}$ and Gm8p - R at 12K.

\begin{tabular}{|c|c|c|c|}
\hline Difference & $G m 8 m-Y$ & Gm8m-0 & Gm8p-R \\
\hline$a / \AA$ & -0.0688 & 0.0040 & -0.0628 \\
\hline b/Å & 0.0840 & -0.1463 & -0.1306 \\
\hline$c / A ̊$ & -1.0600 & -0.3329 & -0.4300 \\
\hline$\alpha / /^{\circ}$ & 0.0000 & -1.4880 & 0.0000 \\
\hline$\beta /^{\circ}$ & 0.2630 & -0.5430 & -0.7410 \\
\hline$\gamma /^{\circ}$ & 0.0000 & 0.6230 & 0.0000 \\
\hline
\end{tabular}

Table 14 Differences in crystallographic parameters acquired from Rietveld refinement of powder patterns of $\mathrm{Gm} 8 \mathrm{~m}-\mathrm{Y}, \mathrm{Gm} 8 \mathrm{~m}$ - $O$ and Gm8p - R at 300K and $12 \mathrm{~K}$.

\subsubsection{High and low temperature forms of Gm8p - B}

Gm8p - B showed a rapid change in the powder x-ray diffraction pattern between 110-170 K, suggesting a transition. Single crystal $\mathrm{x}$-ray diffraction data subsequently taken at $240 \mathrm{~K}$ and $100 \mathrm{~K}$, produced a similar cell with small changes in the cell lengths (upon cooling $a \sim+0.3 \AA, b \sim-0.1 \AA, c \sim-0.1 \AA$ ) and a larger decrease in the $\beta$ angle of $\sim 5^{\circ}$, resulting in a decrease of $\sim 43 \AA^{-3}$ in the unit cell volume. The two structures had similar molecular configurations (Figure 8), with the largest difference being in the position of the dimethylamino group. The structures vary only slightly in the double 1-3 ring stacking (3666). The two structures are so similar that they can be overlaid with each other ( $\operatorname{RMSD}_{20}=0.533 \AA$ ) (Figure 8). Parameters from single crystal diffraction experiments are summarized in Table 15. 


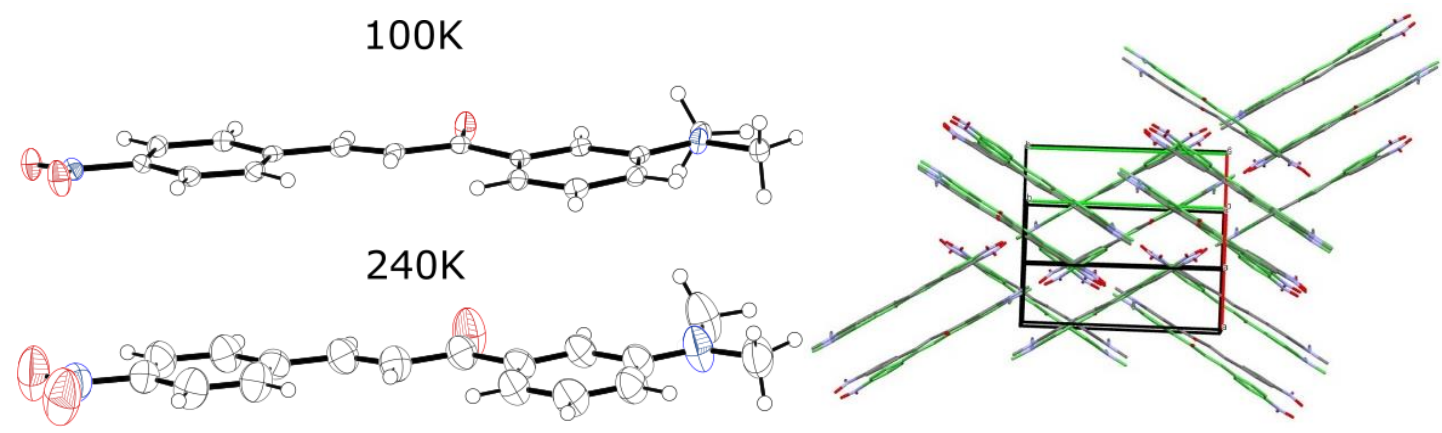

Figure 8 (left) Thermal ellipsoids of Gm8p - B crystal structures solved at temperatures between 100-250 K. Thermal ellipsoids are plotted with a probability level of $50 \%$; (right) the overlay of 20 -molecule clusters of the $100 \mathrm{~K}$ (elements) and $240 \mathrm{~K}$ (green) structures of Gm8p - B.

\begin{tabular}{|c|c|c|}
\hline Identification code & $\begin{array}{l}\text { Gm8p - B } \\
\text { Low Temperature }\end{array}$ & $\begin{array}{l}\text { Gm8p - B } \\
\text { High Temperature }\end{array}$ \\
\hline CCDC Identifier & 1983904 & 1983908 \\
\hline Empirical formula & $\mathrm{C}_{17} \mathrm{H}_{16} \mathrm{~N}_{2} \mathrm{O}_{3}$ & $\mathrm{C}_{17} \mathrm{H}_{16} \mathrm{~N}_{2} \mathrm{O}_{3}$ \\
\hline Formula weight & 296.32 & 296.32 \\
\hline Temperature/K & $100(2)$ & $240(2)$ \\
\hline Crystal system & monoclinic & monoclinic \\
\hline Space group & $P 21 / c$ & $P 2_{1} / c$ \\
\hline$a / \AA$ & $7.8167(2)$ & $8.1180(5)$ \\
\hline b/Å & $13.4438(4)$ & $13.3417(7)$ \\
\hline$c / \AA ̊$ & $13.7862(5)$ & $13.6713(8)$ \\
\hline$\alpha /^{\circ}$ & 90 & 90 \\
\hline$\beta /^{\circ}$ & $97.413(2)$ & $92.261(4)$ \\
\hline$\gamma / /^{\circ}$ & 90 & 90 \\
\hline Volume/Å ${ }^{3}$ & $1436.63(8)$ & $1479.56(15)$ \\
\hline$Z$ & 4 & 4 \\
\hline$\rho_{\text {calcg }} / \mathrm{cm}^{3}$ & 1.37 & 1.33 \\
\hline$\mu / \mathrm{mm}^{-1}$ & 0.095 & 0.093 \\
\hline$F(000)$ & 624 & 624 \\
\hline Crystal size $/ \mathrm{mm}^{3}$ & $0.45 \times 0.409 \times 0.224$ & $0.45 \times 0.409 \times 0.224$ \\
\hline Radiation & $\operatorname{MoK} \alpha(\lambda=0.71073)$ & $\operatorname{MoK} \alpha(\lambda=0.71073)$ \\
\hline $2 \theta$ range for data collection $/^{\circ}$ & 4.25 to 50.696 & 4.268 to 54.96 \\
\hline Index ranges & $\begin{array}{l}-9 \leq h \leq 9 \\
-16 \leq k \leq 16 \\
-16 \leq 1 \leq 16\end{array}$ & $\begin{array}{l}-10 \leq h \leq 10 \\
-17 \leq k \leq 17 \\
-17 \leq 1 \leq 17\end{array}$ \\
\hline Reflections collected & 20915 & 25811 \\
\hline$R_{\text {int }} / R_{\text {sigma }}$ & $0.0682 / 0.0322$ & $0.0395 / 0.0240$ \\
\hline Data/restraints/parameters & $2631 / 0 / 201$ & $3395 / 0 / 201$ \\
\hline Goodness-of-fit on $F^{2}$ & 1.035 & 1.024 \\
\hline Final $R$ indexes $[\mid>=2 \sigma(I)]$ & $\begin{array}{l}R_{1}=0.0336 \\
W R_{2}=0.0860\end{array}$ & $\begin{array}{l}R_{1}=0.0465 \\
w R_{2}=0.1124\end{array}$ \\
\hline Final $R$ indexes [all data] & $\begin{array}{l}R_{1}=0.0452, \\
w R_{2}=0.0902\end{array}$ & $\begin{array}{l}R_{1}=0.0806, \\
w R_{2}=0.1295\end{array}$ \\
\hline Largest diff. peak/hole / e $\AA^{-3}$ & $0.21 /-0.19$ & $0.23 /-0.18$ \\
\hline
\end{tabular}

Table 15 Crystallographic data for Gm8p - B high temperature and low temperature forms. 
Room temperature and $12 \mathrm{~K}$ powder patterns match well with generated powder patterns from the single crystal x-ray structure solutions (Figure 9).

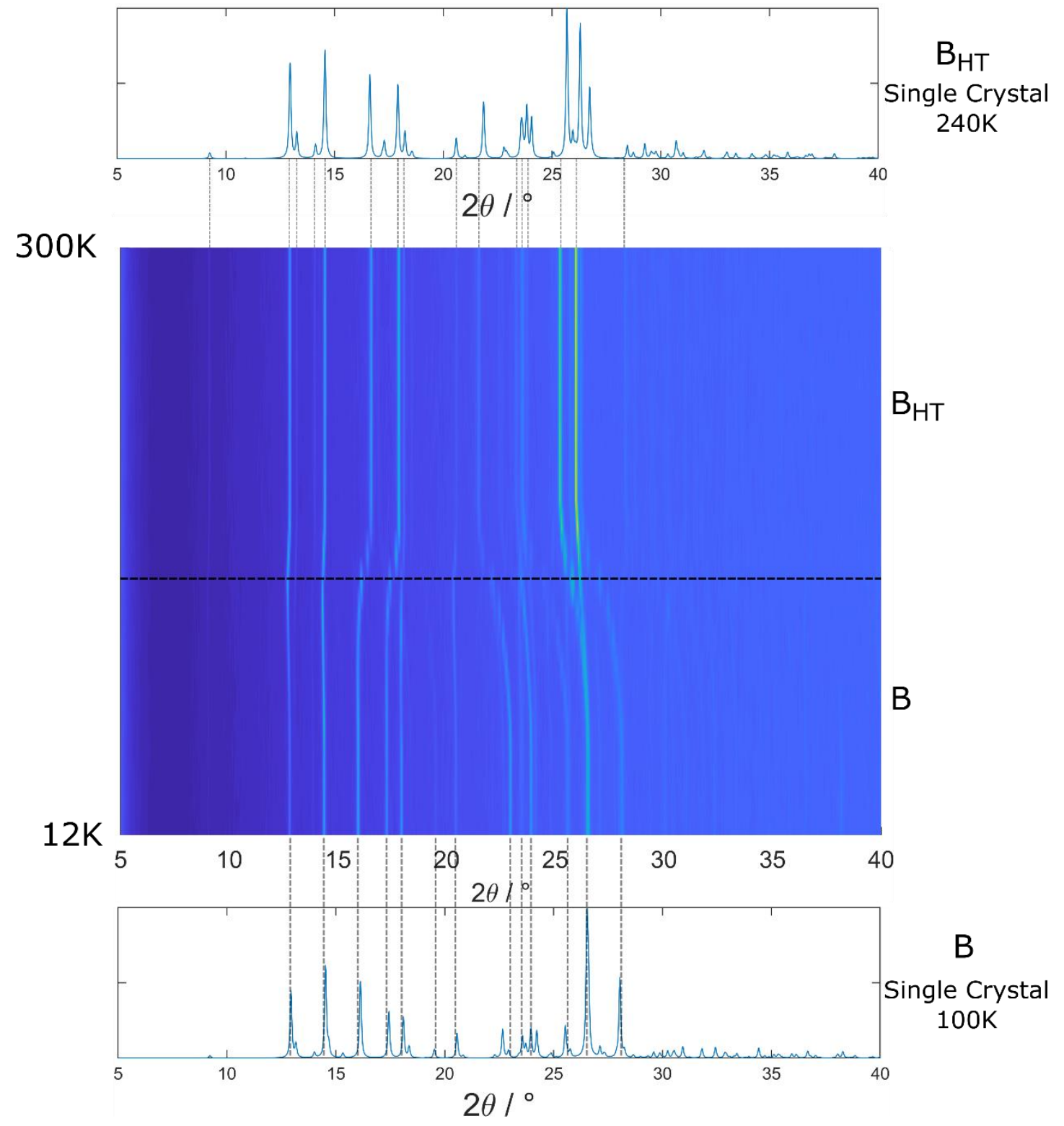

Figure 9 Surface map of powder $\mathrm{x}$-ray diffraction patterns taken between $12 \mathrm{~K}$ and $300 \mathrm{~K}$ on heating with continuous data collection as the temperature was being ramped up. Generated powder patterns of the high temperature and, low temperature structures, from single crystal diffraction, are shown above, and below the surface map to show that the structures match.

\subsection{Characterization of the orange form of Gm8p.}

An orange form of Gm8p was observed under particular crystallization conditions, as shown by the solvent screen (SI 1.2). The crystals grew as very thin, twinned needles which appeared to have low crystallinity under polarized light (Figure 10). The poor crystallinity of the sample meant the structure could not be 
determined via single crystal X-ray diffraction, though the powder X-ray diffraction data (Figure 11) confirms that the sample has some diffraction peaks that could not have come from the known polymorphs $\mathrm{Gm} 8 \mathrm{p}-\mathrm{R}$ and $\mathrm{Gm} 8 \mathrm{p}-\mathrm{B}$.

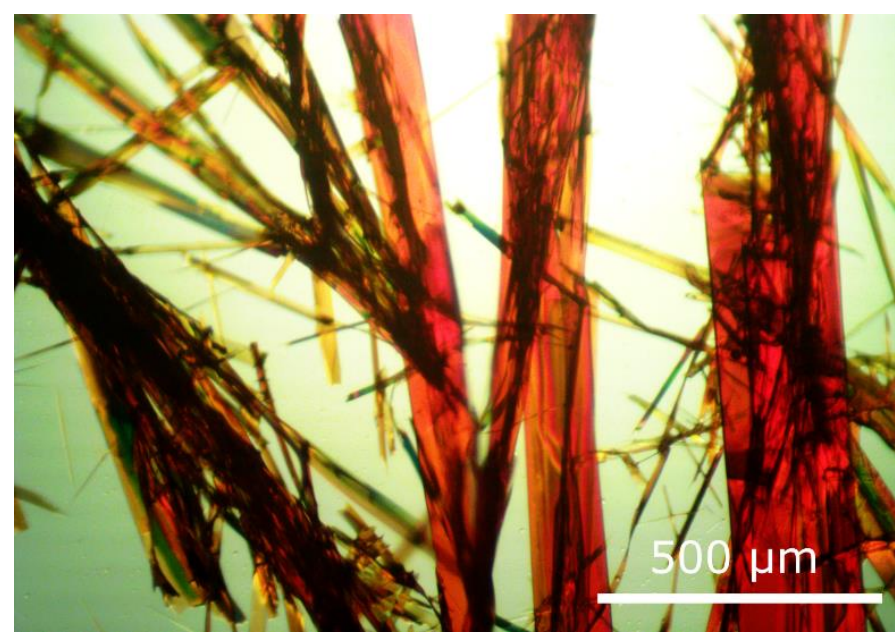

Figure 10 Image of the orange sample of Gm8p under polarized light.

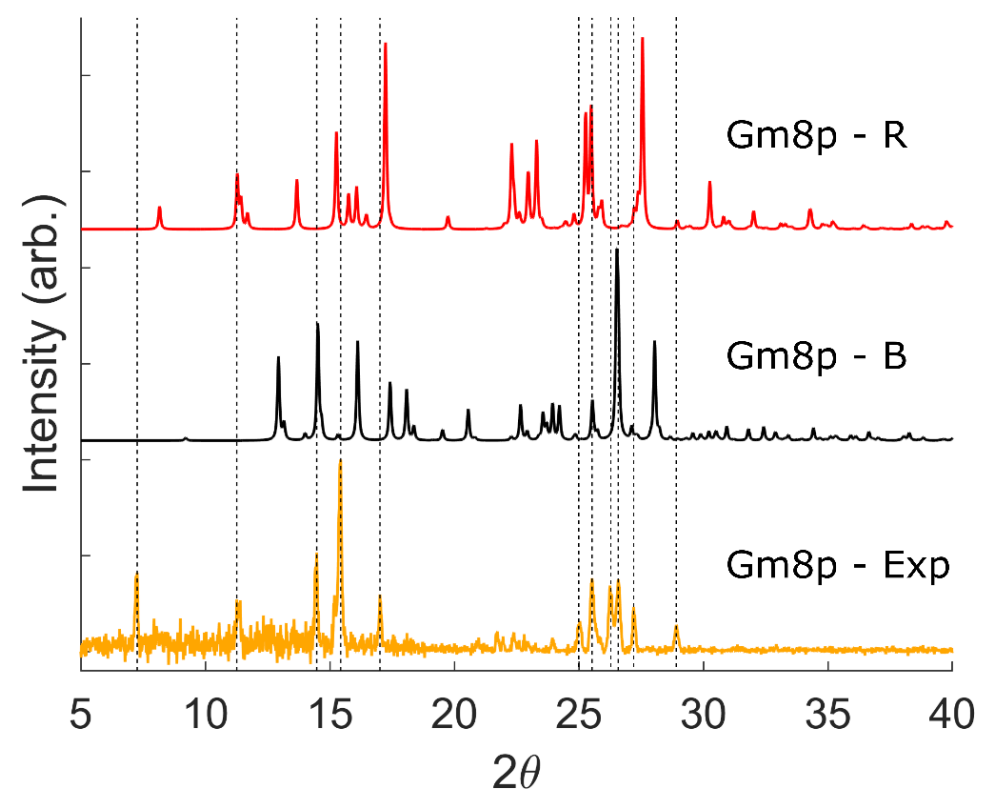

Figure 11 Experimental powder X-ray diffraction pattern of the orange form of Gm8p compared to generated powder patterns of Gm8p - B and Gm8p - R. Dashed lines show the positions of the peaks from the experimental Gm8p pattern (Gm8p - Exp) as a guide for the eye.

\subsubsection{D Electron Diffraction (3D ED)}

High angle annular dark-field scanning transmission electron microscopy (HAADF-STEM) imaging and electron diffraction (ED) data were recorded with a Zeiss Libra TEM operating at $120 \mathrm{kV}$ and equipped with a $\mathrm{LaB}_{6}$ source. 3D ED was performed in STEM mode after defocusing the beam in order to have a pseudo-parallel illumination on the sample. A beam size of about $150 \mathrm{~nm}$ in diameter was obtained using 
a $5 \mu \mathrm{m}$ condenser aperture (C2). An extremely low-dose illumination was adopted in order to avoid or slow down the amorphization of the sample and allowed acquiring data at room temperature.

Data collection was performed rotating the sample around the TEM goniometer axis in step of $1^{\circ}$. After each tilt, a diffraction pattern was acquired and crystal position was tracked by defocused STEM imaging. ED patterns were recorded by a single-electron ASI MEDIPIX detector ${ }^{2}$ which is delivering virtually background-free patterns. 3D ED data were analyzed using the software PETS ${ }^{3}$ which allowed pattern centering, 3D diffraction reconstruction and visualization, cell parameter determination and reflection intensity extraction. Least-square structure refinement was performed with the software SHELXL. ${ }^{3}$

A few needles of the orange sample of Gm8p were gently crushed (Figure 12) and directly loaded on a carbon-coated CU TEM grid without any solvent or sonication. 3D ED data were recorded from three crystal fragments with size less than $1 \mu \mathrm{m}$ (Figure 13). 3D ED acquisition was performed in tilt ranges from $50^{\circ}$ to $70^{\circ}$. Camera lengths was $180 \mathrm{~mm}$, allowing resolution in real space up to $0.7 \AA$.

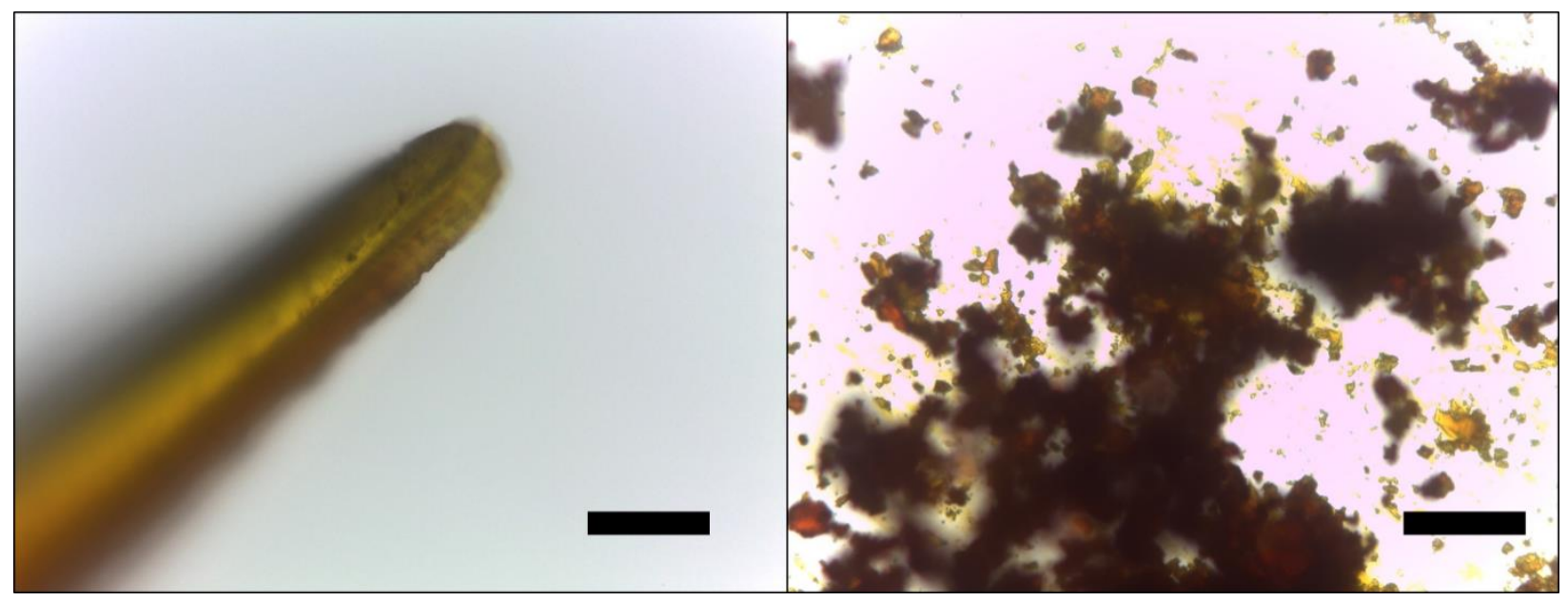

Figure 12 Crystals of the orange form of Gm8p under light microscope before (left) and after (right) crushing. The scale bars are $500 \mu \mathrm{m}$ and $50 \mu \mathrm{m}$ respectively. 

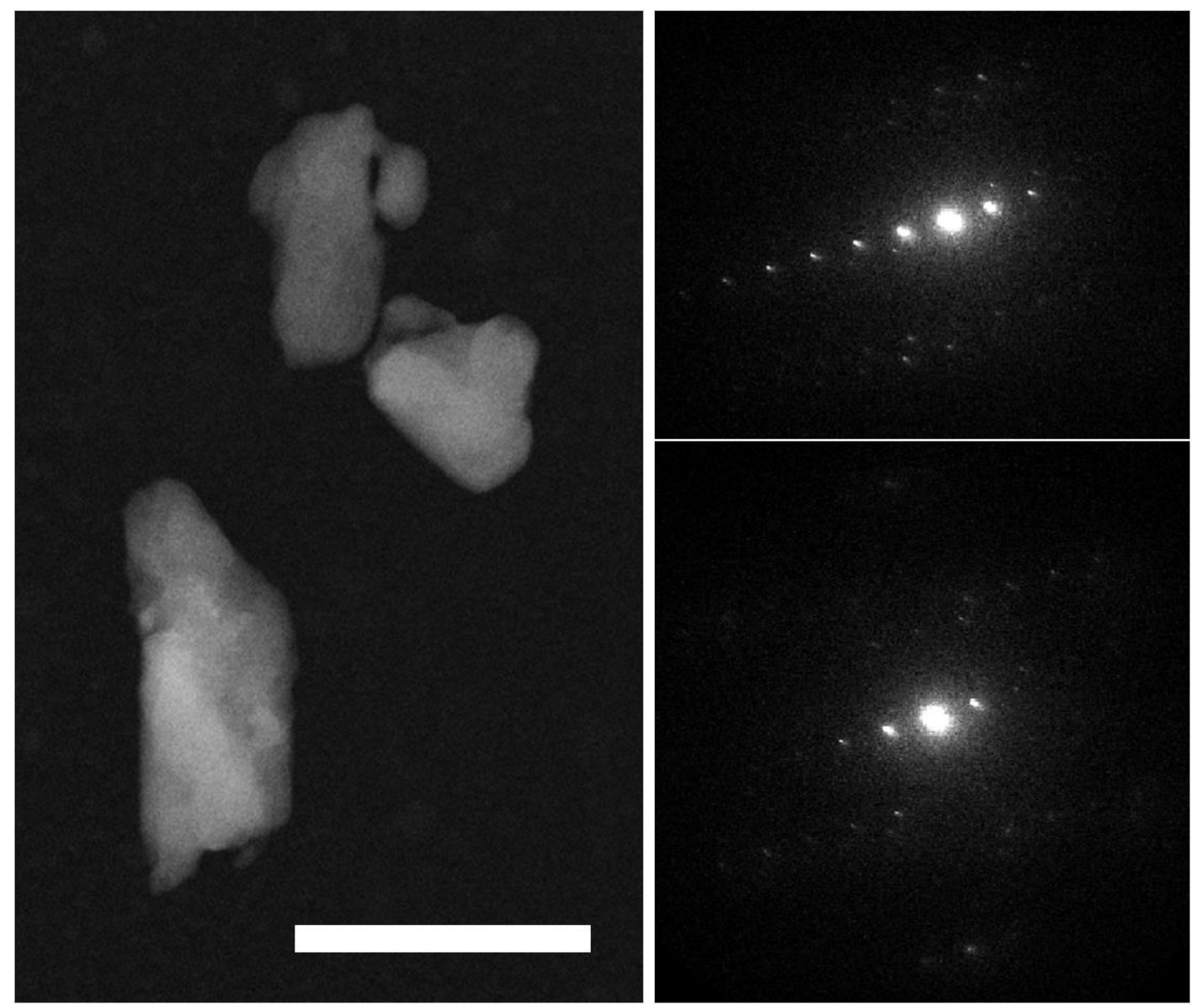

Figure 13 STEM image of nanocrystals of orange sample (left) and example ED patterns from single nanocrystals (right). The scale bar is $1 \mu \mathrm{m}$.

3D ED analysis showed that two data sets were consistent with a triclinic cell with approximate parameters $a=8.2 \AA, b=8.4 \AA, c=12.3 \AA, \alpha=106.5^{\circ}, b=96^{\circ}, \gamma=99^{\circ}$ (Figure 14 top) and the third data set gave a triclinic cell with approximate parameters $a=7.6 \AA, b=8.3 \AA, c=13.4 \AA, \alpha=107.6^{\circ}, b=101.6^{\circ}, y=93.8^{\circ}$ (Figure 14 bottom). These results can indicate that the orange Gm8p sample consists of at least two polymorphs with related molecular packing. The space group of the system is either $P 1(1)$ or $P-1(2)$. Such cells can host only two Gm8p molecules, limiting the range of possible structural configurations. In the current case, due to the poor crystallinity, short tilt range during data collections, polymorphism and, evidently, low symmetry, the structure could not be solved by direct methods or simulated annealing. 


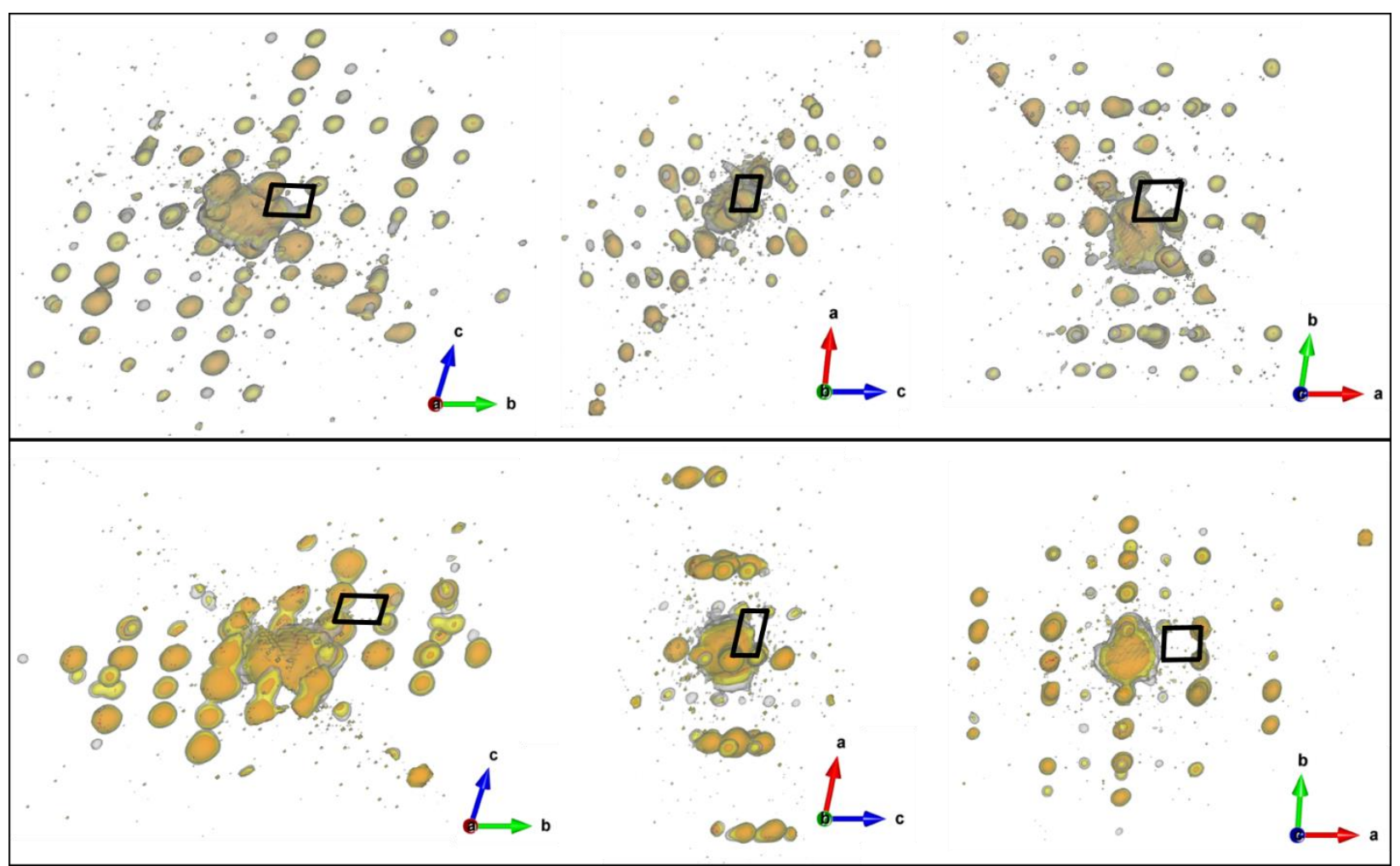

Figure 14 3D ED volume reconstructions of two different crystals inside the orange Gm8p sample. Cell edges are sketched in black. Top data from a crystal with $1^{\text {st }} 3 D$ ED cell, bottom data from a crystal with $2^{\text {nd }}$ 3D ED cell.

\subsubsection{Crystal Structure Prediction (CSP)}

A limited crystal structure prediction study was run on the orange form of Gm8p in the $P$-1 space group with one Gm8p PBE0/6-31G(d,p) optimized molecule in the asymmetric unit, and in $P 1$ with two such molecules, using CrystalPredictor. ${ }^{4,5}$ The resultant structures were energy minimized using CrystalOptimizer, ${ }^{5}$ allowing all the torsion angles except those within the aromatic rings and the bond angles in the carbonyl backbone to change with the packing forces, using the PBE0/6-31G(d,p) charge density for the intramolecular energy term and the distributed multipole model of the charge density. The intermolecular lattice energy was calculated using DMACRYS ${ }^{77}$ with the distributed multipoles for the electrostatic energy and the FIT parameters ${ }^{7}$ in an empirical exp-6 model for the remaining (repulsiondispersion) contributions to the lattice energy.

The lowest energy structure, CSP\#16 was a $P$ - 1 structure with standard cell parameters $a=7.05050 \AA$, $b=8.49910 \AA, c=13.66932 \AA, \alpha=106.80486^{\circ}, \beta=102.81669^{\circ}, \gamma=92.28550^{\circ}$. This gave a low angle peak similar to that seen in the powder diffraction pattern, as did at least two other structures that were not much higher in energy (Figure 15) from this limited search, and also contained the same stacking. 


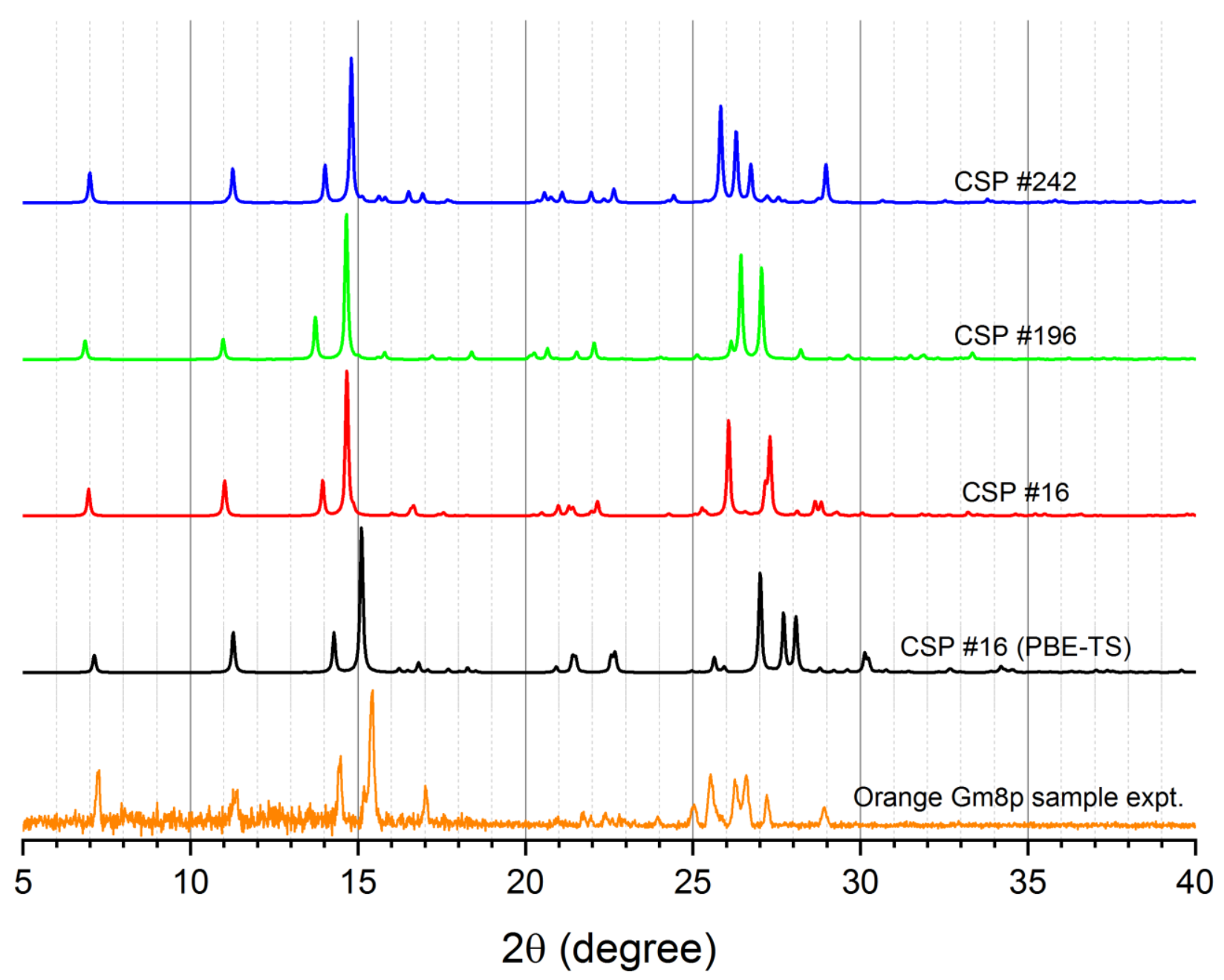

Figure 15 The experimental powder X-ray diffraction pattern of the new form of Gm8p (with possible impurities from Gm8p $R$ and $\mathrm{Gm} 8 \mathrm{p}-\mathrm{B}$ as seen from Figure 11) compared with those simulated from three computer-generated crystal structures, CSP\#16 $\Delta \mathrm{E}_{\text {latt }}=0$, CSP\#196 $\Delta \mathrm{E}_{\text {latt }}=1.6 \mathrm{~kJ} \mathrm{~mol}^{-1}, \mathrm{CSP} \# 242 \Delta \mathrm{E}_{\text {latt }}=\mathbf{2 . 2} \mathrm{kJ} \mathrm{mol}^{-1}$. The powder pattern from the structure obtained by periodic PBE-TS optimization of CSP\#16 is also shown. All calculated patterns ignore thermal expansion.

The most stable structure CSP\#16 was used as an input model for refining against the electron diffraction data. A refined model was produced, but $R 1$ factor was above $60 \%$. The normal $R 1$ factor for a satisfactory structure solution for an organic crystal by electron diffraction is about $30 \%$.

The optimization of CSP\#16 using periodic PBE-TS (i.e. the same method used in SI 2.2) gave a structure that was an arguably better match to the powder pattern (SI Figure 15) than CSP\#16, emphasizing the sensitivity of the powder pattern to the cell dimensions. This structure was less stable than $\mathrm{Gm} 8 \mathrm{p}-\mathrm{R}$ by $2.6 \mathrm{~kJ} \mathrm{~mol}^{-1}\left(2.5 \mathrm{~kJ} \mathrm{~mol}^{-1}\right.$ with MBD* dispersion) and much less stable than $\mathrm{Gm} 8 \mathrm{p}-\mathrm{B}$ by $6.2 \mathrm{~kJ} \mathrm{~mol}^{-1}(7.6 \mathrm{~kJ}$ $\mathrm{mol}^{-1}$ with $\left.\mathrm{MBD}^{*}\right) \mathrm{kJ} \mathrm{mol}^{-1}$ in lattice energy. This lattice energy shows that the structure is not thermodynamically implausible, but is highly metastable and so any powder pattern might include peaks arising from crystals that had transformed to Gm8p - R and/or Gm8p-B as seems possible from SI Figure 11. 
The approximate model (PBE-TS optimized CSP\#16) had the double 1-3 ring stacked dimer (SI Table18) in common with $\mathrm{Gm} 8 \mathrm{p}-\mathrm{B}\left(\mathrm{RMSD}_{2}=0.186 \AA\right.$ ) ) and a side by side interaction (short-axis translation motif, $\mathrm{SI}$ Table 17) in common with $G m 8 p-R\left(R_{M S D}=0.263 \AA\right.$ ), so a crystal with this structure is likely to be colored and could have a low barrier transformation pathway to the other polymorphs. CSP\#16 is metastable, but the close similarity of CSP\#196 and CSP\#242 (Figure 16) is suggestive of factors that could stabilize the structure at ambient temperatures. There is the possibility of large amplitude thermal averaging over many structures or other forms of dynamic disorder. There may also be static disorder or extensive defects in the structure.

(a)

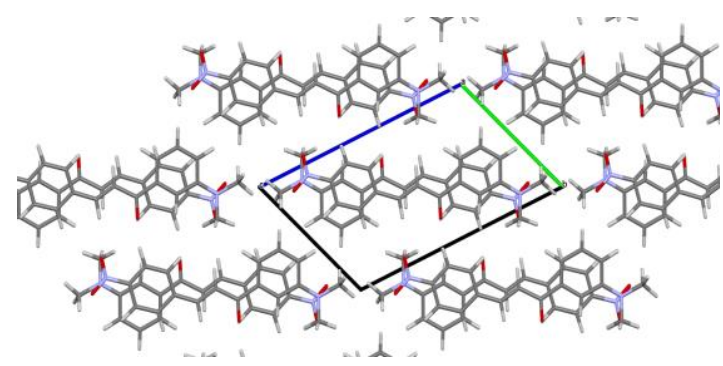

(c)

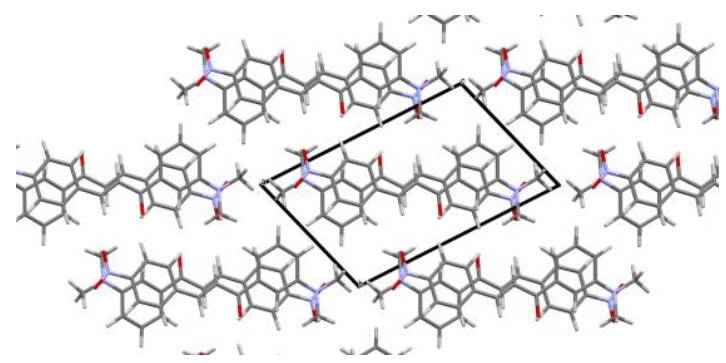

(b)

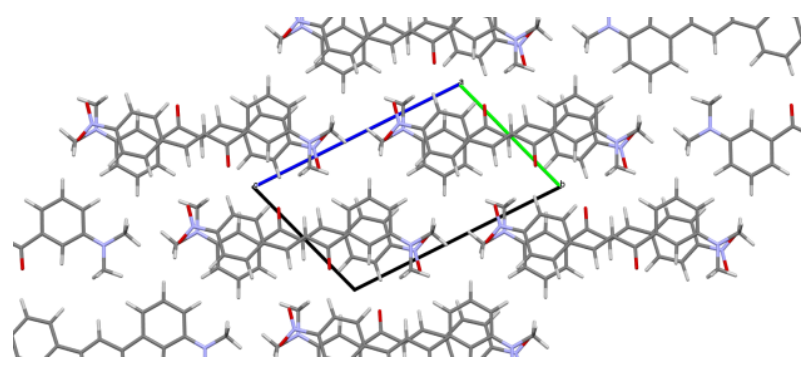

(d)

Figure 16 Packing of common stacks in (a) Structure 16, (b) Structure 196, (c) Structure 242 (d) Side view of unit cell of PBE-TS optimized CSP\#16 (green) overlaid with ED refined structure (in atomic colors).

Hence, there is experimental evidence for more polymorphs of the orange form of Gm8p that are probably based on variations on the stack in CSP\#16 which is similar to the stacking motif seen in Gm8p - B. Our efforts to grow better crystals for analysis have not yet yielded any good single crystals or powder samples that are known to be phase pure. Whether this is a consequence of not finding the right conditions or inevitable disorder is uncertain.

\subsection{Thermal analysis}

On cooling from the melt, Gm8m shows no crystallization and only a glass transition at $-3^{\circ} \mathrm{C}$. On heating, the reverse glass transition is seen at $3^{\circ} \mathrm{C}$, which then is followed by a cold crystallization and subsequent endotherm at $117.7^{\circ} \mathrm{C}$ ( $\mathrm{SI}$ Figure 17). This suggests that the crystallization of $\mathrm{Gm} 8 \mathrm{~m}$ from the melt is unfavorable. At ramp rates of $5^{\circ} \mathrm{C} \cdot \mathrm{min}^{-1}$ and $10^{\circ} \mathrm{C} \cdot \mathrm{min}^{-1} \mathrm{Gm} 8 \mathrm{p}$ crystallizes readily from the melt upon cooling. 
SI Table 16 shows a summary of the differential scanning calorimetry measurements carried out on $\mathrm{Gm} 8 \mathrm{~m}$ and Gm8p polymorphs.

Assuming that the thermograms of $G m 8 p-R$ were showing a melt-mediated phase transition to $G m 8 p-$ $\mathrm{B}$, thermograms were produced at ramp rates of $5^{\circ} \mathrm{C} \cdot \mathrm{min}^{-1}, 10^{\circ} \mathrm{C} \cdot \mathrm{min}^{-1}, 20 \mathrm{C} \cdot \mathrm{min}^{-1}, 35 \mathrm{C} \cdot \mathrm{min}^{-1}$ and $50^{\circ} \mathrm{C} \cdot \mathrm{min}^{-1}$ to assess the melting enthalpy of $\mathrm{Gm} 8 \mathrm{p}-\mathrm{R}$ (SI Figure 18). The enthalpy of the first endothermic peak is larger for $5^{\circ} \mathrm{C} \cdot \mathrm{min}^{-1}$ than $10^{\circ} \mathrm{C} \cdot \mathrm{min}^{-1}$, which suggests that more of the $\mathrm{Gm} 8 \mathrm{p}-\mathrm{R}$ is melting before the transformation to $\mathrm{Gm} 8 \mathrm{p}-\mathrm{B}$. This is also backed up by the second endothermic peak being larger for $5^{\circ} \mathrm{C} \cdot \mathrm{min}^{-1}$ than $10^{\circ} \mathrm{C} \cdot \mathrm{min}^{-1}$. At $50^{\circ} \mathrm{C} \cdot \mathrm{min}^{-1}$ only a single endothermic transition is seen, suggesting that the ramp rate is too high for any transformation to $\mathrm{Gm} 8 \mathrm{p}-\mathrm{B}$ to occur.

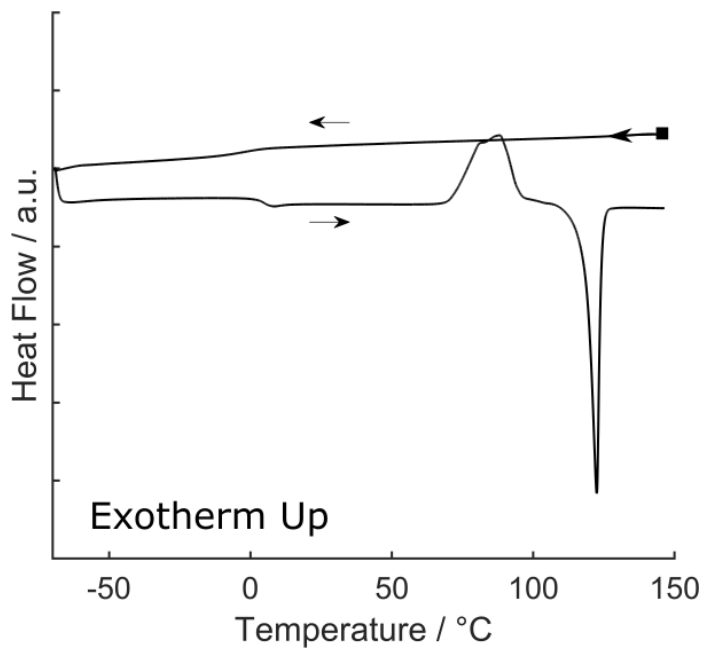

Figure 17 Thermogram of $\mathrm{Gm} 8 \mathrm{~m}$ cooled from the melt, followed by heating through a cold crystallization a subsequent melt. The cycle was run between $150^{\circ} \mathrm{C}$ and $-50^{\circ} \mathrm{C}$ at a ramp rate of $5^{\circ} \mathrm{C} . \mathrm{min}^{-1}$. The start of the cycle is indicated by a black box and arrow.

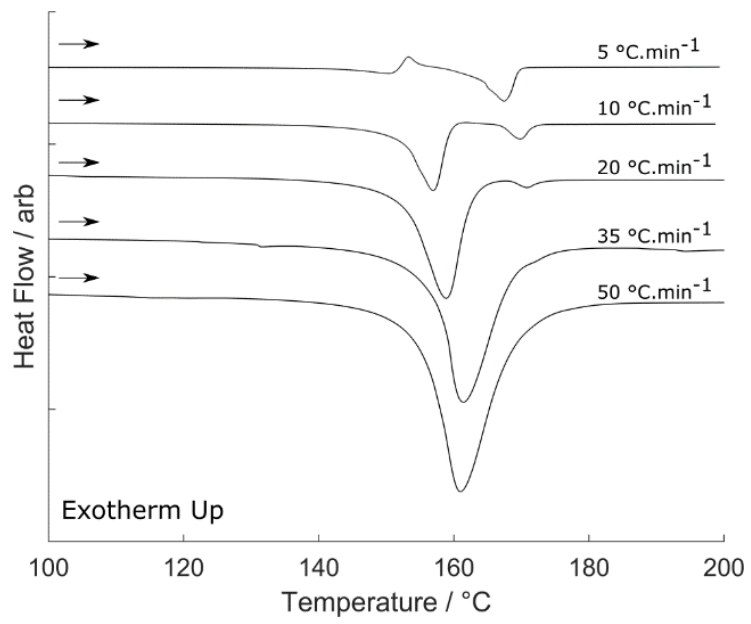

Figure 18 Thermogram of $\mathrm{Gm} 8 \mathrm{p}-\mathrm{R}$ heated at ramp rates between $5^{\circ} \mathrm{C} \cdot \mathrm{min}^{-1}-50^{\circ} \mathrm{C} \cdot \mathrm{min}^{-1}$ to assess the enthalpy of fusion of Gm8p-R. 


\begin{tabular}{|c|c|c|c|c|c|c|c|}
\hline Initial sample & $\begin{array}{l}\text { Ramp } \\
\text { Rate } \\
/{ }^{\circ} \mathrm{C} \text {. } \\
\min ^{-1}\end{array}$ & $\begin{array}{l}\text { Melt } 1 \\
\text { Temperature } \\
/{ }^{\circ} \mathrm{C}\end{array}$ & $\begin{array}{l}\text { Enthalpy } \\
\text { / J.g-1 }\end{array}$ & $\begin{array}{l}\text { Error } \\
/ \mathrm{J}^{-\mathrm{g}^{-1}}\end{array}$ & $\begin{array}{l}\text { Melt } 2 \\
\text { Temperature } \\
/{ }^{\circ} \mathrm{C}\end{array}$ & $\begin{array}{l}\text { Enthalpy } \\
\text { / J.g-1 }\end{array}$ & $\begin{array}{l}\text { Error } \\
/ \mathrm{J.g}^{-1}\end{array}$ \\
\hline Gm8m - Y & 5 & 121.6 & 97 & 3 & & & \\
\hline Gm8m - Y & 10 & 121.7 & 100 & 2 & & & \\
\hline Gm8m - O & 5 & 120.1 & 95 & 4 & & & \\
\hline Gm8m-0* & 10 & 119.0 & 67 & 5 & & & \\
\hline Gm8p - $\mathbf{R}^{*}$ & 5 & 143.0 & 16 & 2 & 163.2 & 75 & 2 \\
\hline Gm8p - R* & 10 & 151.9 & 84 & 2 & 167.0 & 10 & 1 \\
\hline Gm8p - R* & 20 & 152.4 & 93 & 3 & 168.6 & 1.8 & 0.1 \\
\hline Gm8p-R* & 35 & 157.3 & 91 & 4 & & & \\
\hline Gm8p - R & 50 & 155.4 & 93 & 3 & & & \\
\hline Gm8p - B & 10 & 167.4 & 114 & 3 & & & \\
\hline Gm8p - B & 50 & 167.7 & 116 & 5 & & & \\
\hline
\end{tabular}

Table 16 Summary of differential scanning calorimetry experiments run on $\mathrm{Gm} 8 \mathrm{~m}$ and $\mathrm{Gm} 8 \mathrm{p}$ polymorphs. Instrument error in temperature is approximately $0.5^{\circ} \mathrm{C}$. $*$ There is overlap of the peaks, so values of enthalpies are inaccurate.

To assure that any phase changes seen were not arising due to a mixture of polymorphs being present at the beginning of the DSC run, powder X-ray diffraction was carried out on all samples before measurement, with typical examples being shown (SI Figure 19). 


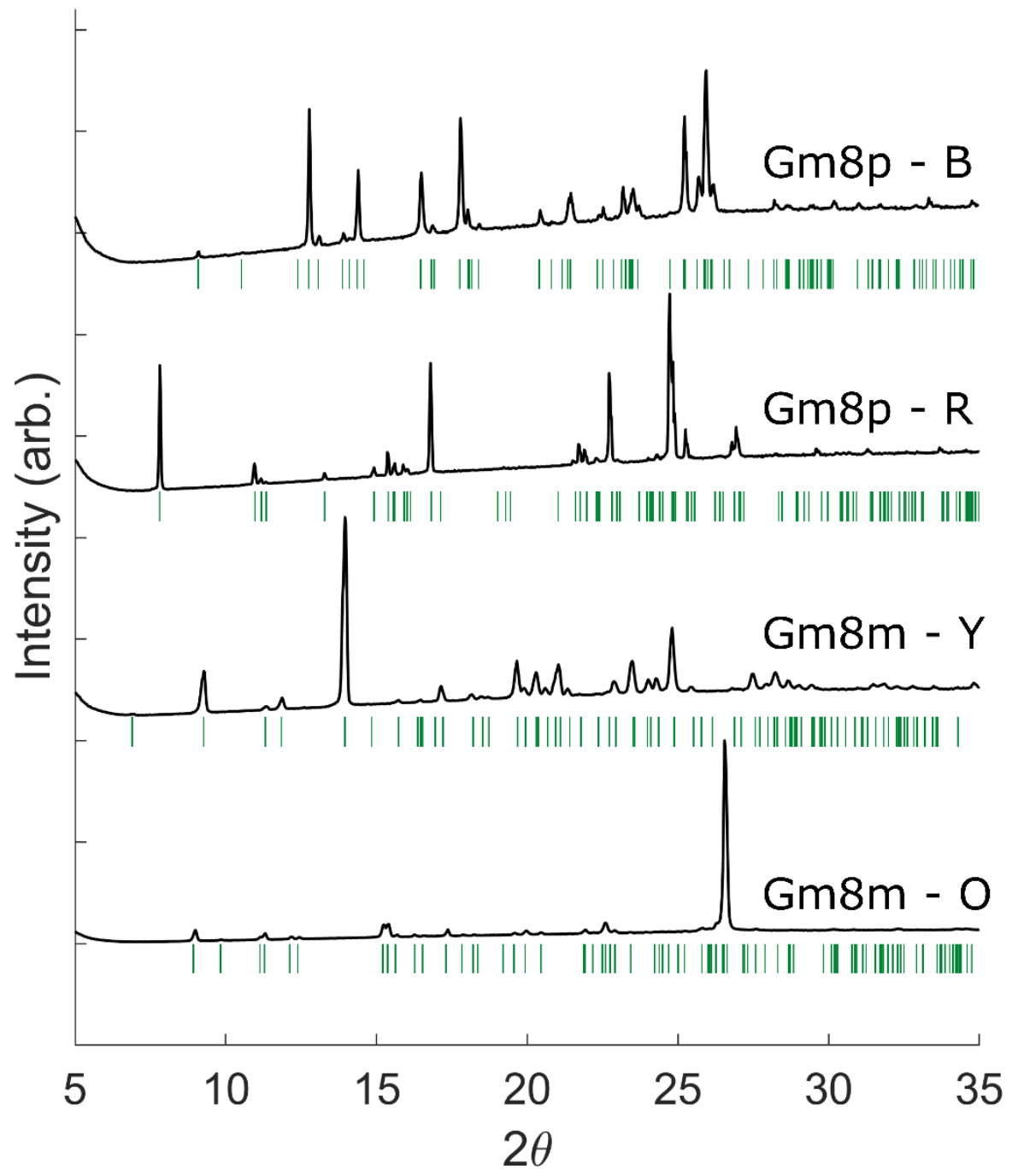

Figure 19 Typical powder x-ray diffraction patterns for phase pure samples of Gm8m and Gm8p polymorphs. Reference peaks calculated from the single crystal structures were obtained using the Profex software ${ }^{1}$. 


\subsection{UV-Vis spectra}

\subsubsection{Solution}
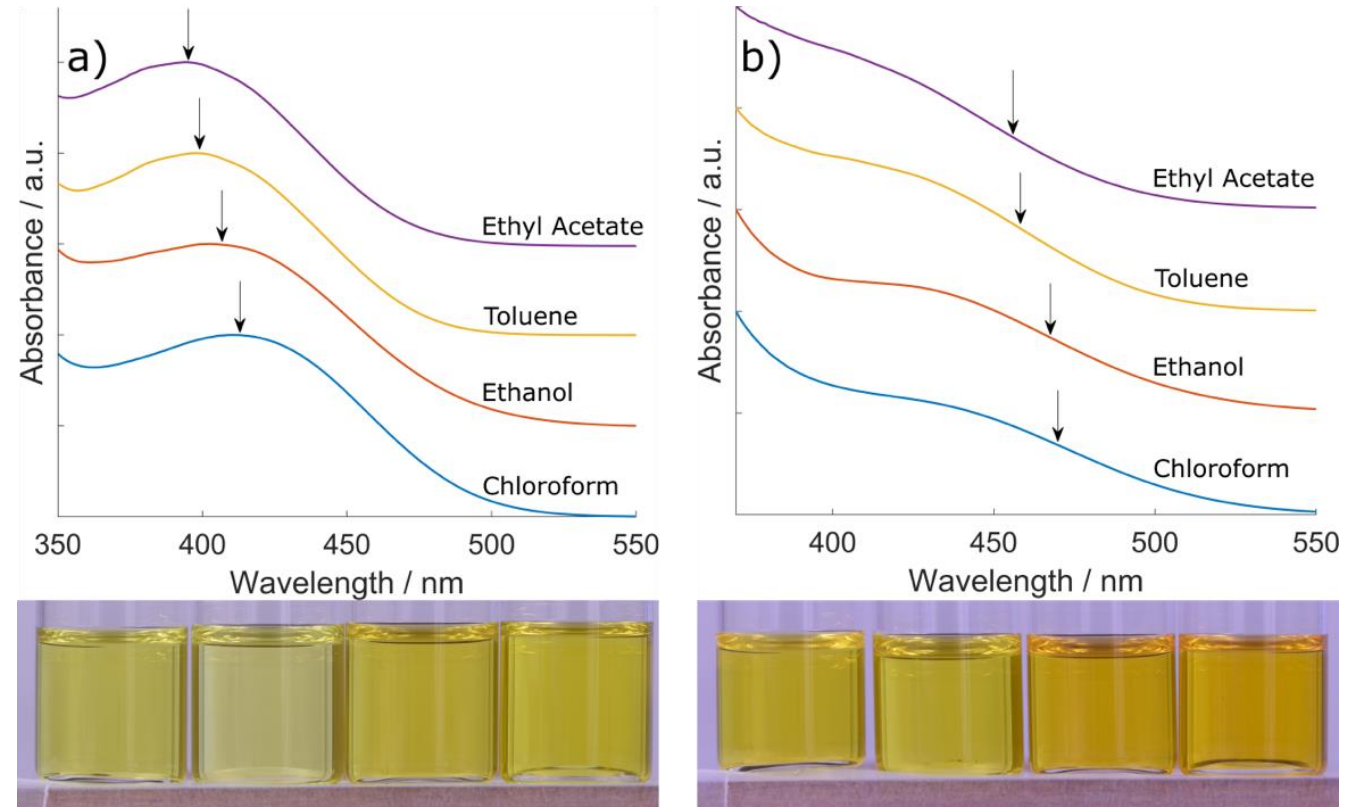

Figure 20 Solution UV-Vis data for a) $\mathrm{Gm} 8 \mathrm{~m}$ and b) $\mathrm{Gm} 8 \mathrm{p}$ solutions at a concentration of $0.25 \mathrm{mg} \cdot \mathrm{mL}^{-1}$ in ethyl acetate (purple), toluene (yellow), ethanol (orange) and chloroform (blue). Arrows give an indication of the trend in absorbance with changes in solvent indicating the peak maxima in a) and the point of inflection in b). The intensity is saturated between 200 and 350 $\mathrm{nm}$ and so is not shown. Images below the spectra show the color of the solutions optically to highlight the slight solvatochromism. The vials are $0.25 \mathrm{mg} \cdot \mathrm{mL}^{-1}$ solution of $\mathrm{Gm} 8 \mathrm{~m}$ and $\mathrm{Gm} 8 \mathrm{p}$ in ethyl acetate, toluene, ethanol and chloroform from left to right.

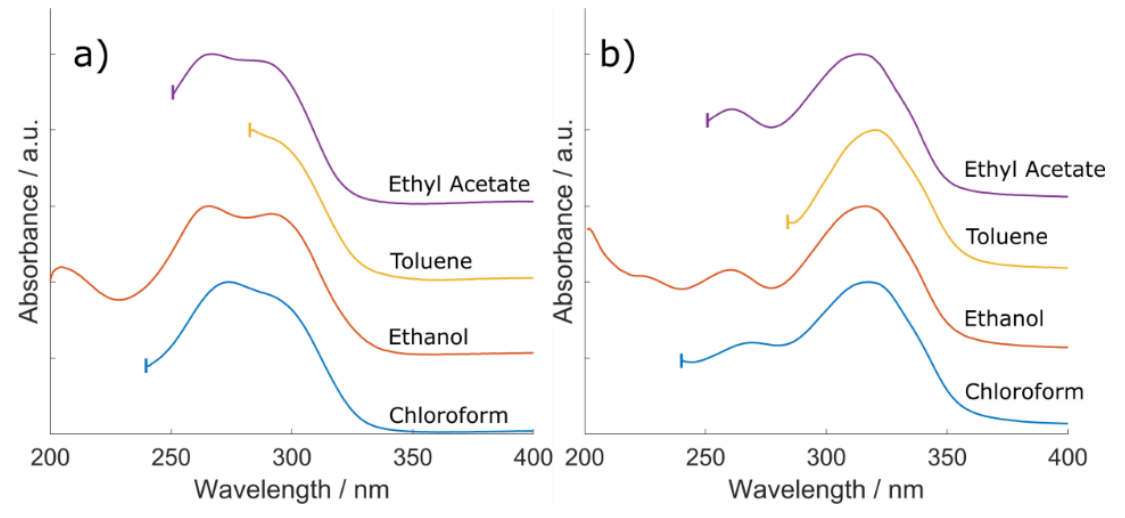

Figure 21 Solution UV-Vis data for a) $\mathrm{Gm} 8 \mathrm{~m}$ and b) $\mathrm{Gm} 8 \mathrm{p}$ solutions at a concentration of $0.008 \mathrm{mg} \cdot \mathrm{mL}^{-1}$ in ethyl acetate (purple), toluene (yellow), ethanol (orange) and chloroform (blue). The spectra have been truncated to show wavelengths above each the solvent cut-offs.

SI Figure 20 and Figure 21 show the UV-Vis spectra of Gm8m and Gm8p in solution at high $\left(0.25 \mathrm{mg} \cdot \mathrm{mL}^{-1}\right)$ and low $\left(0.008 \mathrm{mg} \cdot \mathrm{mL}^{-1}\right)$ respectively. Only a small amount of solvatochromism was seen in across the range of solvents: ethyl acetate, toluene, ethanol and chloroform. The color of the solutions can be attributed to a small peak above $400 \mathrm{~nm}$ in both samples, appearing as a shoulder in $\mathrm{Gm} 8 \mathrm{p}$. These changes are highlighted by an arrow in SI Figure 20. At low concentrations this peak disappears into the noise. The 
changes in the UV-Vis spectra with concentration are given in SI Figure 33 where the calculations show that the appearance of a new peak with concentration is the low intensity onset peak rather than aggregation in solution.

\subsubsection{Raw- crystal UV-Vis spectra}

An approximation of the absorption spectra for the polymorphs of Gm8m and Gm8p is measured using diffuse reflectance of a crushed powder and applying the Kubelka-Munk transformation:

$$
\frac{K}{S}=\frac{1-R_{\infty}}{2 R_{\infty}} \equiv F\left(R_{\infty}\right)
$$

Where $K$ is the absorption coefficient, $S$ is the scattering coefficient, $F\left(R_{\infty}\right)$ is the Kubelka-Munk function and $R_{\infty}$ is the diffuse reflectance of the sample. Under the assumption that the scattering coefficient is a constant the Kubelka-Munk transformation gives an approximation of the absorption of the samples. Relating the Kubekla-Munk function to the linear absorption coefficient allows for an approximation of the absorption onsets of each sample (SI Figure 23). ${ }^{8}$

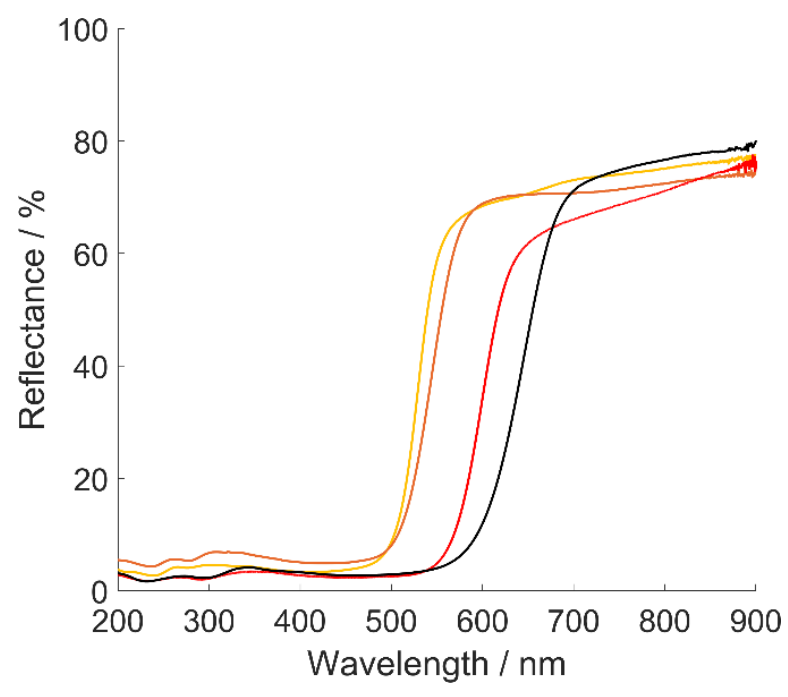

Figure 22 Reflectance data from solid-state diffuse reflectance UV-Vis of powdered samples of Gm8m - Y (yellow), Gm8m - 0 (Orange), Gm8p - R (Red) and Gm8p - B (Black). 


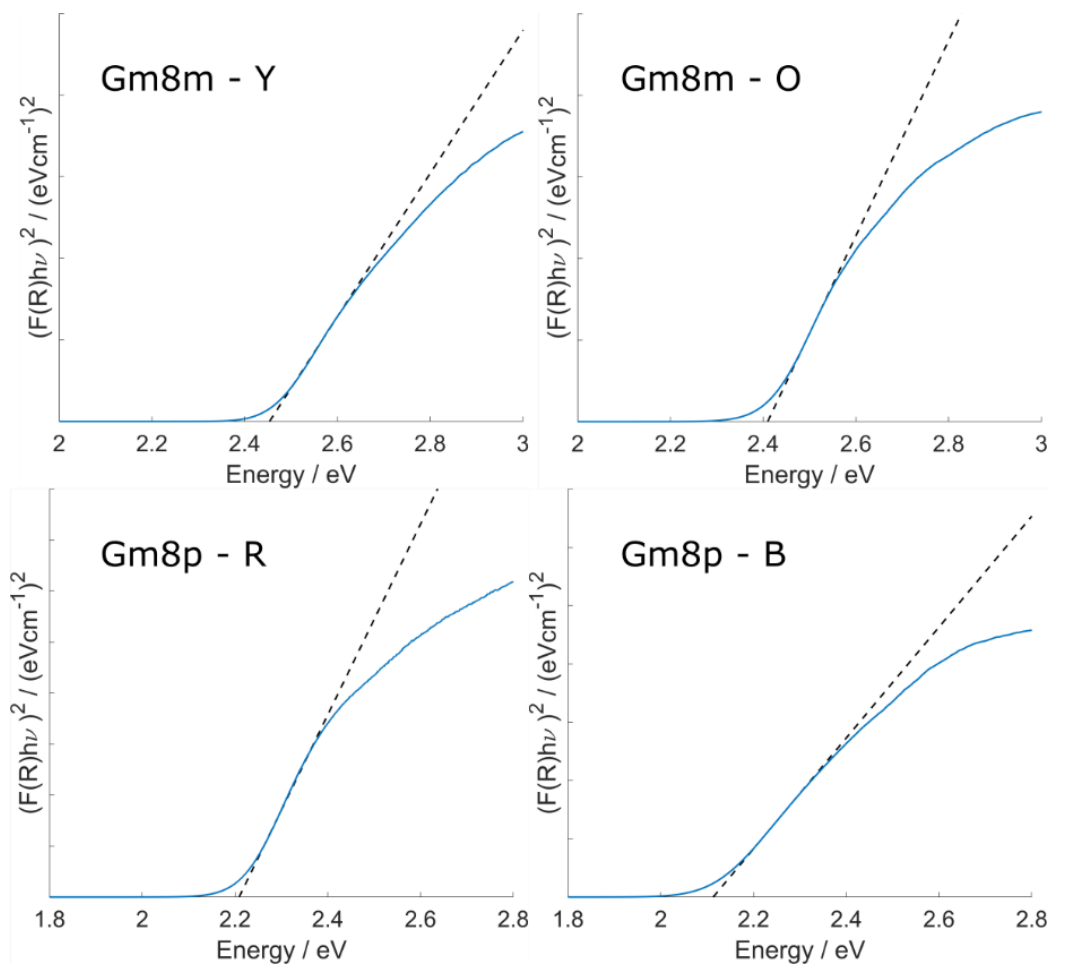

Figure 23 Absorption onset estimation using Kubelka-Munk transformation for Gm8m - Y, Gm8m - 0, Gm8p - R and Gm8p - B from diffuse reflectance measurements.

\begin{tabular}{|l|l|}
\hline Sample & $\begin{array}{l}\text { Absorption onsets } \\
\text { from K-M (eV) }\end{array}$ \\
\hline$G m 8 m-Y$ & 2.45 \\
\hline$G m 8 m-O$ & 2.41 \\
\hline$G m 8 p-R$ & 2.21 \\
\hline$G m 8 p-B$ & 2.11 \\
\hline
\end{tabular}

Table 17 Absorption onsets of $\mathrm{Gm} 8 \mathrm{~m}$ and $\mathrm{Gm} 8 \mathrm{p}$ polymorphs from diffuse reflectance data.

\subsection{Fluorescence}

Along with the color of the crystals, differences in the fluorescence spectra of Gm8m and Gm8p crystals also allow for a clear distinction between the polymorphs present in a sample. Fluorimetry data for solid and solution samples of $\mathrm{Gm} 8 \mathrm{~m}$ and $\mathrm{Gm} 8 \mathrm{p}$ were collected using a Horiba Fluoromax-4P spectrophotometer. Solid samples were placed between quartz slides and solution data was collected using a $10 \mathrm{~mm}$ path length quartz cuvette. The most prominent distinction is between the polymorphs of Gm8m, where Gm8m - Y fluoresces much more intensely than Gm8m - O (SI Figure 24). Solid-state fluorescence spectroscopy (SI Figure 26) shows that the fluorescence intensity of $\mathrm{Gm} 8 \mathrm{~m}-\mathrm{Y}$ is around ten times that of $\mathrm{Gm8m}$ - 0 when illuminated with $365 \mathrm{~nm}$ UV light. Gm8p - R showed fluorescence at a similar level to $\mathrm{Gm} 8 \mathrm{~m}$ - O, with $\mathrm{Gm} 8 \mathrm{p}$ - B showing no appreciable fluorescent intensity. Both $\mathrm{Gm} 8 \mathrm{~m}$ and 
Gm8p are only weakly fluorescent in solution (SI Figure 25), which is likely due to the nitro group in the compounds quenching the fluorescence.

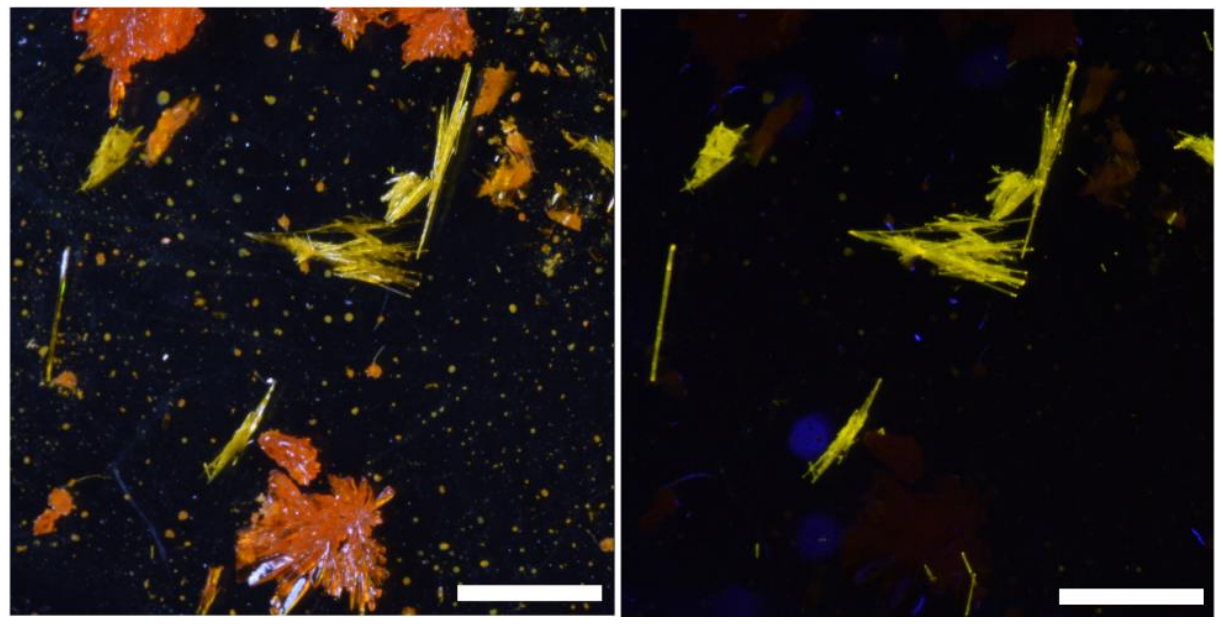

Figure 24 Broadband (Left) and $365 \mathrm{~nm}$ UV illuminated (Right) images of concomitantly grown Gm8m - 0 and Gm8m - Y crystals. Scale bars represent $500 \mu \mathrm{m}$. 


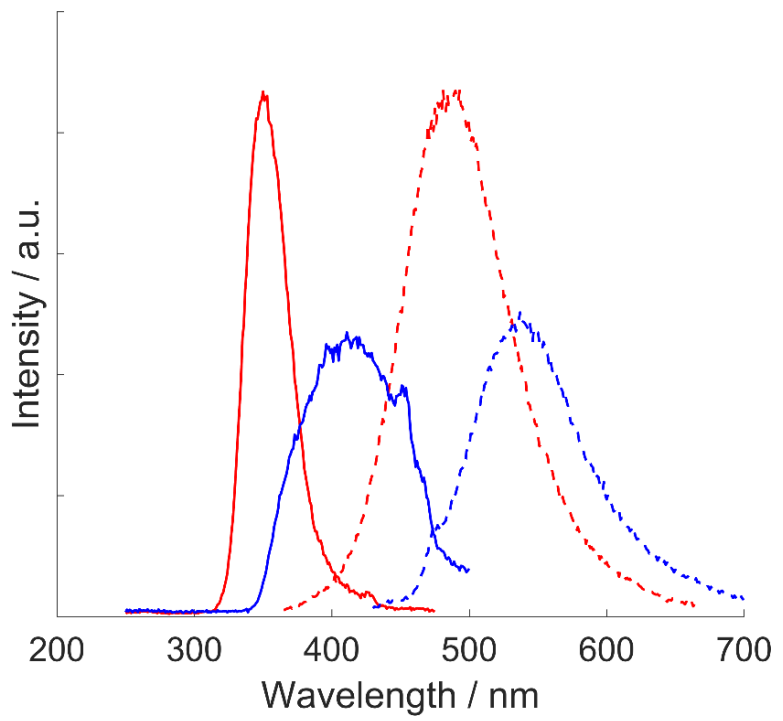

Figure 25 Fluorescence spectra of a $0.5 \mathrm{mg} \cdot \mathrm{mL}^{-1}$ ethanol solution of $\mathrm{Gm} 8 \mathrm{~m}$ (Red) and $\mathrm{Gm} 8 \mathrm{p}$ (Blue). Solid lines show excitation spectra with excitation wavelengths of $490 \mathrm{~nm}$ and $525 \mathrm{~nm}$ for $\mathrm{Gm8m}$ and Gm8p respectively. Dashed lines show emission spectra with emission wavelengths of $350 \mathrm{~nm}$ and $415 \mathrm{~nm}$ for $\mathrm{Gm8m}$ and $\mathrm{Gm8p}$ respectively.
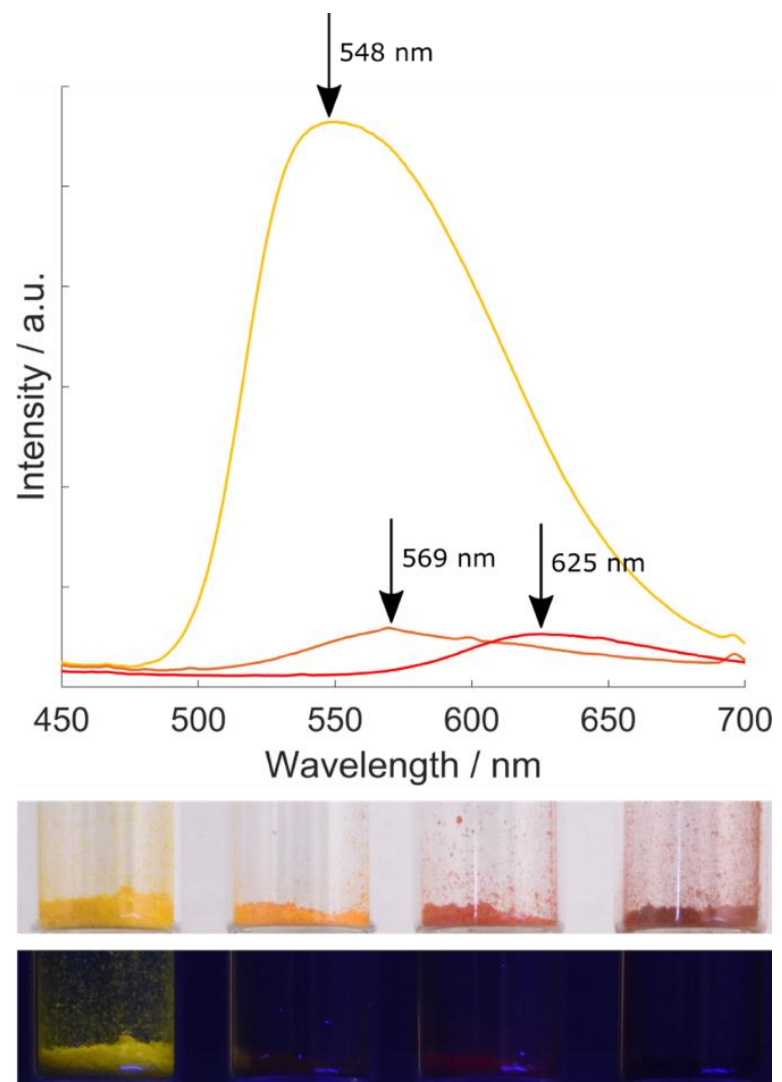

Figure 26 Top: Solid-state fluorescence spectra of Gm8m - Y (yellow) , Gm8m - 0 (orange) and Gm8p - R (red) powders excited at $365 \mathrm{~nm}$ (yellow and orange) and 395nm (red). Gm8p - B has no appreciable fluorescent intensity. Images (from left to right) show powders of $\mathrm{Gm} 8 \mathrm{~m}-\mathrm{Y}, \mathrm{Gm} 8 \mathrm{~m}-0, \mathrm{Gm} 8 \mathrm{p}-\mathrm{R}$ and $\mathrm{Gm} 8 \mathrm{p}-\mathrm{B}$ under optical light (top image) and 385nm UV light (bottom image), highlighting the difference in color and fluorescence of the samples. 


\section{Computational SI}

\subsection{Periodic DFT-D structural optimization}

The experimental structures of chalcones were first processed with DMACRYS ${ }^{7}$ to correct the positions of the hydrogen atoms from the $\mathrm{X}$-ray structures to standard neutron $\mathrm{C}-\mathrm{H}$ and $\mathrm{N}-\mathrm{H}$ bond lengths and provide a good starting point. CASTEP ${ }^{9}$ version 18.1 was used for full structural optimization with the PBE functional, on-the-fly norm-conserving pseudopotentials (NCP) and Tkatchenko and Scheffler's dispersion correction (TS) ${ }^{10}$. After convergence tests of cutoff energies and k-point sampling, a cutoff energy of 1300 $\mathrm{eV}$ and $0.10 \AA^{-1} \mathrm{k}$-point spacing were selected for the current study. Finite basis set correction was used in the structural optimization, which was converged to a maximum residual force of $0.001 \mathrm{eV} / \AA ̊$ with SCF convergence tolerance at $10^{-10} \mathrm{eV}$. Fine grid scale of 4 was used for the FFT grid for charge density. The PBE-TS optimized crystal structures are shown in SI Table 18. As the RMSD 20 indicate, the experimental structures are well reproduced by periodic PBE-TS calculations.

Table 18 crystal structures of chalcones optimized with PBE-TS, compared to experiment.

\begin{tabular}{|c|c|c|c|c|c|c|c|c|}
\hline & $\begin{array}{l}{ }^{*} \mathrm{SG} \\
\mathrm{RMSD} \\
20\end{array}$ & $a(\AA)$ & $b(\AA)$ & $c(\AA)$ & $\alpha\left(^{\circ}\right)$ & $\beta\left({ }^{\circ}\right)$ & $Y\left({ }^{\circ}\right)$ & Vol. $\left(\AA^{3}\right)$ \\
\hline \multicolumn{9}{|l|}{ Gm8m } \\
\hline Yellow form exp & $\mathrm{P} 2_{1} / \mathrm{c}$ & 12.5562 & 6.2891 & 18.0600 & 90 & 92.90 & 90 & 1424.32 \\
\hline PBE-TS opt & 0.163 & 12.5714 & 6.3717 & 17.6518 & 90 & 93.10 & 90 & 1411.85 \\
\hline Orange form exp & $P-1$ & 8.3376 & 9.4304 & 10.0957 & 102.25 & 102.70 & 104.85 & 717.55 \\
\hline PBE-TS opt & 0.154 & 8.3711 & 9.2377 & 10.0415 & 100.44 & 102.58 & 106.33 & 702.50 \\
\hline \multicolumn{9}{|l|}{ Gm8p } \\
\hline Black form exp & $\mathrm{P} 2{ }_{1} / \mathrm{c}$ & 7.8191 & 13.4348 & 13.8068 & 90 & 97.37 & 90 & 1438.40 \\
\hline PBE-TS opt & 0.168 & 7.6181 & 13.5673 & 13.7437 & 90 & 97.40 & 90 & 1408.67 \\
\hline Red form exp & $\mathrm{P} 21 / \mathrm{n}$ & 8.3419 & 8.0686 & 21.6440 & 90 & 91.11 & 90 & 1456.53 \\
\hline PBE-TS opt & 0.165 & 8.4025 & 7.8748 & 21.6600 & 90 & 91.09 & 90 & 1432.93 \\
\hline
\end{tabular}

* The space group for the experimental and optimized structure, followed by the root mean square difference between the positions of the non-hydrogenic atoms in a 20 -molecule cluster $\left(\mathrm{RMSD}_{20}\right)$ in $\AA$ as calculated by Mercury.

\subsection{Periodic DFT-D relative energies using various dispersion corrections}

The relative energies of polymorphs of chalcones at $0 \mathrm{~K}$ are calculated the PBE-TS optimized structures with several different dispersion corrections, including Grimme's ${ }^{11}$ D02 and D03, the pairwise TS correction and its improved many-body version MBD*12.

Although the energy difference depends on the dispersion correction used (SI Figure 27), the ranking of the polymorphs remain the same for two chalcone systems. The more stable form at $0 \mathrm{~K}$ are the $\mathrm{Gm} 8 \mathrm{~m}$ orange form and $\mathrm{Gm} 8 \mathrm{p}$ black form respectively. $\mathrm{Gm} 8 \mathrm{~m}$ yellow is $2-3 \mathrm{~kJ} / \mathrm{mol}$ less stable in lattice energy than $\mathrm{Gm} 8 \mathrm{~m}$ orange. The relative stability of the Gm8p polymorphs is more dependent on the dispersion correction, but Gm8p red could be up to $5 \mathrm{~kJ} / \mathrm{mol}$ (PBE-MBD*) less stable than its black form. 


\section{Gm8m}

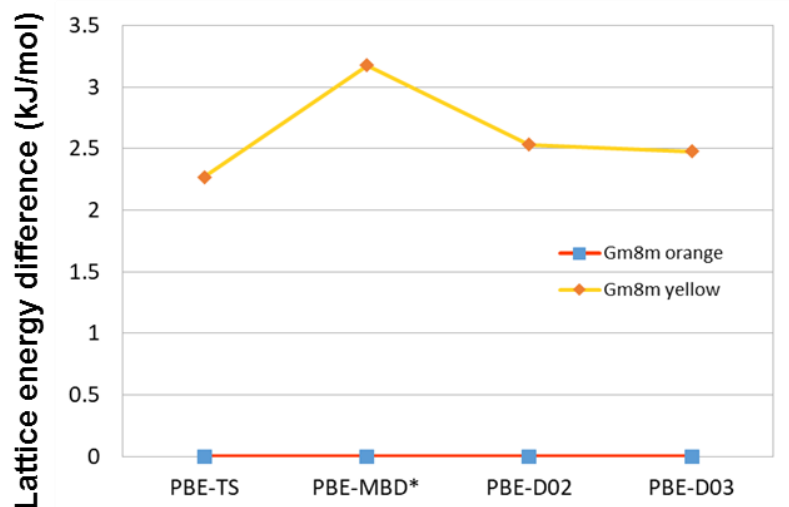

\section{Gm8p}

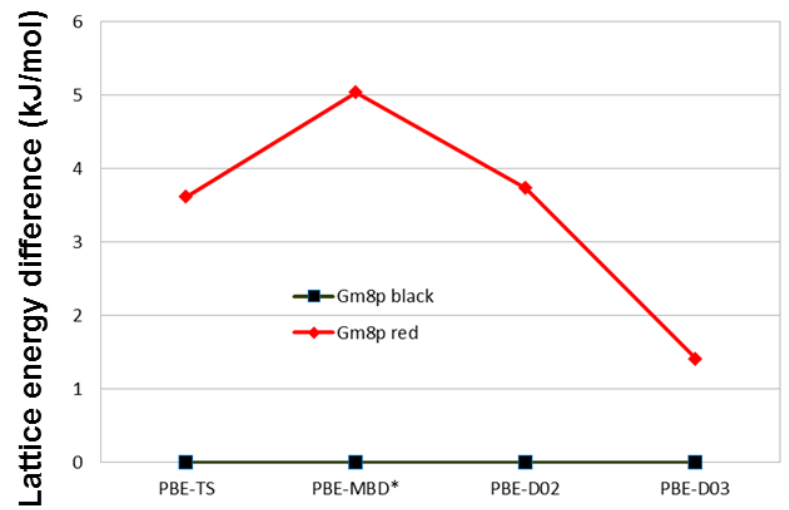

Figure 27 The relative lattice energies of the polymorphs calculated with the PBE functional and various dispersion corrections.

\subsection{Phonon dispersion and free energy calculations}

Harmonic phonon calculations were used to estimate the free energy difference and its change with temperature between polymorphs. Density-functional perturbation theory (DFPT) method was used with SCF convergence tolerance set at $10^{-12} \mathrm{eV}$. Phonon dispersions were plotted along high-symmetry paths suggested by Seek-Path ${ }^{13}$. The phonon q-grid was chosen to be the maximum size that gave no imaginary frequencies on the acoustic branches of phonon dispersion curves (SI Figure 28).

Free energy corrections based on harmonic approximation were calculated for $\mathrm{Gm} 8 \mathrm{~m}$ and Gm8p polymorphs using the converged phonon calculations with PBE-TS method, added to calculated PBE-TS or PBE-MBD* lattice energies (SI Figure 29). Within the harmonic approximation, the Helmholtz free energy of $\mathrm{Gm} 8 \mathrm{~m}$ yellow form is higher than that of the orange form by $4.2 \mathrm{~kJ} / \mathrm{mol}$ at $10 \mathrm{~K}$ at PBE-MBD*/PBE-TS level, or $3.3 \mathrm{~kJ} / \mathrm{mol}$ at $10 \mathrm{~K}$ at PBE-TS level. The relative free energy between the two decreases with increasing temperature, due to the higher entropy of the yellow form. However, the free energy ranking of the two forms does not change even at melting point, i.e. $\mathrm{Gm} 8 \mathrm{~m}$ is calculated to be a monotropic system.

Similarly, the Helmholtz free energy of Gm8p red form is higher than that of the black form by $4.6 \mathrm{~kJ} / \mathrm{mol}$ at $10 \mathrm{~K}$ at PBE-MBD*/PBE-TS level, or $3.2 \mathrm{~kJ} / \mathrm{mol}$ at $10 \mathrm{~K}$ at PBE-TS level. However, the red form has a much larger entropy than the black form, the relative free energy between the two forms decreases with increasing temperature, and the free energy ranking of the two forms changes order at a calculated temperature at around $480 \mathrm{~K}$ (PBE-TS, $>600 \mathrm{~K}$ for PBE-MBD*), much higher than the melting points of Gm8p polymorphs. So Gm8p is calculated to be a monotropic system. 

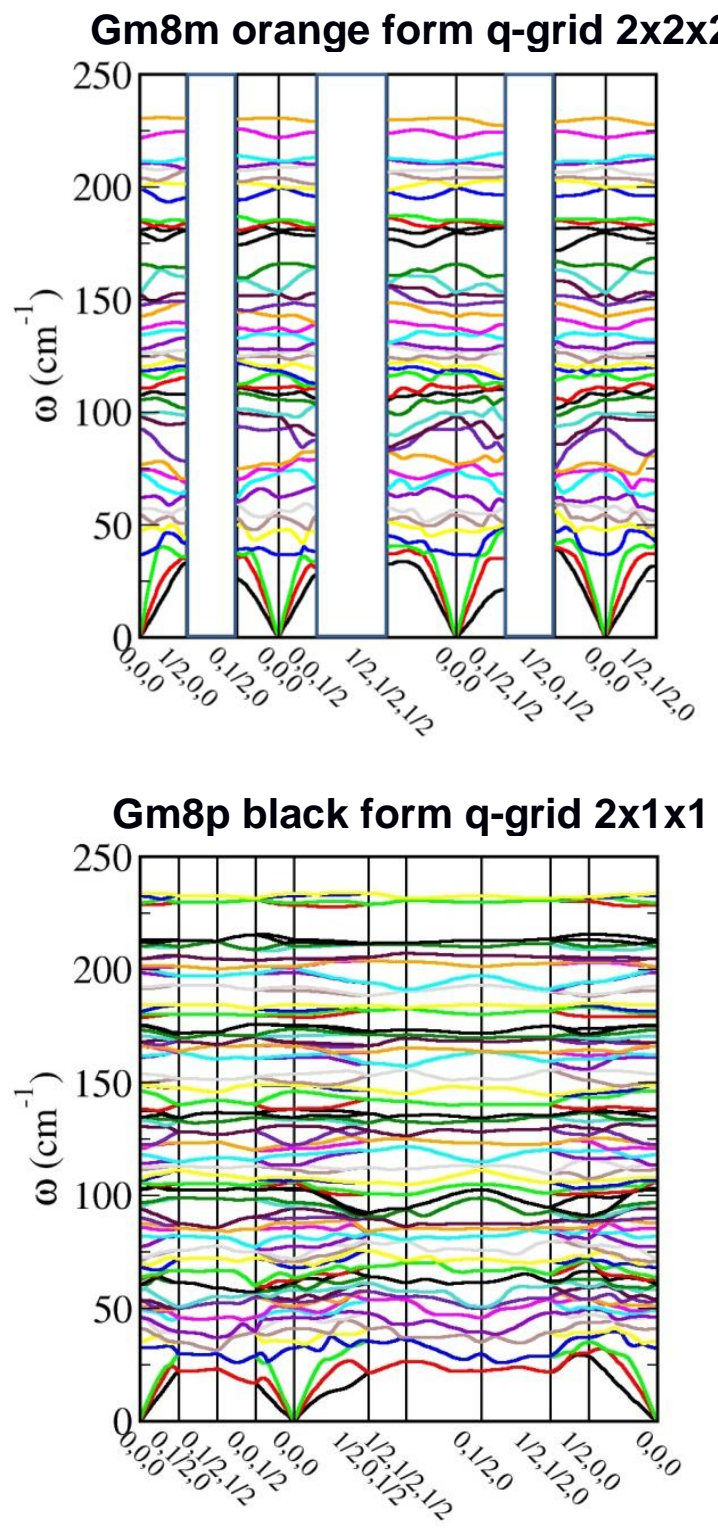
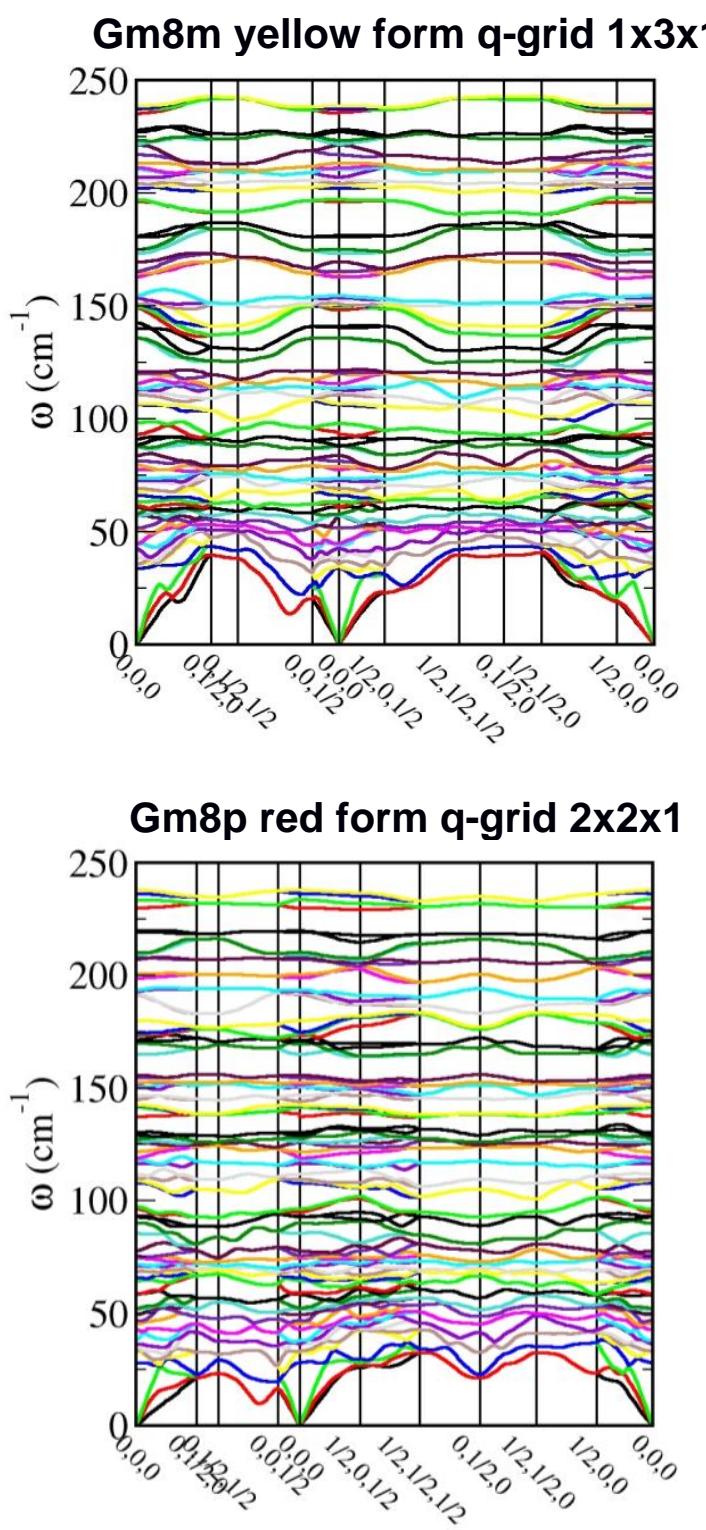

Figure 28 The harmonic phonon dispersion curves in the lattice mode region for the polymorphs. 

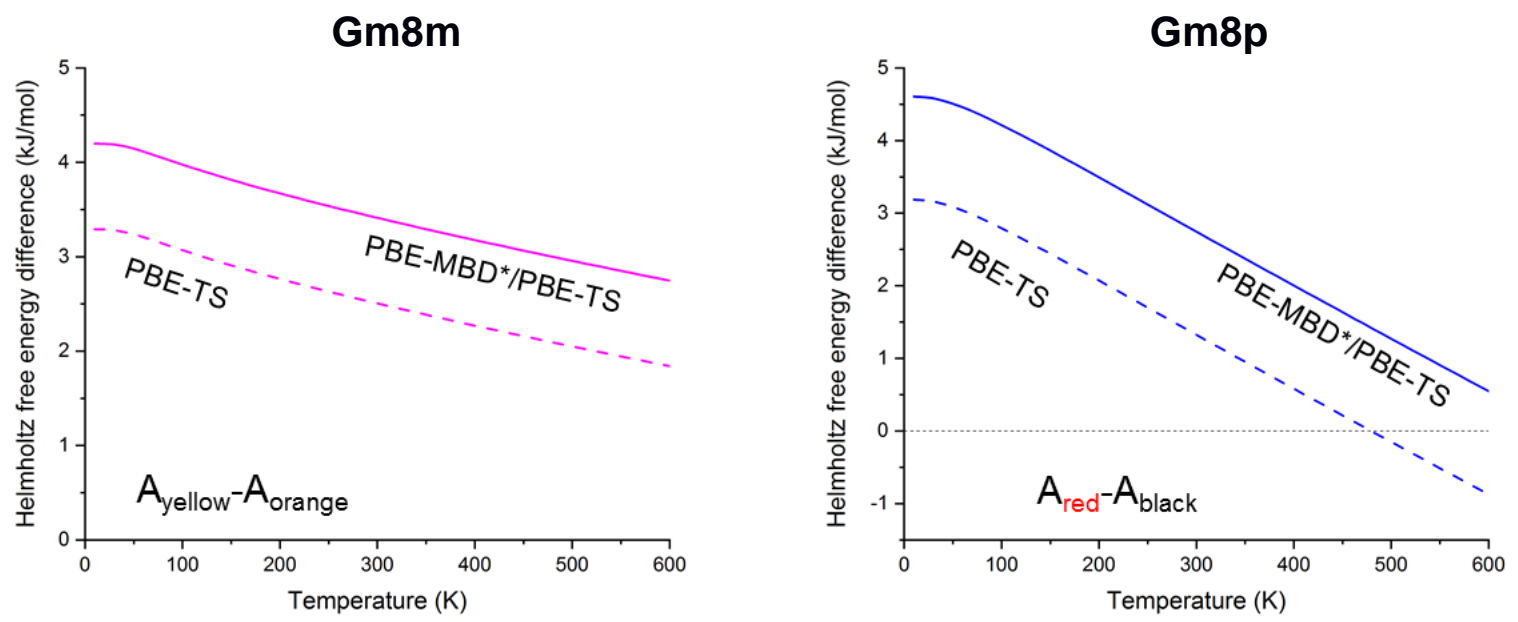

Figure 29 Relative Helmholtz free energies of Gm8m and Gm8p polymorphs.

\subsection{Example of electronic band structure (Gm8m - Y) as calculated by periodic PBE calculations}

For crystals, periodic DFT-D methods can in principle calculate the band structure within the Brillouin zone, thus giving us a full picture of the electronic structure. However, for insulators, there is a well-known problem with calculated band gaps using GGA functionals. This is illustrated by the electronic band structure of the PBE-TS optimized Gm8m - Y structure (SI Figure 30). This PBE calculation gives Gm8m - Y an indirect band gap of $1.13 \mathrm{eV}$, which is considerably lower than the molecular transitions calculated with TDDFT/wB97x (> $3.5 \mathrm{eV}$ ) or estimated from the diffuse reflectance experimental spectra (2.1-2.5 eV, SI Table 17).

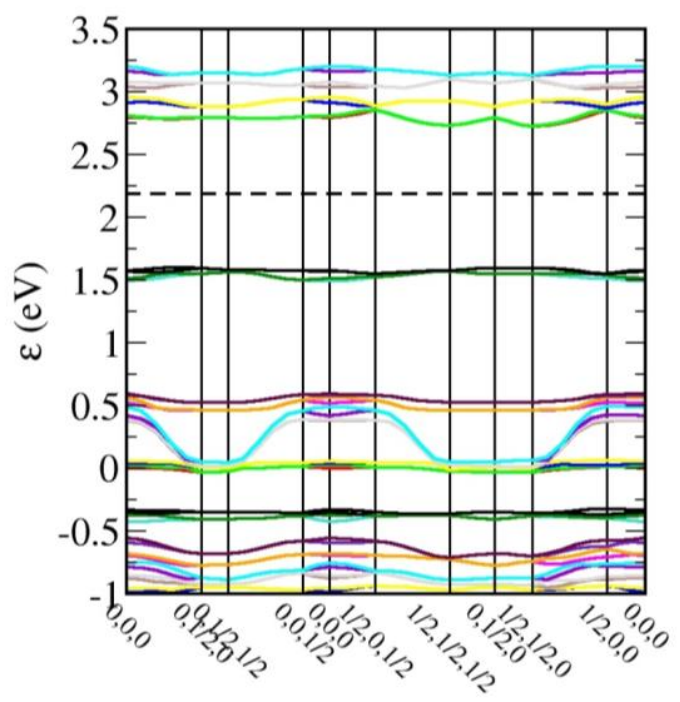

Figure 30 Electronic band structure of $\mathrm{Gm8m}$ yellow form calculated with PBE functional at PBE-TS optimized structure. 


\subsection{Colored chalcones: dimer and cluster color calculations}

\subsubsection{TD-DFT computational details}

TD-DFT calculations of dimers were performed with Gaussian $09^{14}$ using the $\omega B 97 x$ functional and 6$31 \mathrm{G}(\mathrm{d}, \mathrm{p})$ basis set. The choice of functionals in calculating excitation energies with density functional theory is nontrivial as pure functionals such as PBE are notorious for underestimating Kohn-Sham band gaps and hence excitation energies (SI figure 29). Hybrid functionals, such as PBEO and B3LYP, show improvements over their GGA counterparts by introducing a portion of exact Hartree-Fock exchange, yet most of the time this is still not enough for excitations with charge-transfer character. ${ }^{15}$ The long-range corrected functional chosen here, wB97x has been shown to perform better for charge-transfer states, but may also shift the entire spectrum to the blue. ${ }^{16}$

Diffuse functions have been shown to be important for calculating accurate excitation energies. ${ }^{15}$ However calculations with a large $6-311++G(2 d, p)$ basis set and a moderate $6-31 G(d, p)$ basis set for monomers (SI Section 2.5.2) shows qualitatively similar relative shifts in excitation spectra. Since we are more concerned with these relative shifts rather than the absolute values, and intended to do a large number of calculations on a range of size of cluster, the $6-31 G(d, p)$ basis set was used in TDDFT calculations of clusters.

The excited states included in the TD-DFT calculations depend on the spectral region of concern. In this study we are most interested in the onset of the UV-Vis absorption. Therefore, for monomers the first 6 excitations were included in the TD-DFT calculations, covering excitations up to $4.8 \mathrm{eV}$ ( $260 \mathrm{~nm}$ ), which should be enough for the low-lying excited states responsible for the change of absorption in the visible region. For dimers, 18 excitations were included to ensure coverage no smaller than those of the monomers and for tetramers, hexamers and octamers, 30 excitations were included.

The 15-molecule clusters, containing a molecule encompassed by all other molecules in van der Waals contact, contain 570 atoms. This mean that the calculations were extremely costly in computing resource, and the 19-molecule cluster ( 722 atoms) required for $\mathrm{Gm} 8 \mathrm{p}-\mathrm{B}$ is simply too expensive to run. Attempts to run TD-DFT calculations for the 15-molecule clusters using the Gaussian09 proved to be difficult due to the size of the system. Instead, calculations were carried out for the 15-molecule clusters of $\mathrm{Gm} 8 \mathrm{~m}-\mathrm{O}$ and $\mathrm{Gm} 8 \mathrm{~m}-\mathrm{Y}$ using Turbomole with TD-DFT under the resolution-of-the-identity (RI) approximation using the same $\omega B 97 x$ functional and $6-31 G(d, p)$ basis set. This approach was shown to give equivalent results to Gaussian on the monomer (SI Table 39).

\subsubsection{TD-DFT calculations of UV-Vis spectra of monomers in crystals}

The significant torsion angles of $\mathrm{Gm} 8 \mathrm{~m}$ and Gm8p molecules in their polymorphs, PBE-TS optimized structures and optimized isolated molecular configuration are listed in Table 19. The effects of these variations in conformation are shown by the calculated $1^{\text {st }}$ electronic excitations, and those excitations with an oscillator strength $>0.01$ (SI Table 20). The molecular orbitals (MOs) involved in the excitations are shown in SI Table 21 for a monomer optimized in isolation and in each PBE-TS optimized crystal structure. It is worth noting that the first excitation does not always involve the HOMO and LUMO as 
would be expected from Koopman's theorem, partly because of the simplification involved in the oneelectron orbital approximation when there are many $\pi$ orbitals, and also because the TD-DFT calculations relax the excited state orbitals.

To choose a suitable basis set which can provide acceptable yet affordable UV-Vis spectra through TD-DFT calculations, Gm8m and Gm8p molecular geometries were optimized with $\omega B 97 x$ using two basis sets. We evaluated a small 6-31G(d,p) basis set (410 basis functions for one $\mathrm{Gm} 8 \mathrm{~m} / \mathrm{Gm} 8 \mathrm{p}$ molecule) and a much bigger $6-311++G(2 d, p)$ basis set (706 basis functions per molecule) with valence triple-zeta, diffuse and polarization functions on both heavy and light atoms, which has been shown to be important for the correct description of excited electronic states. $6-311++G(2 d, p)$ is too large for anything larger than a $\mathrm{Gm} 8 \mathrm{~m} / \mathrm{Gm} 8 \mathrm{p}$ tetramer, but $6-31 \mathrm{G}(\mathrm{d}, \mathrm{p}$ ) can still be used for larger oligomers (3280 basis functions for each $\mathrm{Gm} 8 \mathrm{~m} / \mathrm{Gm} 8 \mathrm{p}$ octamer). The optimized $\mathrm{Gm} 8 \mathrm{~m} / \mathrm{Gm} 8 \mathrm{p}$ geometries using 6-31G(d,p) and 6-311++G(2d,p) are the same, apart from small differences in the torsion angles (Table 19).

Table 19 Crystalline and optimized conformations of $\mathrm{Gm} 8 \mathrm{~m}$ and $\mathrm{Gm} 8 \mathrm{p}$, in both the PBE-TS optimized crystal structure and optimized in isolation (i). Since both crystal conformations optimize to the same isolated molecule minimum, these are not conformational polymorphs. The minor ( $<14 \%$ ) component of $\mathrm{Gm} 8 \mathrm{~m}-\mathrm{Y}$ only differs from the major component in the $\mathrm{NO}_{2}$ torsion $\left(\phi_{4}=14^{\circ}\right)$ and gave virtually identical results and is not considered further.

\begin{tabular}{|l|l|l|l|l|}
\hline Conformation & $\phi_{1} /{ }^{\circ}$ & $\phi_{2} /{ }^{\circ}$ & $\phi_{3} /{ }^{\circ}$ & $\phi_{4} /{ }^{\circ}$ \\
\hline Gm8m & & & & \\
\hline$G m 8 m-i(\omega B 97 x / 6-31 G(d, p))$ & -175 & -167 & 179 & 0 \\
\hline$G m 8 m-i(\omega B 97 x / 6-311++G(2 d, p))$ & -174 & -165 & 177 & 0 \\
\hline Gm8m - Y major expt. & -162 & -175 & 168 & -17 \\
\hline Gm8m - Y PBE-TS & -165 & -175 & 170 & -18 \\
\hline Gm8m - O expt. & -177 & -173 & 179 & 0 \\
\hline Gm8m - O PBE-TS & -179 & -171 & 179 & 2 \\
\hline Gm8p & & & & \\
\hline$G m 8 p-i(\omega B 97 x / 6-31 G(d, p))$ & 175 & 166 & 177 & 0 \\
\hline$G m 8 p-i(6-311++G(2 d, p))$ & 174 & 165 & 177 & 0 \\
\hline Gm8p-B expt. & 173 & 177 & -175 & -7 \\
\hline Gm8p-B PBE-TS & 174 & 177 & -175 & -7 \\
\hline Gm8p-B HT expt. & 178 & 178 & -180 & -2 \\
\hline
\end{tabular}

The TD-DFT UV-Vis spectra for the crystalline and optimized molecular conformations calculated using $\omega B 97 x / 6-31 G(d, p)$ or $6-311++G(2 d, p)$ are compared in Figure 31. This shows that the smaller 6-31G(d,p) basis set produces qualitatively similar UV-Vis spectra to those calculated with the larger $6-311++G(2 d, p)$, at least for the first few electronic transitions, and the intensities are very similar. Hence we can use the smaller $6-31 G(d, p)$ basis set with $\omega B 97 x$ for the investigation of the relative onsets of UV-Vis absorption in $\mathrm{Gm} 8 \mathrm{~m} / \mathrm{Gm} 8 \mathrm{p}$. 


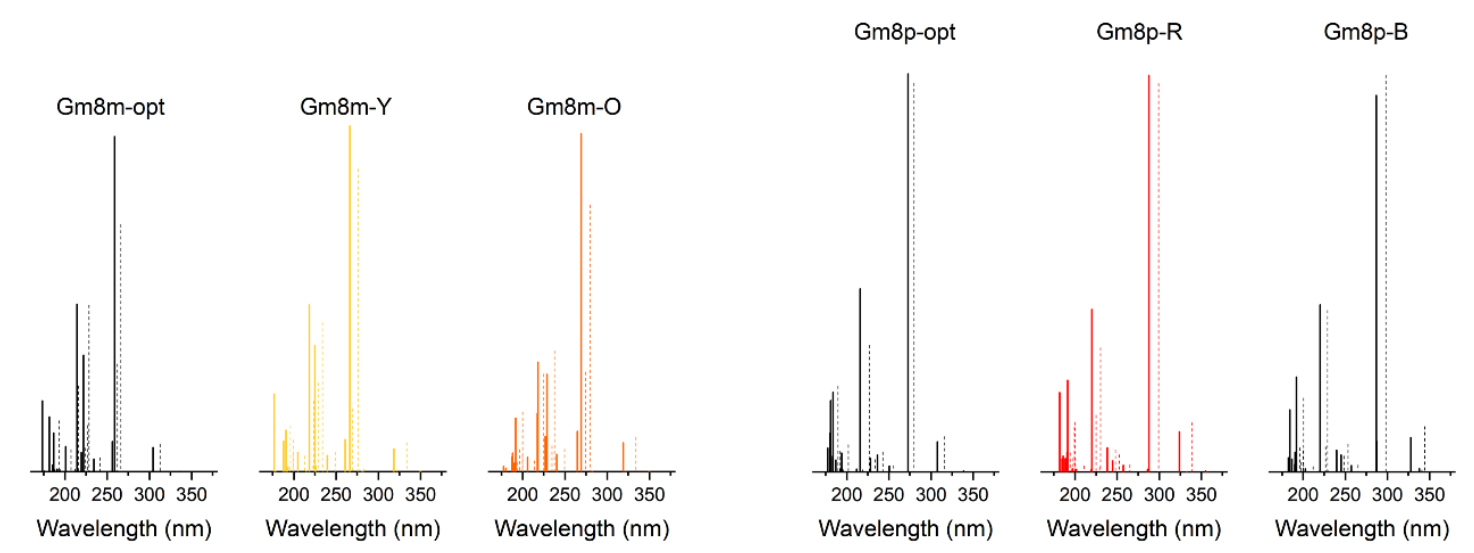

Figure 31 The electronic excitations of Gm8m and Gm8p molecules in the optimized single-molecule and in the PBE-TSoptimized polymorph conformations, calculated with TDDFT using $\omega B 97 x$ and $6-31 G(d, p)$ (solid) or 6-311++G(d,p) (dashed), plotted as stick spectra.

Table 20 The first and most prominent electronic excitations of Gm8m and Gm8p molecules, in the optimized single-molecule and in the PBE-TS-optimized polymorph conformations, calculated with TDDFT using $\omega B 97 x$ and two different basis sets, listed from left to right in the descending order of wavelengths, along with their oscillator strengths (0.s.). For monomers, the HOMO is molecular orbital \#78.

\begin{tabular}{|c|c|c|c|c|c|c|c|c|c|c|}
\hline Polymorph & $\begin{array}{l}\lambda / \mathrm{eV} \\
(\mathrm{nm})\end{array}$ & $\begin{array}{l}\text { MOs } \\
(\text { o.s.) }\end{array}$ & $\begin{array}{l}\lambda / \mathrm{eV} \\
(\mathrm{nm}) \\
\end{array}$ & $\begin{array}{l}\text { MOs } \\
\text { (o.s.) }\end{array}$ & $\begin{array}{l}\lambda / \mathrm{eV} \\
(\mathrm{nm})\end{array}$ & $\begin{array}{l}\text { MOs } \\
\text { (o.s.) }\end{array}$ & $\begin{array}{l}\lambda / \mathrm{eV} \\
(\mathrm{nm})\end{array}$ & $\begin{array}{l}\text { MOs } \\
\text { (o.s.) }\end{array}$ & $\begin{array}{l}\lambda / \mathrm{eV} \\
(\mathrm{nm})\end{array}$ & $\begin{array}{l}\text { MOs } \\
\text { (o.s.) }\end{array}$ \\
\hline \multicolumn{11}{|c|}{ Gm8m } \\
\hline opt./6-31G(d,p) & $\begin{array}{l}3.69 \\
(335.6)\end{array}$ & $\begin{array}{l}75-> \\
79,80 \\
\left(2 \times 10^{-4}\right)\end{array}$ & $\begin{array}{l}4.07 \\
(304.4)\end{array}$ & $\begin{array}{l}78-> \\
79,80,8 \\
1(0.06)\end{array}$ & & & $\begin{array}{l}4.79 \\
(258.9)\end{array}$ & $\begin{array}{l}77-> \\
79,80 \\
(0.89) \\
\end{array}$ & $\begin{array}{l}4.84 \\
(256.3)\end{array}$ & $\begin{array}{l}7-> \\
79,80 \\
(0.08) \\
\end{array}$ \\
\hline $\begin{array}{l}\text { opt./6- } \\
311++G(2 d, p)\end{array}$ & $\begin{array}{l}3.69 \\
(335.8)\end{array}$ & $\begin{array}{l}75-> \\
79,80 \\
(0.001)\end{array}$ & $\begin{array}{l}3.97 \\
(312.4)\end{array}$ & $\begin{array}{l}78-> \\
79,80,8 \\
1(0.07)\end{array}$ & & & $\begin{array}{l}4.66 \\
(266.3)\end{array}$ & $\begin{array}{l}77-> \\
79,80 \\
(0.66) \\
\end{array}$ & $\begin{array}{l}4.73 \\
(262.2)\end{array}$ & $\begin{array}{l}77-> \\
79,80 \\
(0.29) \\
\end{array}$ \\
\hline$Y / 6-31 G(d, p)$ & $\begin{array}{l}3.55 \\
(349.4)\end{array}$ & $\begin{array}{l}75-> \\
79,80 \\
\left(9 \times 10^{-4}\right)\end{array}$ & $\begin{array}{l}3.89 \\
(318.4)\end{array}$ & $\begin{array}{l}78-> \\
79,80,8 \\
1(0.06)\end{array}$ & & & $\begin{array}{l}4.65 \\
(266.4)\end{array}$ & $\begin{array}{l}77-> \\
79,80 \\
(0.92) \\
\end{array}$ & $\begin{array}{l}4.76 \\
(260.7)\end{array}$ & $\begin{array}{l}77-> \\
79,80 \\
(0.09) \\
\end{array}$ \\
\hline $\begin{array}{l}Y / 6- \\
311++G(2 d, p)\end{array}$ & $\begin{array}{l}3.53 \\
(350.8)\end{array}$ & $\begin{array}{l}75-> \\
79,80 \\
(0.003) \\
\end{array}$ & $\begin{array}{l}3.72 \\
(333.5)\end{array}$ & $\begin{array}{l}78-> \\
79,80,8 \\
1(0.08)\end{array}$ & & & $\begin{array}{l}4.49 \\
(276.4)\end{array}$ & $\begin{array}{l}77-> \\
79,80 \\
(0.81) \\
\end{array}$ & $\begin{array}{l}4.60 \\
(269.7)\end{array}$ & $\begin{array}{l}77-> \\
79,80 \\
(0.17) \\
\end{array}$ \\
\hline $0 / 6-31 G(d, p)$ & $\begin{array}{l}3.55 \\
(349.5)\end{array}$ & $\begin{array}{l}75-> \\
79,80 \\
\left(2 \times 10^{-4}\right)\end{array}$ & $\begin{array}{l}3.89 \\
(318.9)\end{array}$ & $\begin{array}{l}78-> \\
79,80,8 \\
1(0.08) \\
\end{array}$ & & & $\begin{array}{l}4.61 \\
(269.0)\end{array}$ & $\begin{array}{l}77-> \\
79,80 \\
(0.90) \\
\end{array}$ & $\begin{array}{l}4.68 \\
(264.7)\end{array}$ & $\begin{array}{l}77-> \\
79,80 \\
(0.11) \\
\end{array}$ \\
\hline $\begin{array}{l}0 / 6- \\
311++G(2 d, p)\end{array}$ & $\begin{array}{l}3.52 \\
(351.9)\end{array}$ & $\begin{array}{l}75-> \\
79,80 \\
\left(6 \times 10^{-4}\right)\end{array}$ & $\begin{array}{l}3.71 \\
(334.1)\end{array}$ & $\begin{array}{l}78-> \\
79,80,8 \\
1(0.09)\end{array}$ & & & $\begin{array}{l}4.43 \\
(279.9)\end{array}$ & $\begin{array}{l}77-> \\
80 \\
(0.71) \\
\end{array}$ & $\begin{array}{l}4.52 \\
(274.4)\end{array}$ & $\begin{array}{l}77-> \\
79 \\
(0.27) \\
\end{array}$ \\
\hline Exptal * & & & $(\sim 410)$ & & & & $(\sim 300)$ & & & \\
\hline \multicolumn{11}{|c|}{ Gm8p } \\
\hline opt./6-31G(d,p) & $\begin{array}{l}3.66 \\
(338.4)\end{array}$ & $\begin{array}{l}75-> \\
79,80 \\
(0.001)\end{array}$ & $\begin{array}{l}4.03 \\
(307.4)\end{array}$ & $\begin{array}{l}78-> \\
79,80 \\
(0.08)\end{array}$ & & & $\begin{array}{l}4.54 \\
(272.8)\end{array}$ & $\begin{array}{l}77-> \\
79 \\
(1.06)\end{array}$ & $\begin{array}{l}4.95 \\
(250.5)\end{array}$ & $\begin{array}{l}74-> \\
79,77 \\
->81 \\
(0.02) \\
\end{array}$ \\
\hline
\end{tabular}




\begin{tabular}{|c|c|c|c|c|c|c|c|c|c|c|}
\hline $\begin{array}{l}\text { opt./6- } \\
311++G(2 d, p)\end{array}$ & $\begin{array}{l}3.66 \\
(338.7)\end{array}$ & $\begin{array}{l}75-> \\
79,80 \\
(0.003)\end{array}$ & $\begin{array}{l}3.92 \\
(316.1)\end{array}$ & $\begin{array}{l}78-> \\
79,80 \\
(0.09)\end{array}$ & & & $\begin{array}{l}4.43 \\
(279.9)\end{array}$ & $\begin{array}{l}77-> \\
79 \\
(1.04)\end{array}$ & $\begin{array}{l}4.85 \\
(255.5)\end{array}$ & $\begin{array}{l}74-> \\
79,77 \\
->81 \\
(0.02)\end{array}$ \\
\hline$R / 6-31 G(d, p)$ & $\begin{array}{l}3.49 \\
(355.0)\end{array}$ & $\begin{array}{l}75-> \\
79,80 \\
(0.002)\end{array}$ & $\begin{array}{l}3.83 \\
(323.8)\end{array}$ & $\begin{array}{l}78-> \\
79,80 \\
(0.11)\end{array}$ & & & $\begin{array}{l}4.31 \\
(287.8)\end{array}$ & $\begin{array}{l}77-> \\
79 \\
(1.06)\end{array}$ & $\begin{array}{l}4.82 \\
(257.3)\end{array}$ & $\begin{array}{l}74-> \\
79,77 \\
->81 \\
(0.02)\end{array}$ \\
\hline $\begin{array}{l}R / 6- \\
311++G(2 d, p)\end{array}$ & $\begin{array}{l}3.47 \\
(357.3)\end{array}$ & $\begin{array}{l}75-> \\
79,80 \\
(0.002)\end{array}$ & $\begin{array}{l}3.66 \\
(339.0)\end{array}$ & $\begin{array}{l}78-> \\
79,80 \\
(0.13)\end{array}$ & & & $\begin{array}{l}4.14 \\
(299.1)\end{array}$ & $\begin{array}{l}77-> \\
79 \\
(1.04)\end{array}$ & $\begin{array}{l}4.67 \\
(265.2)\end{array}$ & $\begin{array}{l}74-> \\
79,77 \\
->81 \\
(0.02)\end{array}$ \\
\hline$B / 6-31 G(d, p)$ & $\begin{array}{l}3.51 \\
(353.0)\end{array}$ & $\begin{array}{l}75-> \\
79,80 \\
\left(2 \times 10^{-4}\right)\end{array}$ & $\begin{array}{l}3.78 \\
(327.8)\end{array}$ & $\begin{array}{l}78-> \\
79,80 \\
(0.09)\end{array}$ & $\begin{array}{l}4.32 \\
(287.1)\end{array}$ & $\begin{array}{l}70-> \\
79,80 \\
(0.08)\end{array}$ & $\begin{array}{l}4.32 \\
(286.9)\end{array}$ & $\begin{array}{l}77-> \\
79 \\
(1.01)\end{array}$ & $\begin{array}{l}4.82 \\
(257.3)\end{array}$ & $\begin{array}{l}74-> \\
79,77 \\
->81 \\
(0.02)\end{array}$ \\
\hline $\begin{array}{l}B / 6- \\
311++G(2 d, p)\end{array}$ & $\begin{array}{l}3.49 \\
(355.4)\end{array}$ & $\begin{array}{l}75-> \\
79,80 \\
\left(8 \times 10^{-4}\right)\end{array}$ & $\begin{array}{l}3.60 \\
(344.1)\end{array}$ & $\begin{array}{l}78-> \\
79,80 \\
(0.12)\end{array}$ & & & $\begin{array}{l}4.16 \\
(298.3)\end{array}$ & $\begin{array}{l}77-> \\
79 \\
(1.06)\end{array}$ & $\begin{array}{l}4.67 \\
(265.2)\end{array}$ & $\begin{array}{l}74-> \\
79,77 \\
->81 \\
(0.02)\end{array}$ \\
\hline Exptal* & & & $(\sim 450)$ & & & & $(\sim 320)$ & & & \\
\hline
\end{tabular}

* The experimental absorption peaks were measured in chloroform solution.

The conformational change between monomers in the polymorphs and isolated molecules in $\mathrm{Gm} 8 \mathrm{~m}$ and Gm8p, leads to red-shifts of HOMO-LUMO transition by $0.18 \mathrm{eV} \mathrm{(14} \mathrm{nm,} \mathrm{in} \mathrm{Gm8m}-0$ ) and $0.25 \mathrm{eV}$ (20 $\mathrm{nm}$, in $\mathrm{Gm} 8 \mathrm{p}-\mathrm{B}$ ), much larger than that from the difference in the position of a $\mathrm{NO}_{2}$ group between $\mathrm{Gm} 8 \mathrm{~m}$ and $\mathrm{Gm} 8 \mathrm{p}$ molecules. For the isolated $\mathrm{Gm} 8 \mathrm{~m}$ and $\mathrm{Gm} 8 \mathrm{p}$ monomers, there is only a red-shift of $0.04 \mathrm{eV}(3 \mathrm{~nm})$ for the HOMO-LUMO transitions. On the other hand, the stronger HOMO-1 to LUMO transition is affected to a larger degree by the position of the $\mathrm{NO}_{2}$ group, red-shifting by $0.25 \mathrm{eV}(14 \mathrm{~nm}$ ) for an isolated Gm8p molecule. This is because HOMO-1 for Gm8p has more density on the $\mathrm{NO}_{2}$ group, but little for $\mathrm{Gm8m}$ (Table 21). The UV-Vis absorptions of monomers in $\mathrm{Gm} 8 \mathrm{~m}-\mathrm{O}$ and $\mathrm{Gm} 8 \mathrm{~m}-\mathrm{Y}$ are very similar, despite a difference of $14^{\circ}$ in $\phi_{1}$, while the monomers in Gm8p - B absorbs at longer wavelength for the HOMO-LUMO peak than monomers of Gm8p - R, correlating with a difference of more than $20^{\circ}$ in $\phi_{2}$. The first dipole-allowed excitations calculated show the similar shifts from conformational or isometric changes, though they are very weak for all monomers considered here.

Despite the difference in their conformations and isomerism, the molecular orbitals Table 21 involved in the strong excitations are largely similar: the HOMO orbital is always localized on 1-ring and the $\mathrm{N}\left(\mathrm{CH}_{3}\right)_{2}$ group, while the HOMO-1 orbitals is mostly localized on the 3-ring, $\mathrm{C}=\mathrm{C}$ bond on the backbone. The LUMO and LUMO+1 orbitals are both of $\pi^{*}$ nature, and similarly localized across the chalcone backbone, 3-ring and $\mathrm{NO}_{2}$ group. The HOMO-LUMO excitations are much weaker than the HOMO-1 to LUMO ones, as the LUMO and HOMO orbitals are localized on different parts of the molecule. MO \#75, which is related to the first excitation, is largely concentrated on the chalcone backbone, with a large contribution from the $\mathrm{C}=\mathrm{O} \pi^{*}$ orbital. 
Table 21 Molecular orbitals involved in the excitations listed in Table 20 using the conformation within each PBE-TS optimized polymorph calculated with TD-DFT/ $\omega B 97 x / 6-31 G(d, p)$.

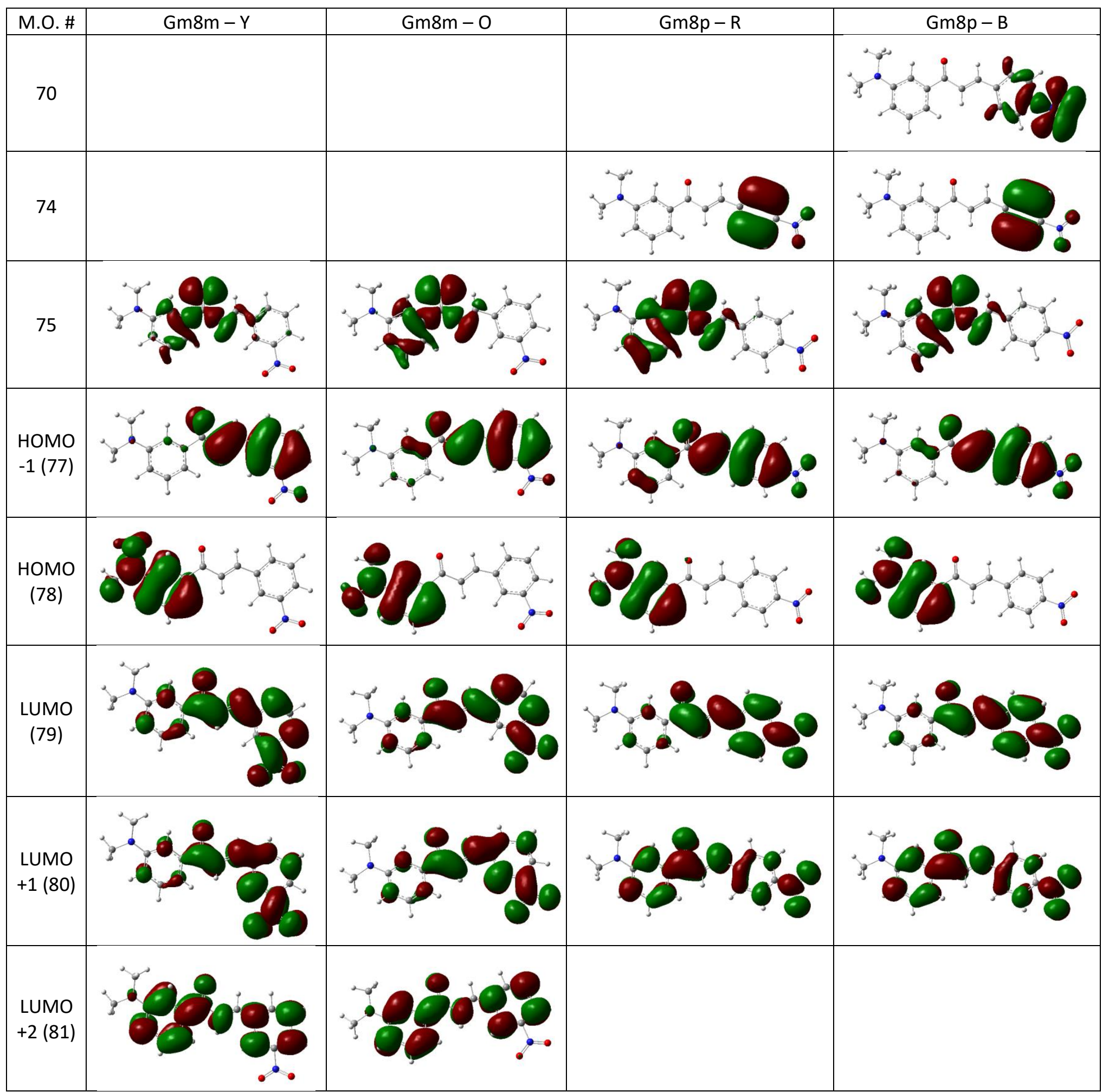

* The MOs are plotted on the isosurfaces of \pm 0.02 a.u. with green and red corresponding to opposite signs. 
The calculated UV-Vis spectra of the monomers are compared to the solution UV-VIS spectra observed for various solvents (SI Figure 32) and in for a series of concentrations in chloroform (SI Figure 33). The solution UV-Vis spectrum for Gm8p is dominated by a broad feature centered around $320 \mathrm{~nm}$, while $\mathrm{Gm} 8 \mathrm{~m}$ showed twin peaks at $\sim 270$ and $300 \mathrm{~nm}$. Compared with excitations shown in SI Table 20, these features probably correspond to the HOMO-1-LUMO excitations. The absolute excitation energies of the main spectral feature have been overestimated in calculations by $\sim 0.65 \mathrm{eV}(\sim 45 \mathrm{~nm})$, as the rangeseparated functional shift the whole spectrum to the blue. However, the relative shifts between $\mathrm{Gm} 8 \mathrm{~m}$ and Gm8p is qualitatively reproduced ( $14 \mathrm{~nm}$ vs. $20 \mathrm{~nm}$ ). The twin-peak line-shape of this absorption for $\mathrm{Gm} 8 \mathrm{~m}$ can be reproduced when more excited states are included in the TD-DFT calculations, however our interest lies in the red-end of absorption spectrum.
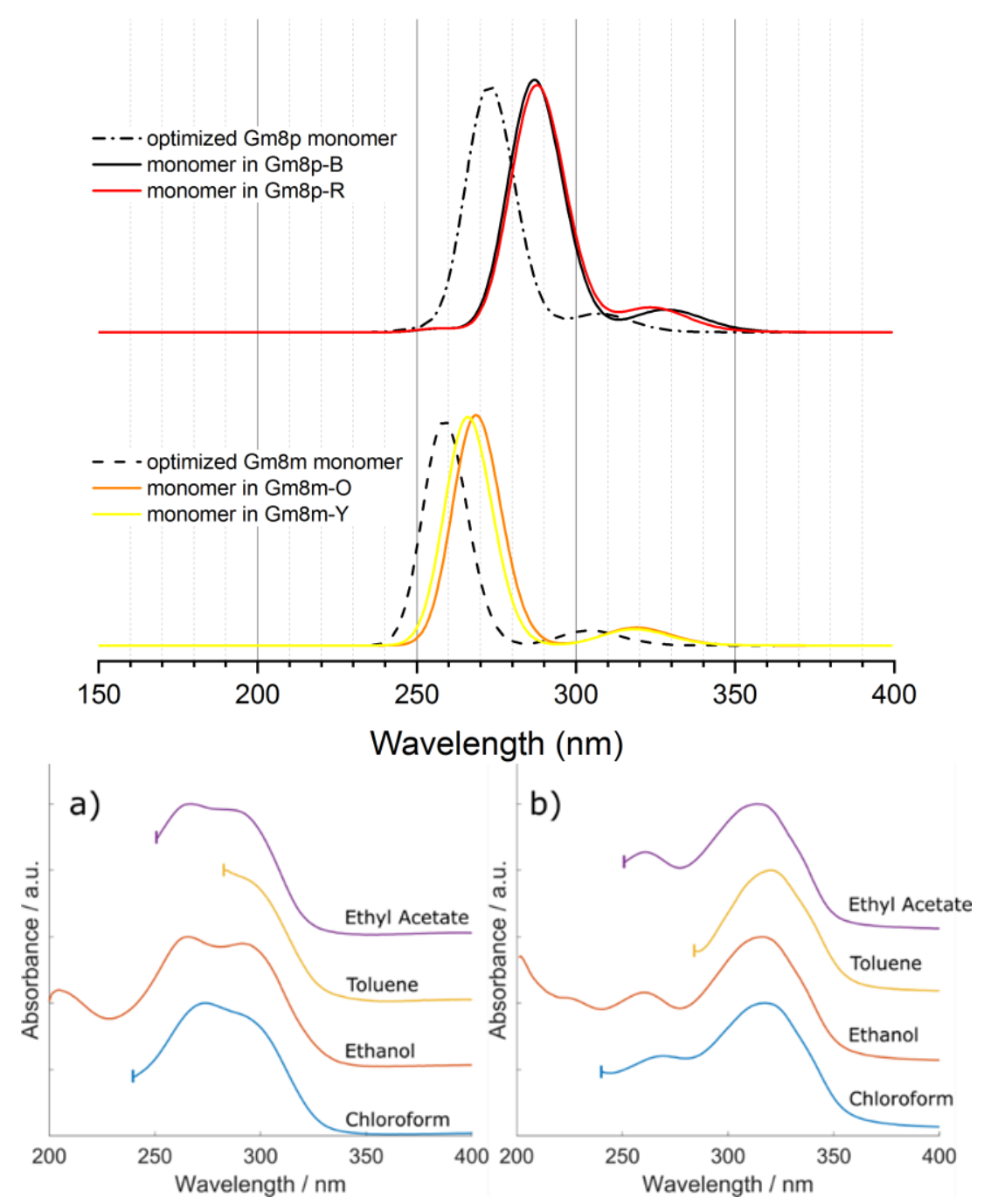

Figure 32 (Top) Calculated UV-Vis spectra from the first 6 excitations for Gm8m and Gm8p for a single molecule in isolation and in the conformation shown in the polymorphs using a Full-Width at the Half-Maximum (FWHM) of $0.3 \mathrm{eV}$, compared to the experimental solution UV-Vis at low concentration $(0.008 \mathrm{mg} / \mathrm{mL}$ or $0.053 \mathrm{mM})$ in various solvents for (a) Gm8m and (b) Gm8p. 
A broad but weaker spectral feature, more obvious at higher concentration, was observed to be centered at $\sim 410 \mathrm{~nm}$ for $\mathrm{Gm} 8 \mathrm{~m}$ and $\sim 450 \mathrm{~nm}$ for Gm8p (SI Figure 33), which most likely corresponds to the HOMOLUMO transitions in Table 20 but additionally might have some contribution due to the formation of aggregates in solution. The transition energies have been shifted more than those for the HOMO-1-LUMO transitions ( $1.0 \mathrm{eV}$ for $\mathrm{Gm} 8 \mathrm{~m}$ and close to $1.3 \mathrm{eV}$ for $\mathrm{Gm} 8 \mathrm{p}$ ). This peak is only observed in higher concentration solutions.

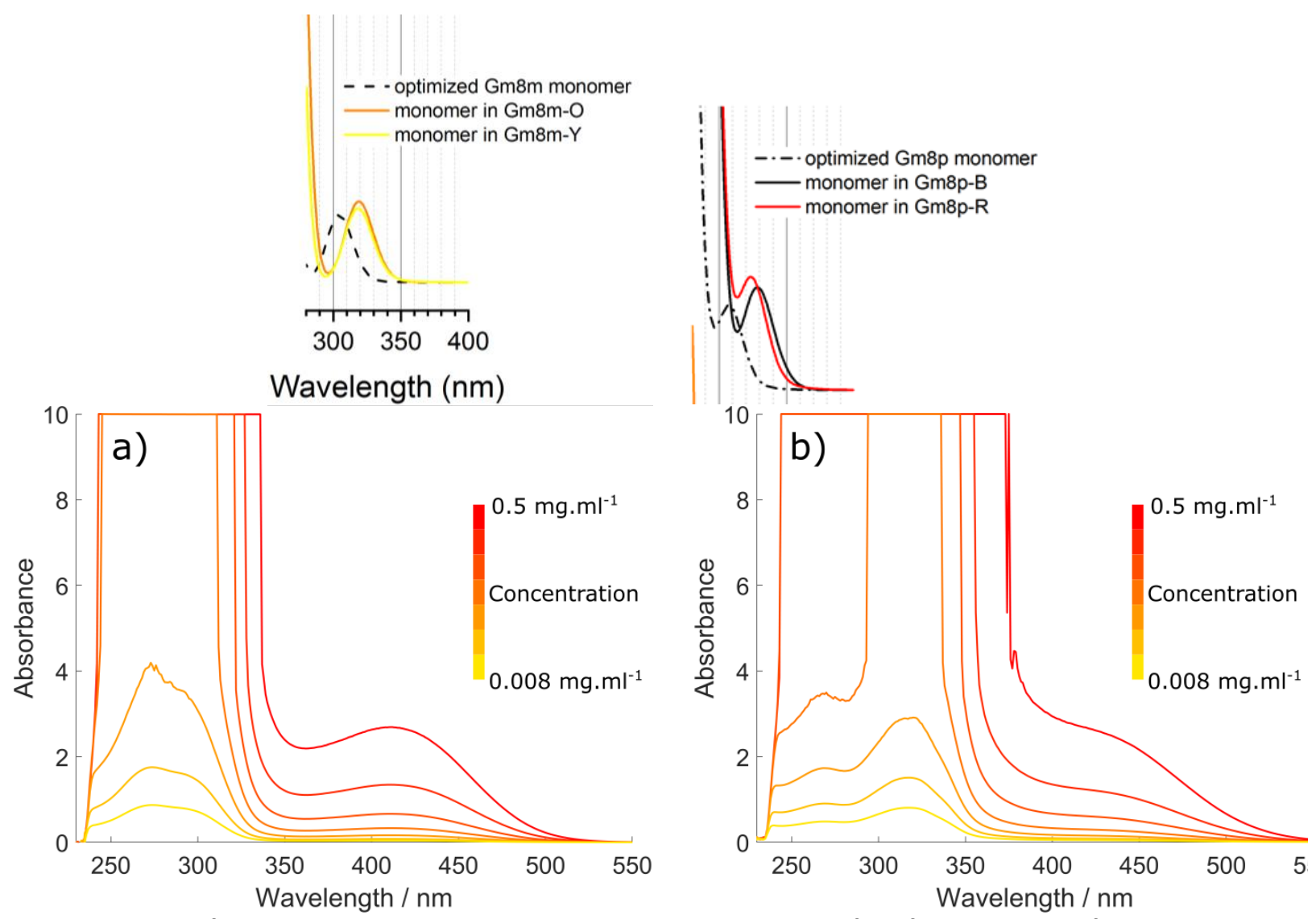

Figure 33 The small first peak in the calculated UV-Vis spectra in the visible region from first 6 excitations for $\mathrm{Gm} 8 \mathrm{~m}$ and $\mathrm{Gm} 8 \mathrm{p}$ for a single molecule in isolation and in the conformation shown in the polymorph, compared to the experimental solution UV-Vis spectra of $\mathrm{Gm} 8 \mathrm{~m}$ (bottom left) and $\mathrm{Gm} 8 \mathrm{p}$ (bottom right) in chloroform at concentration series of $0.5,0.25,0.125,0.0625$, $0.0313,0.0156,0.0078 \mathrm{mg} / \mathrm{mL}$ (equivalent to $1.687,0.844,0.422,0.211,0.105,0.053 \mathrm{mM}$ ).

\subsubsection{TD-DFT calculations of UV-Vis spectra of unique dimer motifs in crystals}

\subsubsection{The asymmetric residue unit (ARU) notation for defining dimers within crystal structures}

Each molecule in an infinite and ideal crystal can be uniquely labelled with its ARU.n notation, which is a multiple-digit number defined as: $\operatorname{ARU}=1000 s+100(5+k)+10(5+l)+5+m$, so that the first digit, $s=$ symmetry operation number from the space group table (see table below for the space groups involved here); the next three digits reflect $(k, I, m)$, i.e. the translation in direction of $a, b$ and $c$, respectively relative to the central molecule whose ARU is always 1555 . The number appended to the ARU, $n$ (= unique 
molecule \#) is only needed for crystals with $Z^{\prime}>1$, and since all the polymorphs considered in this paper are $Z^{\prime}=1$, the.$n$ is not included. This notation is used in Platon ${ }^{17}, \mathrm{XPac}^{18}, \mathrm{MOLPAK}^{19}$ and other crystallography software.

\begin{tabular}{|l|l|l|}
\hline$P-1$ & $P 2_{1} / c$ & $P 2_{1} / n$ \\
\hline $1: x, y, z$ & $1: x, y, z$ & $1: x, y, z$ \\
$2:-x,-y,-z$ & $2:-x, 1 / 2+y, 1 / 2-z$ & $2: 1 / 2-x, 1 / 2+y, 1 / 2-z$ \\
& $3:-x,-y,-z$ & $3:-x,-y,-z$ \\
& $4: x, 1 / 2-y, 1 / 2+z$ & $4: 1 / 2+x, 1 / 2-y, 1 / 2+z$ \\
\hline
\end{tabular}

\subsubsection{Clusters of complete molecular shells of chalcone polymorphs}

Using the PBE-TS optimized structures of Gm8m and Gm8p, molecular clusters were selected with the Molecular Shell tool in Mercury, including any molecule with any atom within $3.2 \AA$ from any atom of the central molecule. For $\mathrm{Gm} 8 \mathrm{~m}-\mathrm{Y}$ and $\mathrm{Gm} 8 \mathrm{~m}-\mathrm{O}$, this setting leads to a 15-molecule cluster, with the central molecule completely surrounded by the other 14 molecules in the cluster. However, for Gm8p$B$, this leads to a 19-molecule cluster. For $G m 8 p-R$, using this setting leads to a 14-molecule cluster, with one side of the central molecule exposed. Since another molecule (mol. ARU=3766) is only $3.4 \AA$ away and with its aromatic ring stacking with the central molecule, and forming a reasonable interacting pair, this molecule was added to the original 14-molecule cluster to make a 15-molecule one. This illustrates the limitations of distance criteria for van der Waals contact for automatically defining coordination clusters, which can also be affected by differences between computationally optimized structures and experimental determinations at different temperatures. Using the ARU notation, with the central molecule denoted as 1555, the molecules included in the selected clusters are in SI Figure 34 to Figure 37.
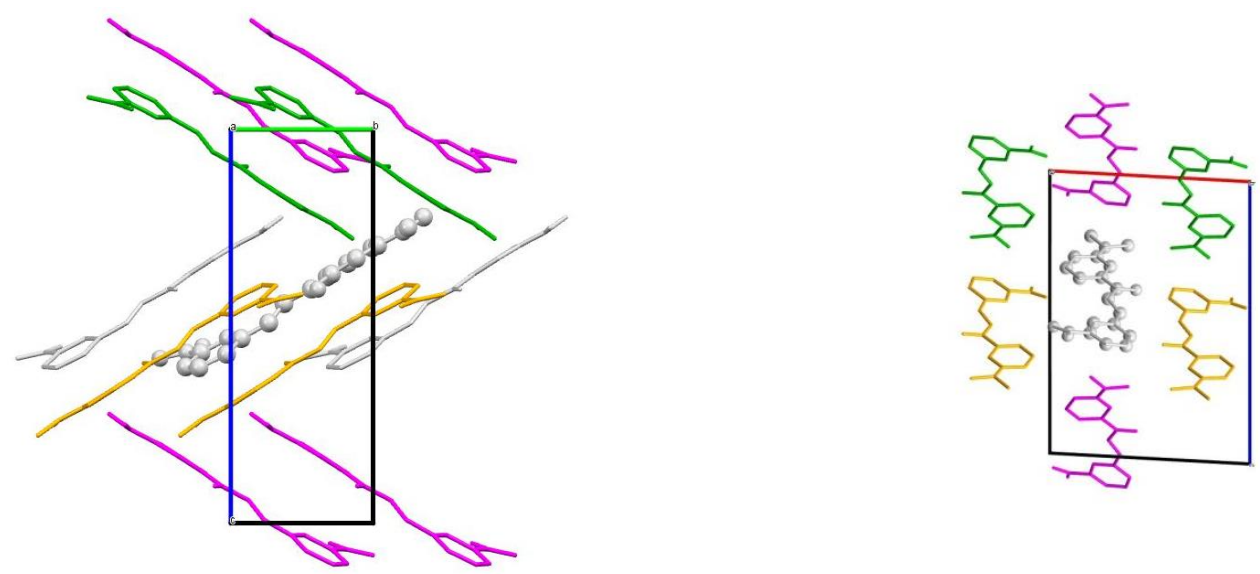

\section{Gm8m - Y}

Figure 34 A 15-molecule cluster (ARU 1555 and 1545, 1565, 2645, 2655, 2745, 2755, 3656, 3666, 3756, 3766, 4554, 4555, 4564, 4565) around a central molecule for $\mathrm{Gm} 8 \mathrm{~m}-\mathrm{Y}$, shown within the PBE-TS optimized unit cell and viewed along the a (left) and b (right) axes. Color indicates the $\mathrm{P} 2_{1} / \mathrm{c}$ symmetry operations: 1-white, 2-green, 3-orange and 4-purple. 

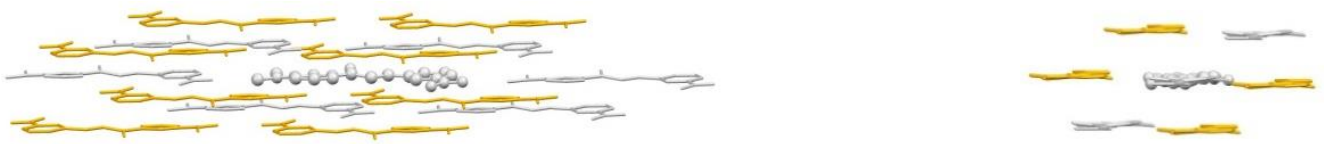

Gm8m - 0

Figure 35 a 15-molecule cluster around a central molecule for Gm8m - O (ARU 1555 and 1344, 1444, 1455, 1655, 1666, 1766, 2456, 2466, 2556, 2566, 2667, 2677, 2767, 2777) viewed along the molecular planes. Color indicates the P-1 symmetry operations: 1-white, 2-orange.

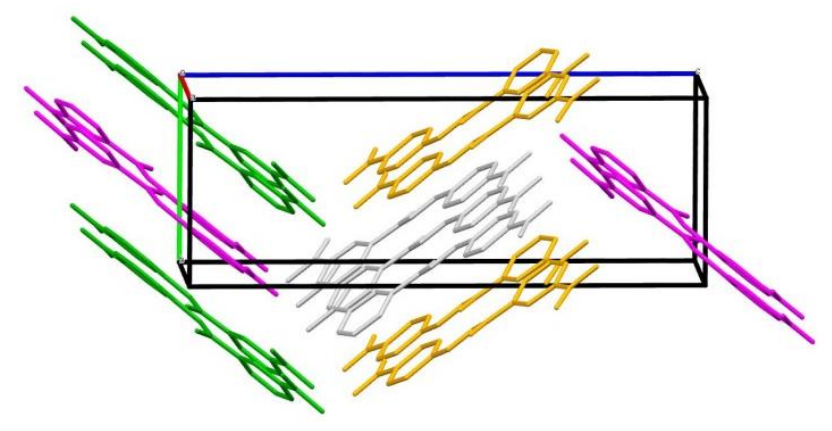

Gm8p - R

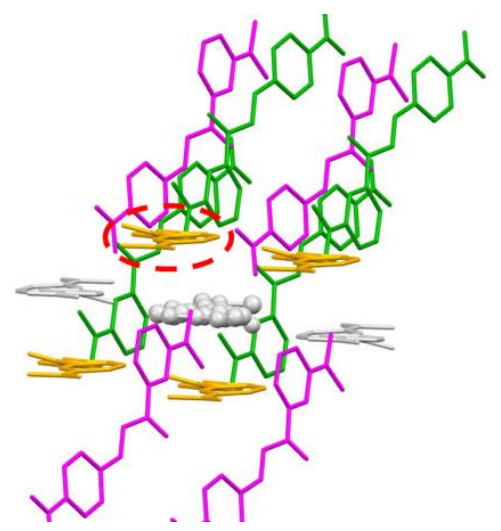

Figure 36 A 15-molecule cluster around a central molecule for Gm8p - R (left) (ARU: 1555 and 1455, 1655, 2445, 2455, 2545, 2555, 3666, 3676, 3766, 3776, 4364, 4464, 4565, 4665.). Color indicates the P2 1 /n symmetry operations: 1-white, 2-green, 3orange and 4-purple. The additional molecule (ARU 3766), circled in red (right) was added to complete the molecular shell around the central molecule.
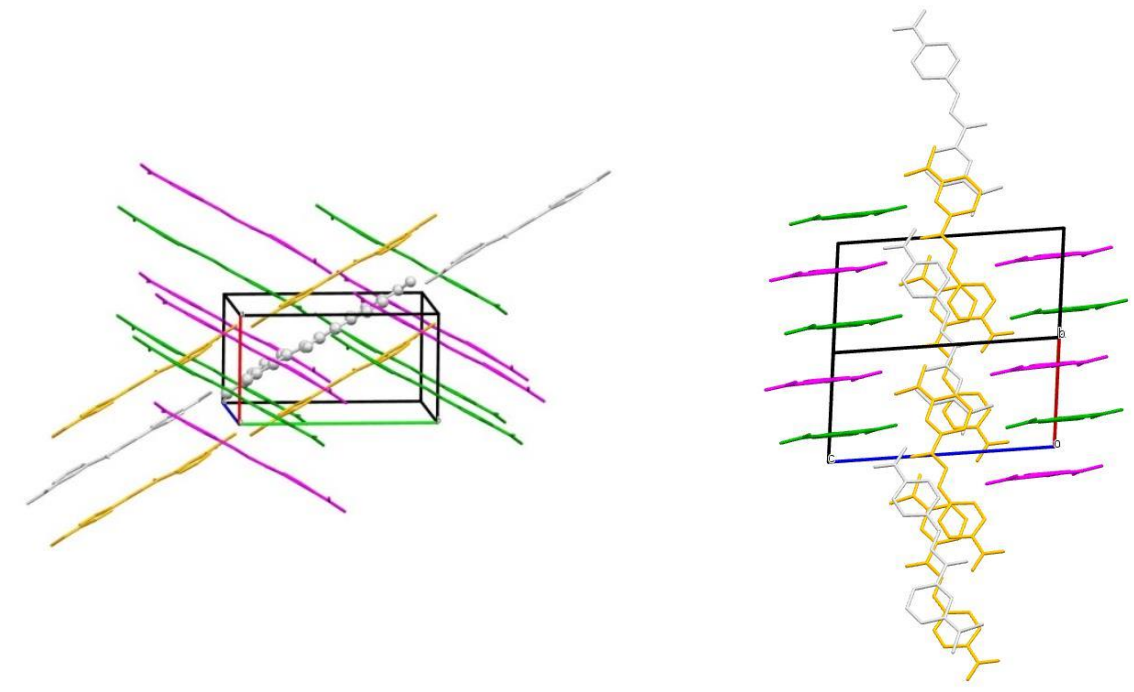

$$
\text { Gm8p - B }
$$

Figure 37 A 19-molecule cluster around a central molecule for Gm8p - B (left) (ARU: 1555 and 1445, 1665, 2645, 2646, 2655, 2656, 2746, 2756, 3556, 3656, 3666, 3766, 4454, 4554, 4555, 4564, 4565, 4655). Color indicates the P2 1 /c symmetry operations: 1-white, 2-green, 3-orange and 4-purple.

\subsubsection{Complete sets of unique dimer motifs}

From the molecular clusters (SI Figure 34, Figure 35, Figure 36, Figure 37), complete sets of symmetricallyunique dimer motifs were extracted. SI Table 22 shows the 9 unique dimers of Gm8m - Y, Table 23 
describes the 11 unique dimers in Gm8m - O, Table 24 the 9 unique dimers in Gm8p - B and Table 25 the 11 unique dimers in Gm8p - B. Close contacts as calculated in Mercury (ver. 4.2.0), that are less than the sum of the van der Waals radii are shown, with a short qualitative description of the relationship between the two molecules. The symmetry relationship in the crystal is also given, as an excitation to the first excited state of dimers related by a center of inversion (ARU code $2 \mathrm{klm}$ ) is dipole-forbidden (i.e. has zero oscillator strengths) if it is of the same symmetry as the ground electronic state $\left(A_{g}\right)$.

Table 22 The complete set of 9 unique dimer motifs of $\mathrm{Gm8m}-\mathrm{Y}$, each formed by the central molecule (1555) with one of the molecules in the 15-molecular cluster in SI Figure 34. The motif with the most significant stacking in shaded green.

\begin{tabular}{|c|c|c|c|c|}
\hline Name & $\begin{array}{c}\text { ARU of the } \\
2^{\text {nd }} \text { molecule }\end{array}$ & Unique dimer & $\begin{array}{c}\text { Short } \\
\text { description }\end{array}$ & Symm. op. \\
\hline $\begin{array}{c}\text { Half- } \\
\text { stacking }\end{array}$ & 1545 & & $\begin{array}{l}\text { 3-ring } \cdots C=0,1- \\
\text { ring } \cdots \text { backbone } \\
\text { stacking }\end{array}$ & $\begin{array}{c}\text { Translation } \\
\text { along } \\
\text { [010] }\end{array}$ \\
\hline $\begin{array}{c}\mathrm{CH}_{3} \cdots \mathrm{O}=\mathrm{C} \\
\text { tilted }\end{array}$ & 2645 & & $\begin{array}{c}\mathrm{C}=\mathrm{O} \text { groups } \\
\text { inside the } \\
\text { dimer, one } \mathrm{CH}_{3} \\
\text { close to } \mathrm{C}=\mathrm{O} \text { of } \\
\text { the other } \\
\text { molecule }\end{array}$ & Screw axis \\
\hline $\begin{array}{c}\mathrm{CH}_{3} \cdots 1 \text {-ring } \\
\text { tilted }\end{array}$ & 2745 & & $\begin{array}{l}\mathrm{C}=\mathrm{O} \text { groups } \\
\text { outside the } \\
\text { dimer, one } \mathrm{CH}_{3} \\
\text { close to the 1- } \\
\text { ring of the } \\
\text { other molecule }\end{array}$ & Screw axis \\
\hline $\begin{array}{c}\mathrm{NO}_{2-}^{-} \\
\text {opposite }\end{array}$ & 3656 & & $\begin{array}{l}\text { No stacking, } \\
\mathrm{NO}_{2} \text { pointing } \\
\text { opposite } \\
\text { direction }\end{array}$ & Inversion \\
\hline $\begin{array}{c}\text { Cyclic } \\
\mathrm{CH}^{*} \mathrm{O}=\mathrm{C}\end{array}$ & 3666 & & $\begin{array}{c}\text { No stacking, } \\
\text { nearly co- } \\
\text { planar }\end{array}$ & Inversion \\
\hline
\end{tabular}




\begin{tabular}{|c|c|c|c|c|}
\hline \multirow[t]{2}{*}{$\begin{array}{c}\text { Cyclic } \\
\mathrm{CH} \cdots \mathrm{NO}_{2}\end{array}$} & 3756 & & Co-planar $\mathrm{NO}_{2}$ & Inversion \\
\hline & 3766 & $200-0$ & $\begin{array}{l}\text { No stacking, no } \\
\text { short contacts }\end{array}$ & Inversion \\
\hline $\begin{array}{c}\mathrm{CH}_{3} \cdots \mathrm{NO}_{2} \\
\text { tilted }\end{array}$ & 4554 & 8 & $\begin{array}{c}\mathrm{N}\left(\mathrm{CH}_{3}\right)_{2} \text { of one } \\
\text { molecule close } \\
\text { to } \mathrm{NO}_{2} \text { of } \\
\text { another } \\
\text { molecule }\end{array}$ & $\begin{array}{l}\text { Glide } \\
\text { plane }\end{array}$ \\
\hline $\begin{array}{c}\mathrm{CH}_{3} \cdots 3 \text {-ring } \\
\quad \text { tilted }\end{array}$ & 4564 & & $\begin{array}{c}\mathrm{N}\left(\mathrm{CH}_{3}\right)_{2} \text { of one } \\
\text { molecule close } \\
\text { to 3-ring } \\
\text { another } \\
\text { molecule }\end{array}$ & $\begin{array}{l}\text { Glide } \\
\text { plane }\end{array}$ \\
\hline
\end{tabular}

Table 23 a complete set of 11 unique dimer motifs of $\mathrm{Gm} 8 \mathrm{~m}-0$, each formed by the central molecule (1555) with one of the molecules in the 15-molecular cluster as depicted in SI Figure 35. The motif with the most significant stacking is shaded green.

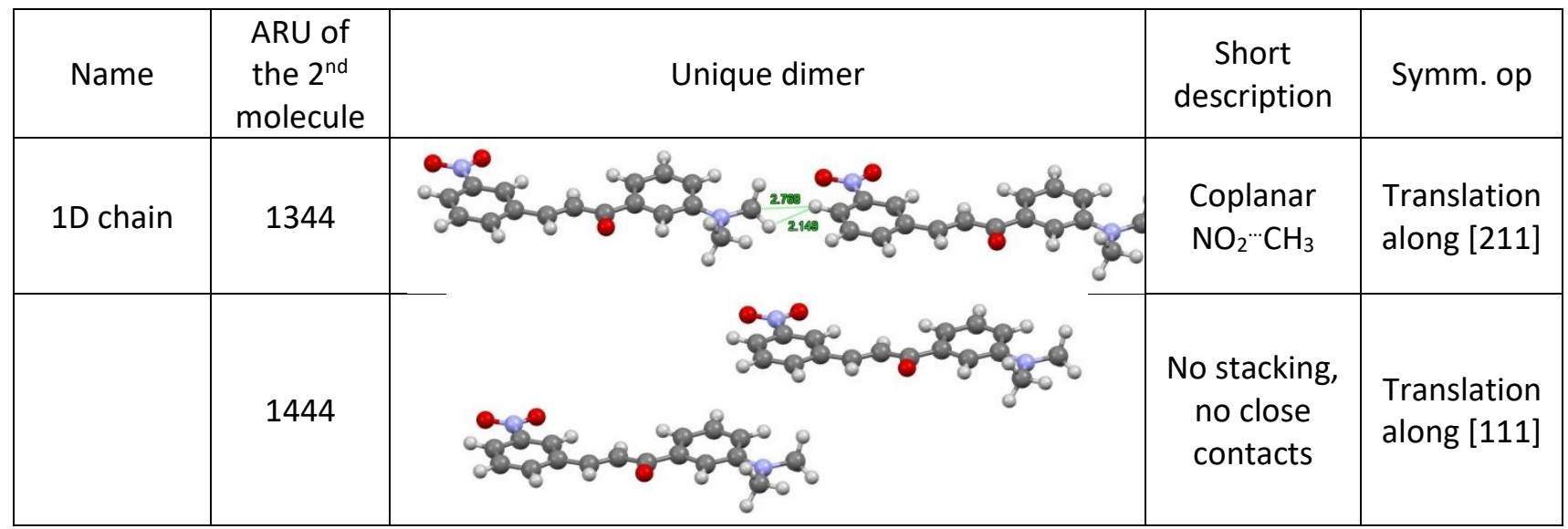




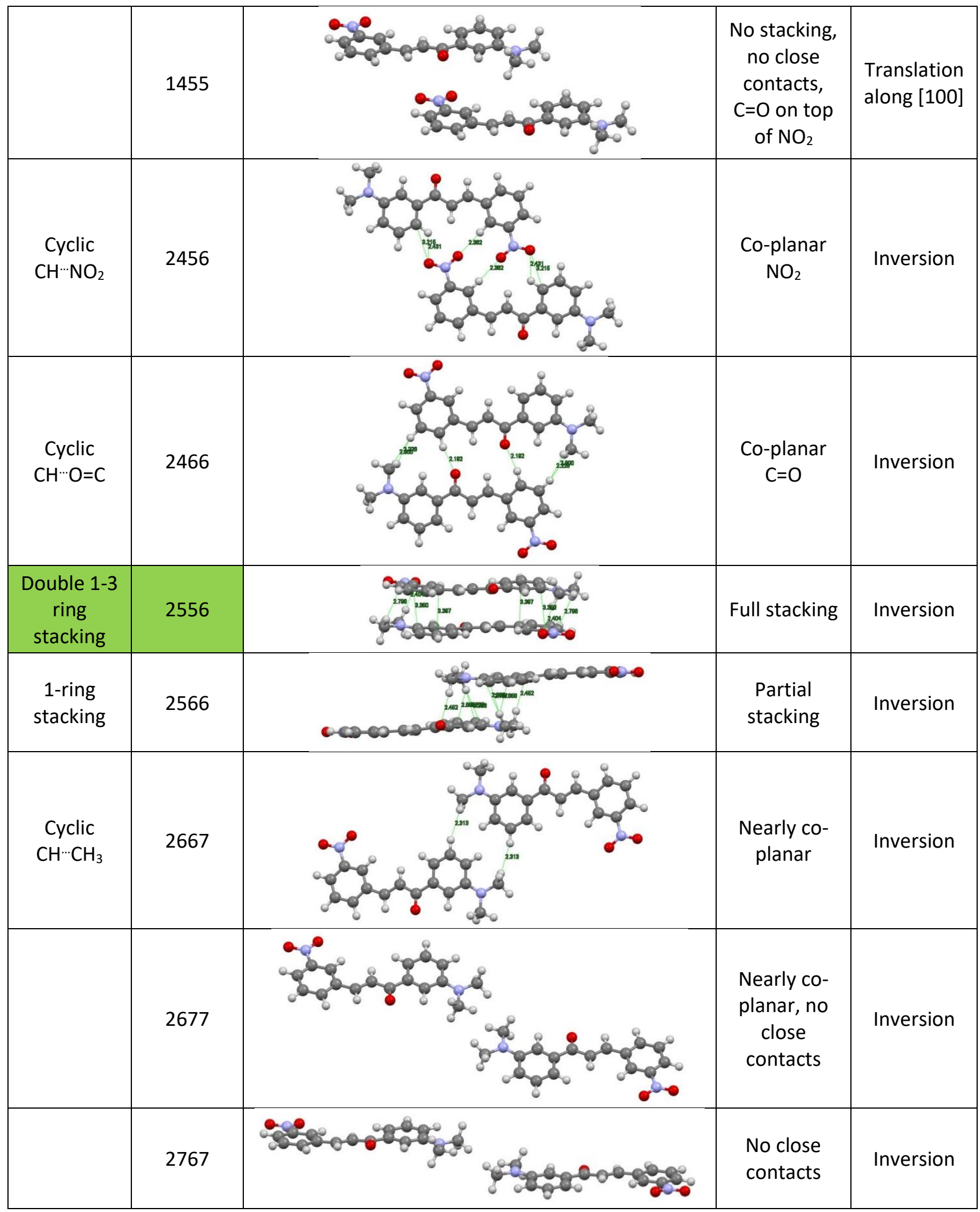




\begin{tabular}{|c|c|c|c|c|}
\hline $\begin{array}{c}\text { 3-ring } \\
\text { stacking }\end{array}$ & 2777 & 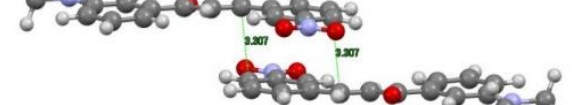 & $\begin{array}{c}\text { Partial } \\
\text { stacking }\end{array}$ & Inversion \\
\hline
\end{tabular}

Table 24 The complete set of 9 unique dimer motifs of Gm8p - R, each formed by the central molecule (1555) with one of the molecules in the 15-molecular cluster as depicted in Figure 36. The motif with the most significant stacking is shaded green.

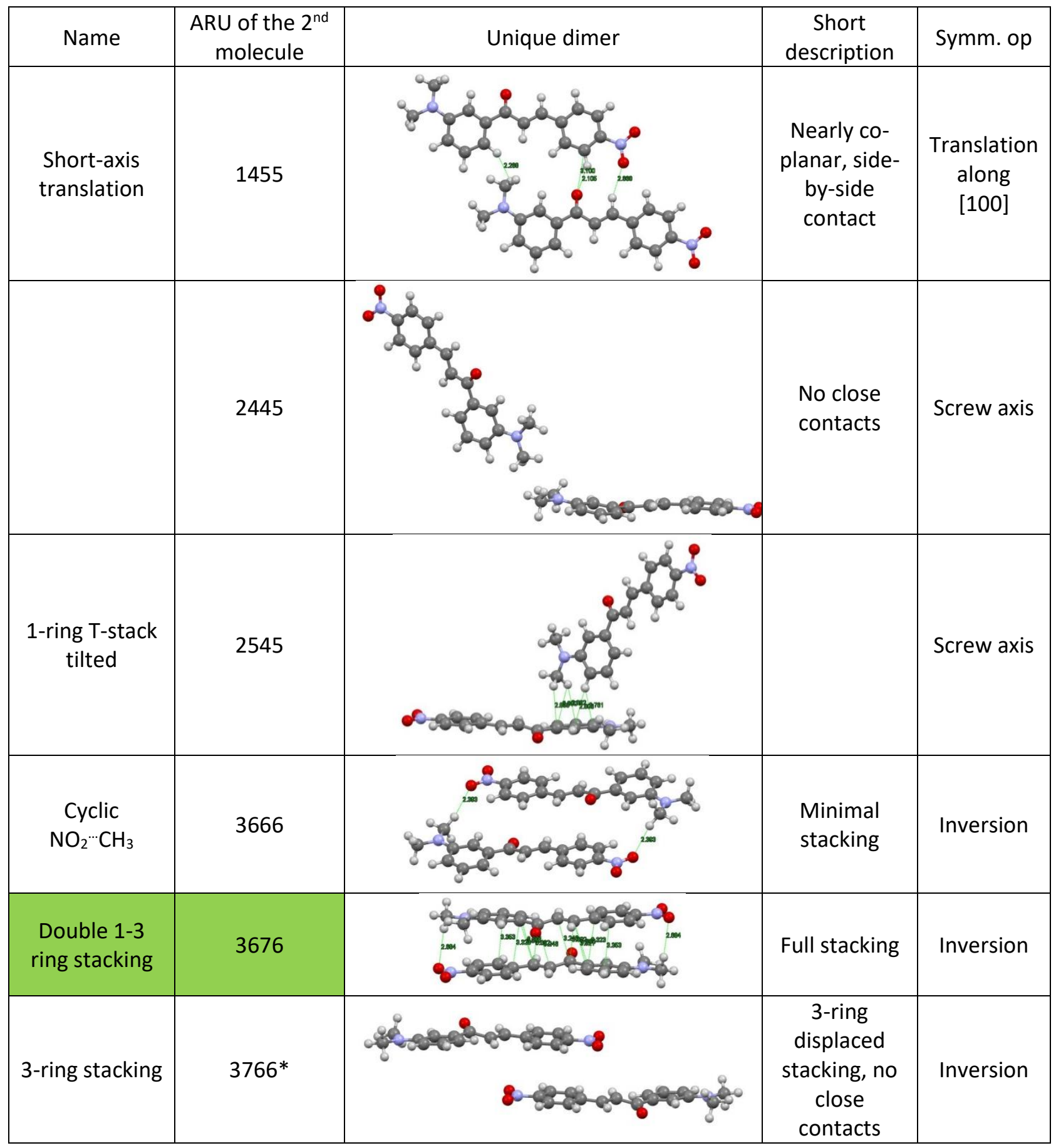




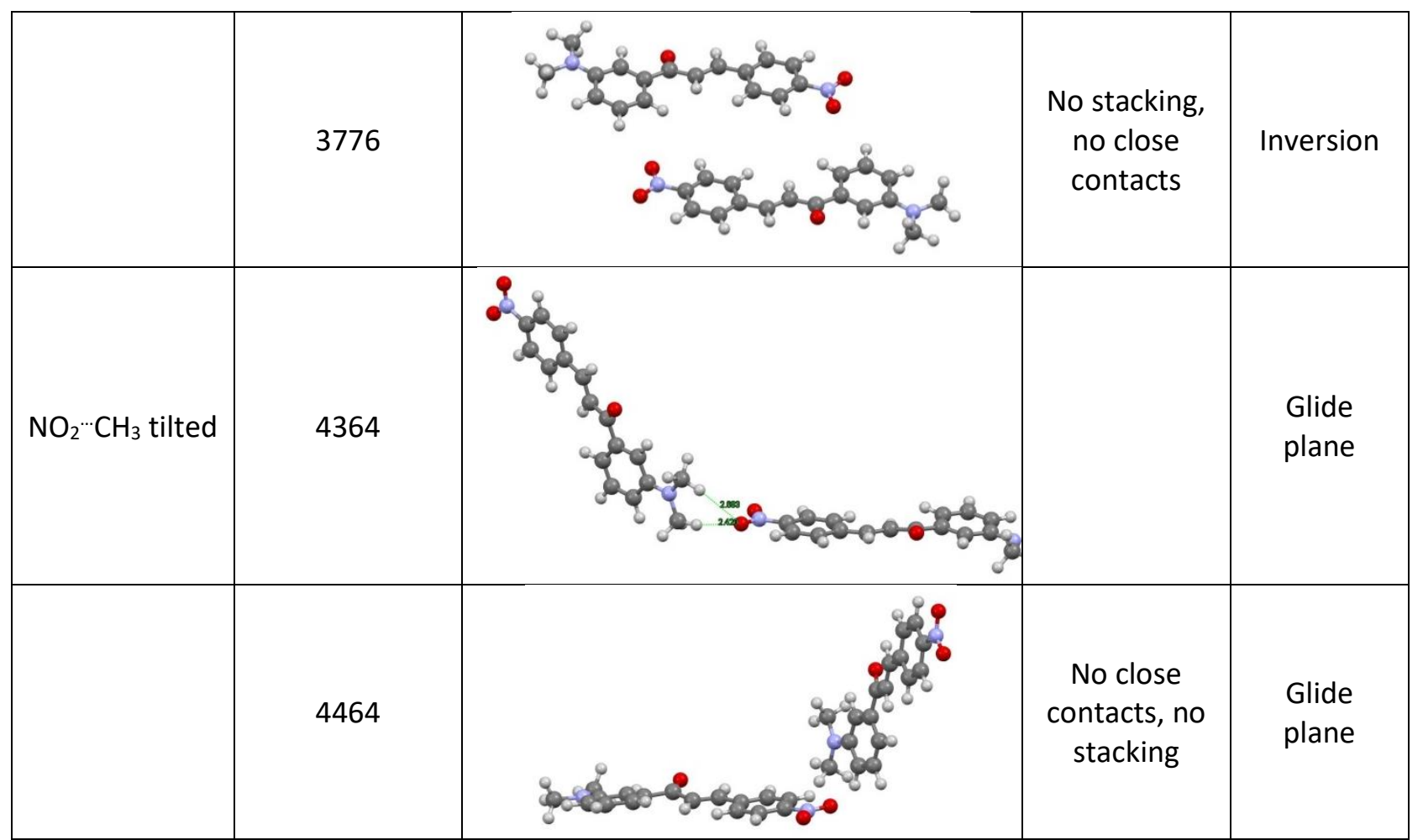

* Additional molecule added to complete the molecular shell.

Table 25 The complete set of 11 unique dimer motifs of Gm8p - B, each formed by the central molecule (1555) with one of the molecules in the 15-molecular cluster as depicted in Figure 36. The motif with the most significant stacking is shaded green.

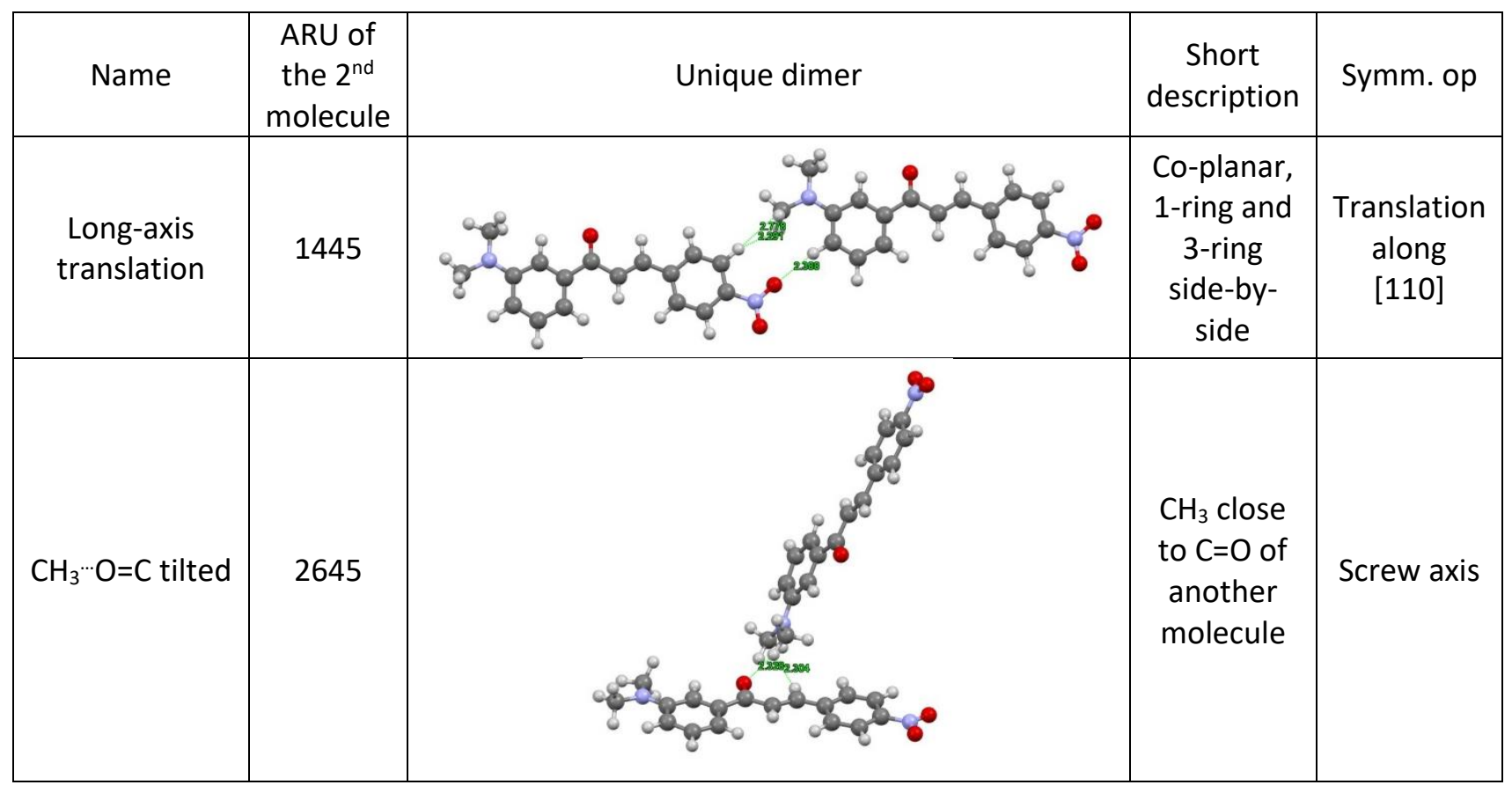




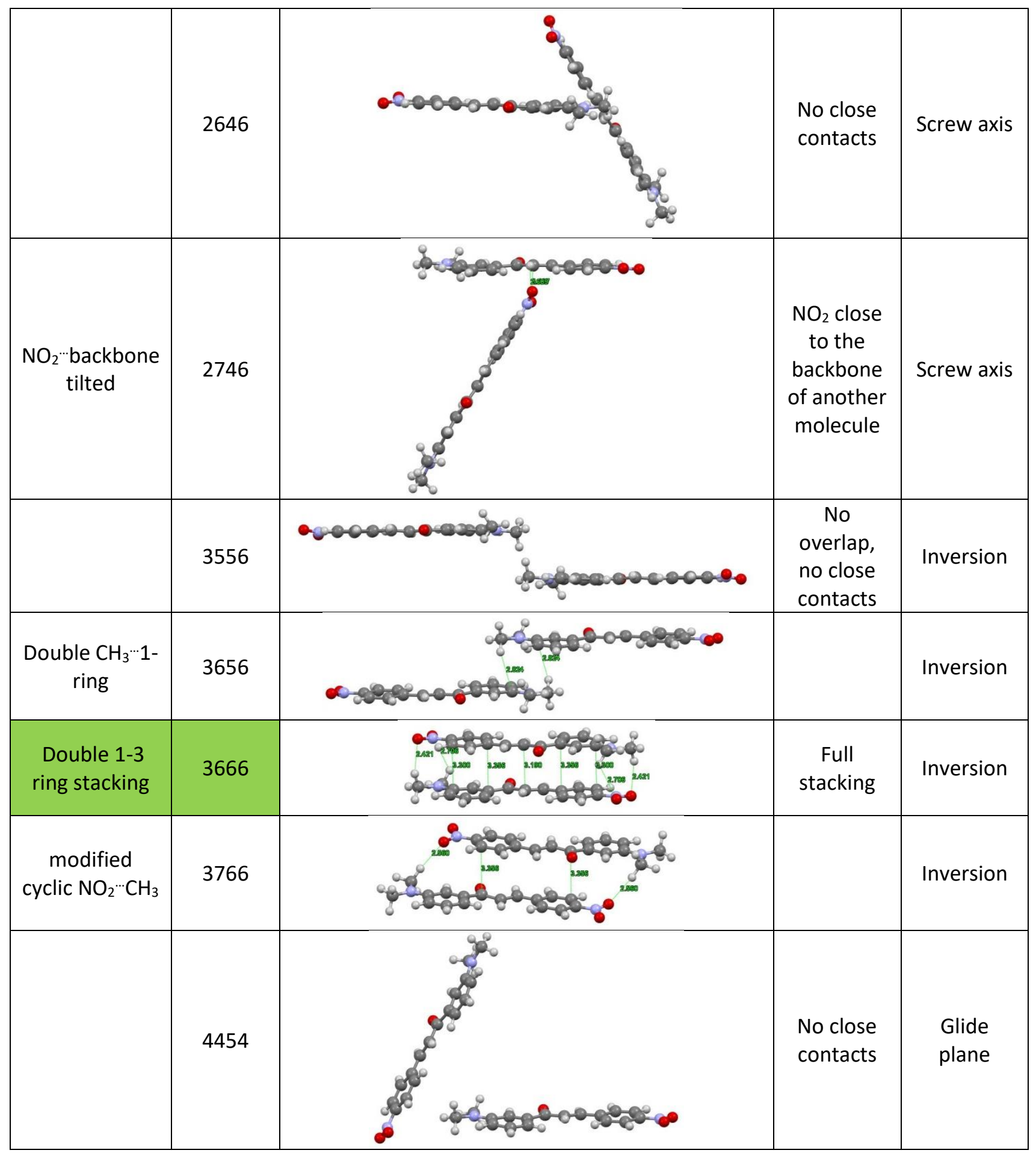




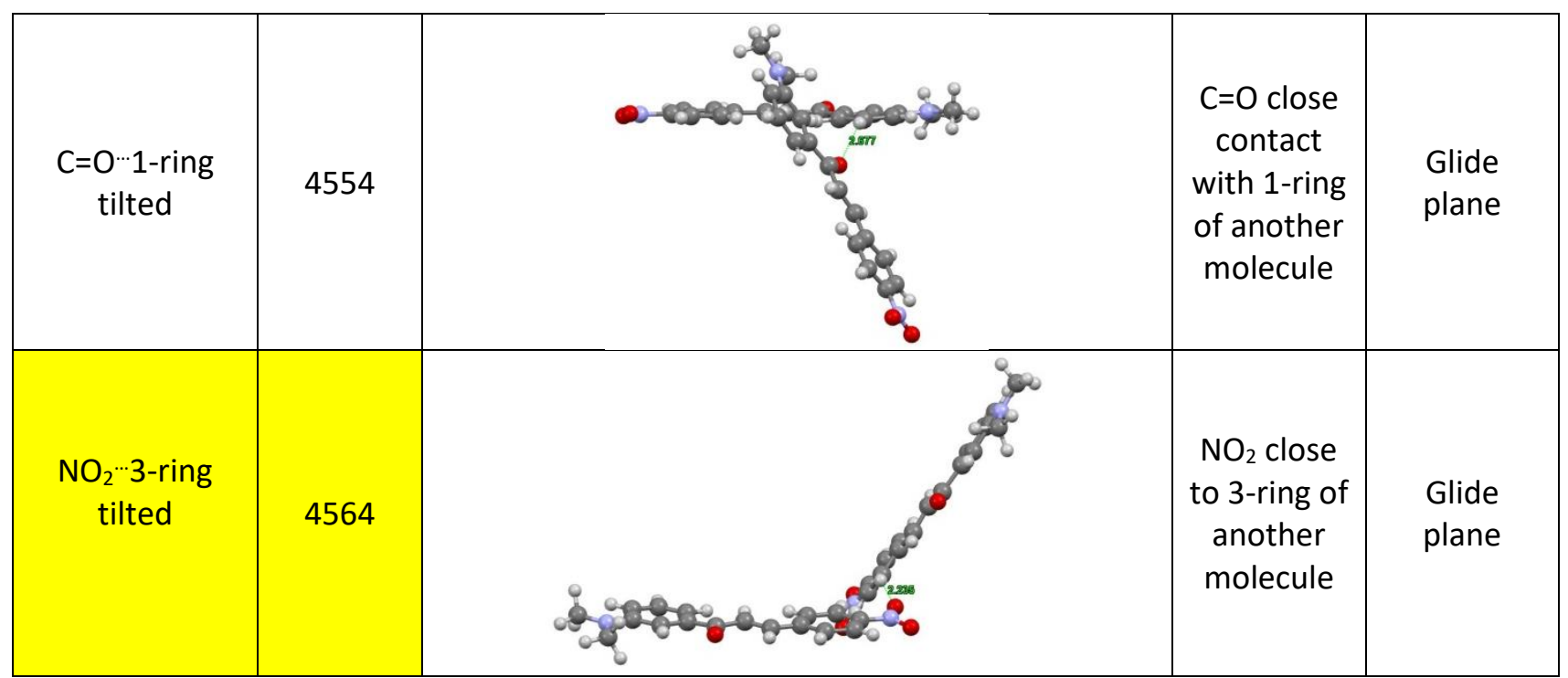

\subsubsection{Calculated UV-Vis spectra of unique dimers in crystals}

Since the difference in the color of $\mathrm{Gm} 8 \mathrm{~m}$ and $\mathrm{Gm} 8 \mathrm{p}$ polymorphs cannot be due to the differences in the crystalline conformations, we calculated the spectra of all the dimers extracted from the crystal structures.

Gm8m - Y

Comparison of the first-allowed excitations of the dimers with that calculated for its monomer (SI Table 26), reveals that none of the first-allowed excitations of the dimers are red-shifted by more than $2 \mathrm{~nm}$. Two dimer motifs, the cyclic $\mathrm{CH} \cdots \mathrm{O}=\mathrm{C}$ and $\mathrm{NO}_{2}$-opposite dimers, blue-shift their first-allowed excitations by $5 \mathrm{~nm}$ and $13 \mathrm{~nm}$ respectively. However, in all dimer and monomer cases, excitations to the first-allowed excitations are calculated to be very weak, with oscillator strengths $<0.002$. Therefore, these changes on the first-allowed excitations may have only little effect on the color of crystals.

Table 26 The first-allowed electronic excitations of the 9 unique dimer motifs of $\mathrm{Gm} 8 \mathrm{~m}-\mathrm{Y}$ compared to that of its monomer, calculated with TD-DFT. For dimers with inversion centers, the $2^{\text {nd }}$ excited states were also listed as the $1^{\text {st }}$ excited states may be symmetry-forbidden.

\begin{tabular}{|c|c|c|c|c|}
\hline & & Excitation energy* & & \\
\hline Name & $\begin{array}{l}\text { ARU of } \\
\text { the } 2^{\text {nd }} \\
\text { molecule }\end{array}$ & $\begin{array}{l}\text { To } 1^{\text {st }} \text { excited state } \\
\text { in } \mathrm{eV} \text { (in } \mathrm{nm} \text { ) }\end{array}$ & $\begin{array}{l}\text { To } 2^{\text {nd }} \text { excited state } \\
\text { in } \mathrm{eV} \text { (in } \mathrm{nm} \text { ) }\end{array}$ & $\begin{array}{l}\text { Shift }(\mathrm{nm}) \text { compared } \\
\text { to monomer }\end{array}$ \\
\hline monomer & & 3.55 (349.4) & & - \\
\hline Half stacking & 1545 & $3.54(350.3)$ & & 0.9 \\
\hline $\mathrm{CH}_{3} \cdots \mathrm{O}=\mathrm{C}$ tilted & 2645 & $3.54(350.1)$ & & 0.7 \\
\hline $\mathrm{CH}_{3} \cdots$ 1-ring tilted & 2745 & 3.55 (349.2) & & -0.2 \\
\hline $\mathrm{NO}_{2}$-opposite & 3656 & $3.60(344.6)$ & $3.60(344.4)$ & -5.0 \\
\hline Cyclic $\mathrm{CH} \cdots \mathrm{O}=\mathrm{C}$ & 3666 & $3.68(337.0)$ & 3.68 (336.9) & -12.6 \\
\hline \multirow[t]{2}{*}{ Cyclic $\mathrm{CH}^{\prime \cdots \mathrm{NO}_{2}}$} & 3756 & $3.53(350.7)$ & 3.54 (350.7) & 1.3 \\
\hline & 3766 & 3.54 (350.5) & 3.54 (350.5) & 1.1 \\
\hline $\mathrm{CH}_{3} \cdots \mathrm{NO}_{2}$ tilted & 4554 & 3.55 (349.1) & & -0.3 \\
\hline $\mathrm{CH}_{3} \cdots 3$-ring tilted & 4564 & $3.53(351.5)$ & & 2.1 \\
\hline
\end{tabular}

* Excitations prohibited by symmetry are shown in light grey. 
As shown in SI Table 27, the calculated excitations with oscillator strength $>0.03$ and wavelength $>250$ $\mathrm{nm}$ ) of each dimer motif show a shift of no more than $5 \mathrm{~nm}$ of the HOMO-LUMO absorption (at $318 \mathrm{~nm}$ for the monomer) for some dimer motifs, i.e. the $\mathrm{CH}_{3}{ }^{\cdots} \mathrm{O}=\mathrm{C}$ tilted, the $\mathrm{NO}_{2}$-opposite, the 3766 dimer motif. In contrast, the transitions of the half-stacking dimer split into two, with the stronger one blue-shifted by $\sim 5 \mathrm{~nm}$. The small and yet opposite effects these dimer motifs produce in the HOMO-LUMO excitation is consistent with the similarity in color of $\mathrm{Gm} 8 \mathrm{~m}-\mathrm{Y}$ crystal and its solution, suggesting that the molecular packing within the $\mathrm{Gm} 8 \mathrm{~m}-\mathrm{Y}$ crystal does not significantly change the UV-Vis absorption from that of the monomer (SI Figure 38).

Table 27 Calculated electronic excitations of 9 unique dimer motif of $\mathrm{Gm} 8 \mathrm{~m}-\mathrm{Y}$ with oscillator strength $>0.03$ (normalized to one molecule) and wavelength $>250 \mathrm{~nm}$. Highlighted are notable shifts (red and blue) of absorptions compared to those in a monomer.

\begin{tabular}{|c|c|c|c|c|c|c|c|c|}
\hline Monomer & & $\begin{array}{l}3.89 \\
(318.4) \\
(0.06)\end{array}$ & & & & $\begin{array}{l}4.65 \\
(266.4) \\
(0.92)\end{array}$ & & $\begin{array}{l}4.76 \\
(260.7) \\
(0.09) \\
\end{array}$ \\
\hline Half stacking & $\begin{array}{l}3.85 \\
(322.1) \\
(0.02)\end{array}$ & & $\begin{array}{l}3.96 \\
(313.0) \\
(0.04)\end{array}$ & & $\begin{array}{l}4.57 \\
(271.3) \\
(0.65)\end{array}$ & $\begin{array}{l}4.67 \\
(265.5) \\
(0.12)\end{array}$ & & \\
\hline $\mathrm{CH}_{3} \cdots \mathrm{O}=\mathrm{C}$ tilted & $\begin{array}{l}3.84 \\
(323.0) \\
(0.03) \\
\end{array}$ & $\begin{array}{l}3.88 \\
(319.7) \\
(0.04)\end{array}$ & & & $\begin{array}{l}4.61 \\
(269.1) \\
(0.34) \\
\end{array}$ & $\begin{array}{l}4.67 \\
(265.6) \\
(0.57) \\
\end{array}$ & & $\begin{array}{l}4.75 \\
(261.1) \\
(0.05) \\
\end{array}$ \\
\hline $\mathrm{CH}_{3} \cdots 1$-ring tilted & & $\begin{array}{l}3.91 \\
(317.3) \\
(0.07) \\
\end{array}$ & & & $\begin{array}{l}4.63 \\
(267.7) \\
(0.31) \\
\end{array}$ & $\begin{array}{l}4.66 \\
(265.8) \\
(0.60) \\
\end{array}$ & $\begin{array}{l}4.76 \\
(260.6) \\
(0.04) \\
\end{array}$ & $\begin{array}{l}4.77 \\
(260.1) \\
(0.04) \\
\end{array}$ \\
\hline $\mathrm{NO}_{2}$-opposite & $\begin{array}{l}3.83 \\
(323.4) \\
(0.08)\end{array}$ & & & & & $\begin{array}{l}4.61 \\
(268.8) \\
(0.87)\end{array}$ & & $\begin{array}{l}4.76 \\
(260.3) \\
(0.06) \\
\end{array}$ \\
\hline Cyclic $\mathrm{CH}^{\prime \cdots} \mathrm{O}=\mathrm{C}$ & & $\begin{array}{l}3.91 \\
(316.7) \\
(0.09)\end{array}$ & & & & $\begin{array}{l}4.64 \\
(267.5) \\
(0.78)\end{array}$ & & $\begin{array}{l}4.77 \\
(259.7) \\
(0.13) \\
\end{array}$ \\
\hline Cyclic $\mathrm{CH} \cdots \mathrm{NO}_{2}$ & $\begin{array}{l}3.86 \\
(321.6) \\
(0.06)\end{array}$ & & & & & & $\begin{array}{l}4.70 \\
(263.9) \\
(0.95) \\
\end{array}$ & \\
\hline 3766 & $\begin{array}{l}3.83 \\
(323.4) \\
(0.06)\end{array}$ & & & & & & $\begin{array}{l}4.70 \\
(263.9) \\
(0.63)\end{array}$ & $\begin{array}{l}4.74 \\
(261.4) \\
(0.30)\end{array}$ \\
\hline $\mathrm{CH}_{3} \cdots \mathrm{NO}_{2}$ tilted & & $\begin{array}{l}3.90 \\
(317.8) \\
(0.03)\end{array}$ & & $\begin{array}{l}4.51 \\
(275.0) \\
(0.04) \\
\end{array}$ & $\begin{array}{l}4.60 \\
(269.6) \\
(0.32)\end{array}$ & $\begin{array}{l}4.68 \\
(264.9) \\
(0.46)\end{array}$ & $\begin{array}{l}4.73 \\
(261.9) \\
(0.12)\end{array}$ & $\begin{array}{l}4.76 \\
(260.3) \\
(0.06) \\
\end{array}$ \\
\hline $\mathrm{CH}_{3}$ ”3-ring tilted & & $\begin{array}{l}3.89 \\
(318.7) \\
(0.03) \\
\end{array}$ & & & $\begin{array}{l}4.62 \\
(268.4) \\
(0.29) \\
\end{array}$ & $\begin{array}{l}4.67 \\
(265.7) \\
(0.48) \\
\end{array}$ & $\begin{array}{l}4.75 \\
(260.9) \\
(0.05) \\
\end{array}$ & $\begin{array}{l}4.76 \\
(260.6) \\
(0.14) \\
\end{array}$ \\
\hline
\end{tabular}




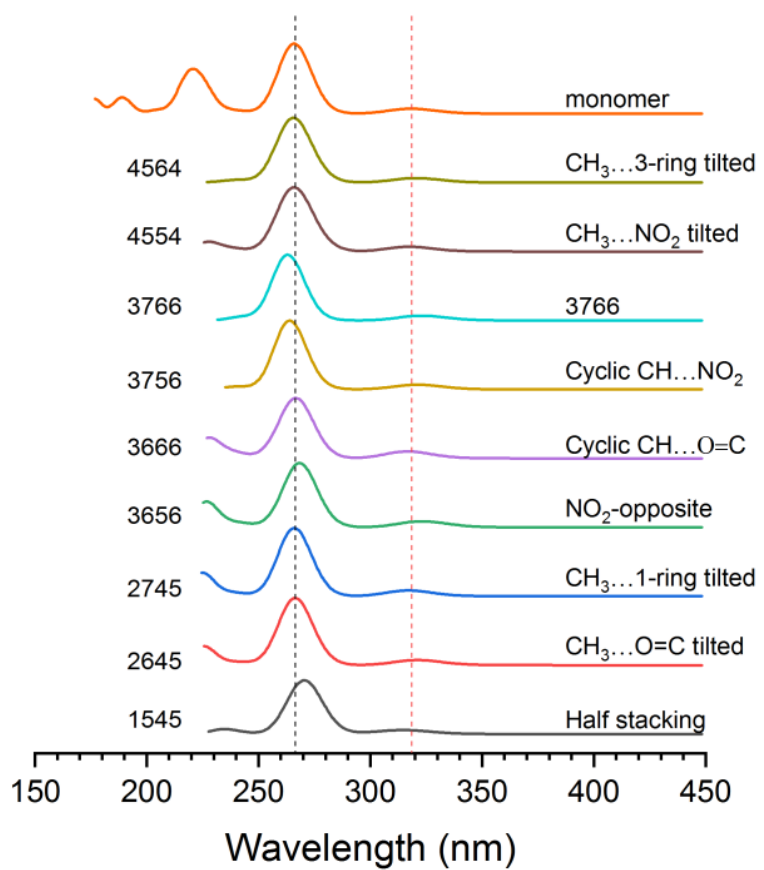

(a)

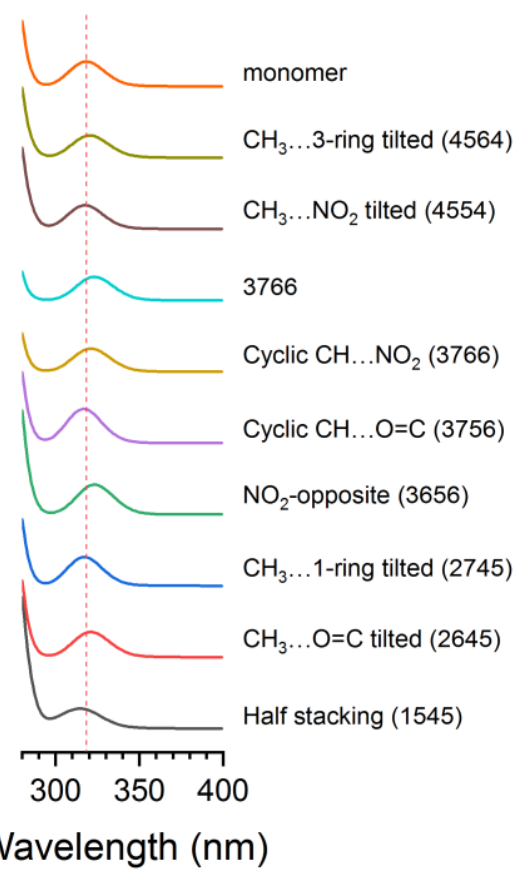

(b)

Figure 38 Absorption spectra of the dimers taken from $\mathrm{Gm8m}-\mathrm{Y}$ PBE-TS optimized structure, shown as (a) the entire spectra and (b) the onset of absorption shown with an increased vertical scale, simulated using the first 18 excitations calculated by TD-DFT with $\omega$ B97x. Each dimer is labelled as in Table 22 above using the ARU code for the second molecule and the qualitative description.

The largest shifts for the dimers within $\mathrm{Gm} 8 \mathrm{~m}-\mathrm{Y}$ are for the half-stacking dimer which forms 1D stacks (SI Figure 39 (b)). These stacks then interact with each other through cyclic $\mathrm{CH} \cdots \mathrm{O}=\mathrm{C}, \mathrm{Cyclic} \mathrm{CH}^{\cdots} \mathrm{NO}_{2}$ and $\mathrm{NO}_{2}$-opposite dimers to form zigzagging 2D sheets, which through the group of tilted dimer motifs to form the 3D structure of $\mathrm{Gm} 8 \mathrm{~m}-\mathrm{Y}$.

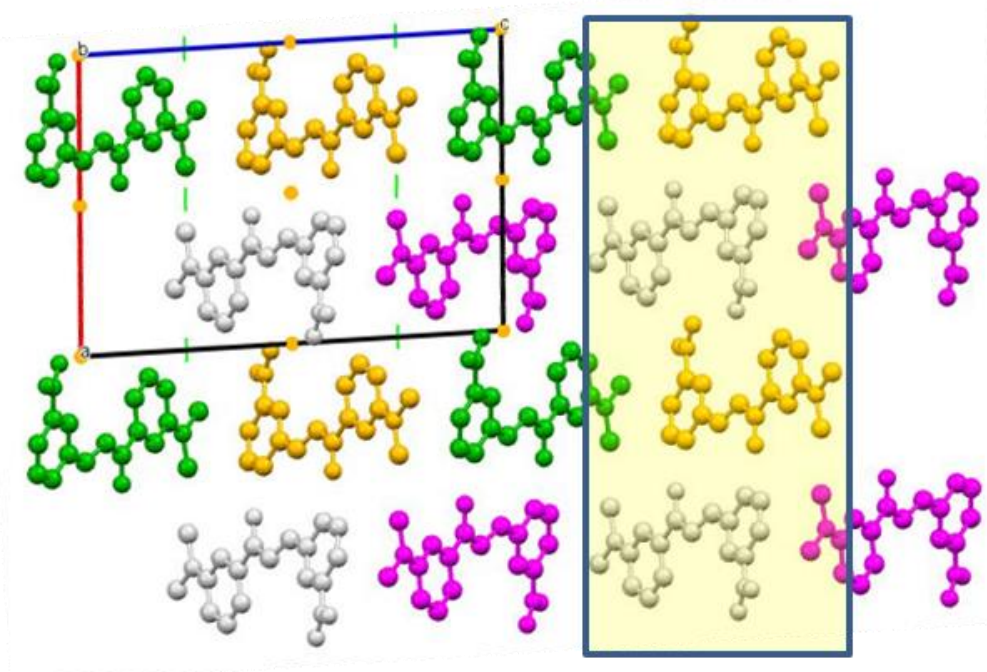

(a)

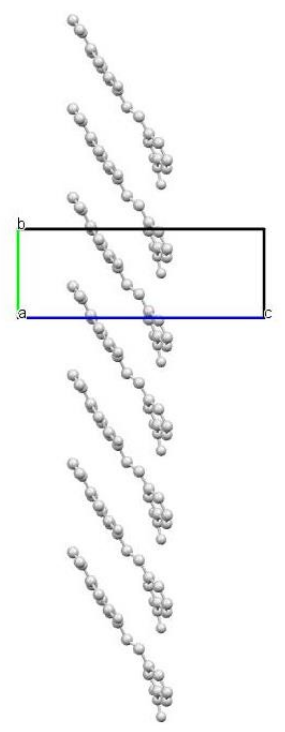

(b)

Figure 39 (a) The packing of $\mathrm{Gm8m}$ half-stacks in $\mathrm{Gm8m}-\mathrm{Y}$ form to 2D sheets (as yellow square) and to 3D structure, each "molecule" shown represents a 1D-stack of half-stacking molecules, shown as (b). 
Gm8m - 0

The first-allowed excitations of all 11 dimer motifs (SI Table 28), show that the dimer with double 1-3 ring stacking motif has the largest red-shift ( $6 \mathrm{~nm}$ ), and a dimer with a cyclic $\mathrm{CH} \cdots \mathrm{O}=\mathrm{C}$ motif blue-shifts the energy of the first excited state by $\sim 18 \mathrm{~nm}$. Again in nearly all dimer and monomer cases the first-allowed excitations are weak with oscillator strength $<0.002$, with the only exception being the first-allowed excitation of the double 1-3 ring stacking motif, which has an oscillator strength $\sim 0.02$, making it just noticeable in SI Figure 40(b).

Table 28 TD-DFT calculated first-allowed electronic excitations of the 11 unique dimer motifs of Gm8m - 0 compared to that of its monomer.

\begin{tabular}{|c|c|c|c|c|}
\hline & & Excitation energy* & & \\
\hline Name & $\begin{array}{c}\text { ARU of } \\
\text { the } 2^{\text {nd }} \\
\text { molecule }\end{array}$ & $\begin{array}{l}\text { To } 1^{\text {st }} \text { excited state in } \\
\mathrm{eV}(\mathrm{nm})\end{array}$ & $\begin{array}{l}\text { To } 2^{\text {nd }} \text { excited state in } \\
\text { eV }(n m)\end{array}$ & $\begin{array}{l}\text { Shift }(\mathrm{nm}) \\
\text { compared to } \\
\text { monomer }\end{array}$ \\
\hline Monomer & & 3.55 (349.5) & & - \\
\hline \multirow[t]{3}{*}{ 1D chain } & 1344 & $3.54(350.4)$ & & 0.9 \\
\hline & 1444 & 3.55 (349.3) & & -0.2 \\
\hline & 1455 & $3.56(348.3)$ & & -1.1 \\
\hline Cyclic $\mathrm{CH} \cdots \mathrm{NO}_{2}$ & 2456 & $3.53(351.3)$ & $3.53(351.3)$ & 1.8 \\
\hline cyclic $\mathrm{CH} \cdots \mathrm{O}=\mathrm{C}$ & 2466 & $3.73(332.1)$ & $3.73(332.0)$ & -17.5 \\
\hline $\begin{array}{l}\text { Double 1-3 ring } \\
\text { stacking }\end{array}$ & 2556 & $3.49(355.6)$ & $3.49(355.4)$ & 5.9 \\
\hline 1-ring stacking & 2566 & 3.55 (349.3) & 3.55 (349.2) & -0.3 \\
\hline \multirow[t]{3}{*}{ Cyclic $\mathrm{CH}^{\prime \cdots} \mathrm{CH}_{3}$} & 2667 & 3.55 (349.5) & 3.55 (349.5) & 0.0 \\
\hline & 2677 & 3.55 (348.9) & $3.55(348.9)$ & -0.6 \\
\hline & 2767 & 3.55 (349.3) & 3.55 (349.3) & -0.2 \\
\hline 3-ring stacking & 2777 & $3.53(350.8)$ & $3.53(350.8)$ & 1.3 \\
\hline
\end{tabular}

* Excitations prohibited by symmetry are shown in light grey.

From the calculated excitation features with oscillator strength in the visible region (oscillator strength > 0.03 and wavelength $>250 \mathrm{~nm}$ ) in SI Table 29, the double 1-3 ring stacking leads not only to an exceptionally strong first-allowed excitation, it also has a noticeable absorption at $292 \mathrm{~nm}$, red-shifted by nearly $23 \mathrm{~nm}$ from the strong feature at $269 \mathrm{~nm}$ for a monomer. The 1-ring stacking dimer motif leads to an absorption at $336 \mathrm{~nm}$, red-shifted by $18 \mathrm{~nm}$ from the monomer HOMO-LUMO excitation at 319 $\mathrm{nm}$, and another absorption at $283 \mathrm{~nm}$, red-shifted by $14 \mathrm{~nm}$ from the monomer HOMO-1-LUMO absorption at $269 \mathrm{~nm}$. The 3-ring stacking dimer motif has a very strong absorption at $278 \mathrm{~nm}$, red-shifted by $8 \mathrm{~nm}$ from the monomer HOMO-1-LUMO absorption at $269 \mathrm{~nm}$. Although this is quite a small shift, it is the most obvious one in SI Figure 40(b) due to its intensity. 
Table 29 Calculated absorption features of every dimer motif in $\mathrm{Gm8m}-0$ with oscillator strength $>0.03$ (normalized to one molecule) and wavelength $>250 \mathrm{~nm}$. Highlighted are notable shifts of absorptions compared to those in a monomer, along with the first-allowed excitation of the double 1-3 ring stacking dimer (highlighted in green).

\begin{tabular}{|c|c|c|c|c|c|c|c|}
\hline monomer & & $\begin{array}{l}3.89 \\
(318.9) \\
(0.08)\end{array}$ & & & $\begin{array}{l}4.61 \\
(269.0) \\
(0.90) \\
\end{array}$ & & $\begin{array}{l}4.68 \\
(264.7) \\
(0.11) \\
\end{array}$ \\
\hline 1D chain & $\begin{array}{l}3.86 \\
(321.0) \\
(0.04)\end{array}$ & $\begin{array}{l}3.90 \\
(318.3) \\
(0.04)\end{array}$ & & & $\begin{array}{l}4.59 \\
(270.3) \\
(1.08)\end{array}$ & $\begin{array}{l}4.66 \\
(266.1) \\
(0.03)\end{array}$ & \\
\hline 1444 & $\begin{array}{l}3.87 \\
(320.1) \\
(0.06)\end{array}$ & $\begin{array}{l}3.91 \\
(317.4) \\
(0.04)\end{array}$ & & & $\begin{array}{l}4.58 \\
(270.7) \\
(0.99) \\
\end{array}$ & & \\
\hline 1455 & & $\begin{array}{l}3.94 \\
(315.0) \\
(0.05)\end{array}$ & & $\begin{array}{l}4.57 \\
(271.4) \\
(0.63) \\
\end{array}$ & $\begin{array}{l}4.57 \\
(271.1) \\
(0.22) \\
\end{array}$ & & $\begin{array}{l}4.71 \\
(263.2) \\
(0.04) \\
\end{array}$ \\
\hline Cyclic $\mathrm{CH}^{\prime \cdots \mathrm{NO}_{2}}$ & $\begin{array}{l}3.86 \\
(321.5) \\
(0.07)\end{array}$ & & & & & $\begin{array}{l}4.65 \\
(266.7) \\
(0.94)\end{array}$ & \\
\hline cyclic $\mathrm{CH}^{\prime \cdots O} \mathrm{O}=\mathrm{C}$ & & $\begin{array}{l}3.92 \\
(316.3) \\
(0.10)\end{array}$ & & & $\begin{array}{l}4.59 \\
(270.2) \\
(0.74) \\
\end{array}$ & & $\begin{array}{l}4.72 \\
(262.4) \\
(0.18) \\
\end{array}$ \\
\hline $\begin{array}{l}\text { Double 1-3 ring } \\
\text { stacking }\end{array}$ & $\begin{array}{l}3.49 \\
(355.4) \\
(0.02)\end{array}$ & $\begin{array}{l}3.86 \\
(321.5) \\
(0.04)\end{array}$ & $\begin{array}{l}4.25 \\
(291.5) \\
(0.04)\end{array}$ & & $\begin{array}{l}4.62 \\
(268.5) \\
(0.47)\end{array}$ & $\begin{array}{l}4.64 \\
(267.1) \\
(0.24)\end{array}$ & \\
\hline 1-ring stacking & $\begin{array}{l}3.68 \\
(336.6) \\
(0.05)\end{array}$ & & $\begin{array}{l}4.38 \\
(282.8) \\
(0.05) \\
\end{array}$ & $\begin{array}{l}4.54 \\
(273.3) \\
(1.06)\end{array}$ & & & $\begin{array}{l}4.69 \\
(264.1) \\
(0.04) \\
\end{array}$ \\
\hline Cyclic $\mathrm{CH}^{\prime \cdots} \mathrm{CH}_{3}$ & & $\begin{array}{l}3.88 \\
(319.6) \\
(0.11) \\
\end{array}$ & & & $\begin{array}{l}4.59 \\
(270.1) \\
(0.96) \\
\end{array}$ & & $\begin{array}{l}4.69 \\
(264.6) \\
(0.08) \\
\end{array}$ \\
\hline 2677 & & $\begin{array}{l}3.91 \\
(317.4) \\
(0.08)\end{array}$ & & & $\begin{array}{l}4.59 \\
(269.9) \\
(0.98) \\
\end{array}$ & & $\begin{array}{l}4.69 \\
(264.5) \\
(0.08) \\
\end{array}$ \\
\hline 2767 & & $\begin{array}{l}3.92 \\
(316.5) \\
(0.08)\end{array}$ & & & $\begin{array}{l}4.59 \\
(269.9) \\
(0.99) \\
\end{array}$ & & $\begin{array}{l}4.69 \\
(264.5) \\
(0.08) \\
\end{array}$ \\
\hline 3-ring stacking & & $\begin{array}{l}3.87 \\
(320.5) \\
(0.09)\end{array}$ & & $\begin{array}{l}4.46 \\
(277.8) \\
(0.79) \\
\end{array}$ & & & $\begin{array}{l}4.67 \\
(265.5) \\
(0.05) \\
\end{array}$ \\
\hline
\end{tabular}




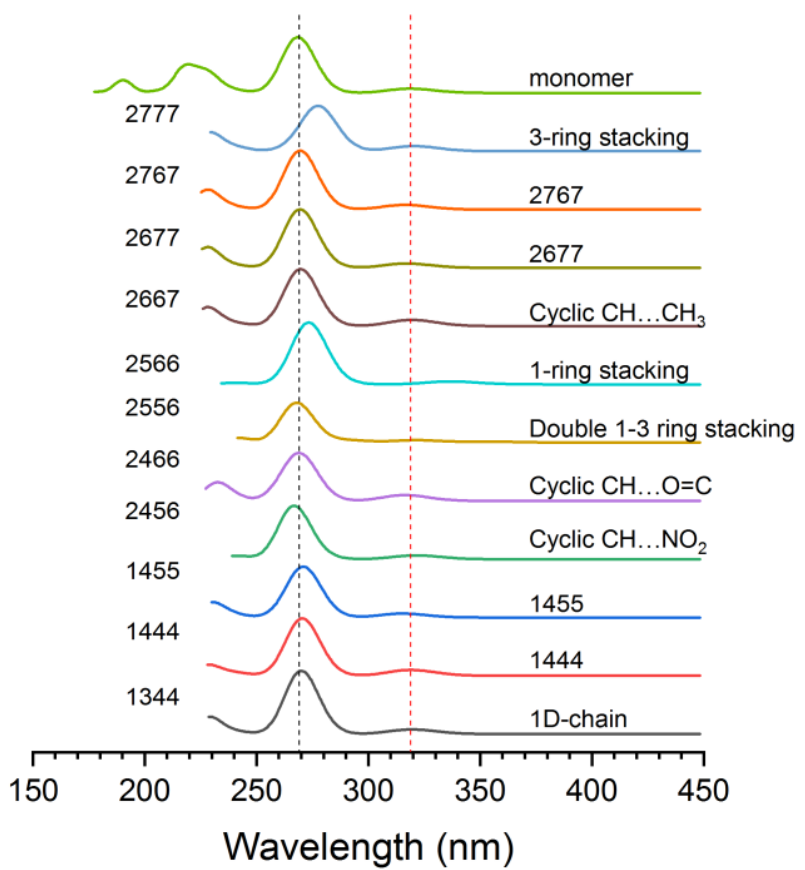

(a)

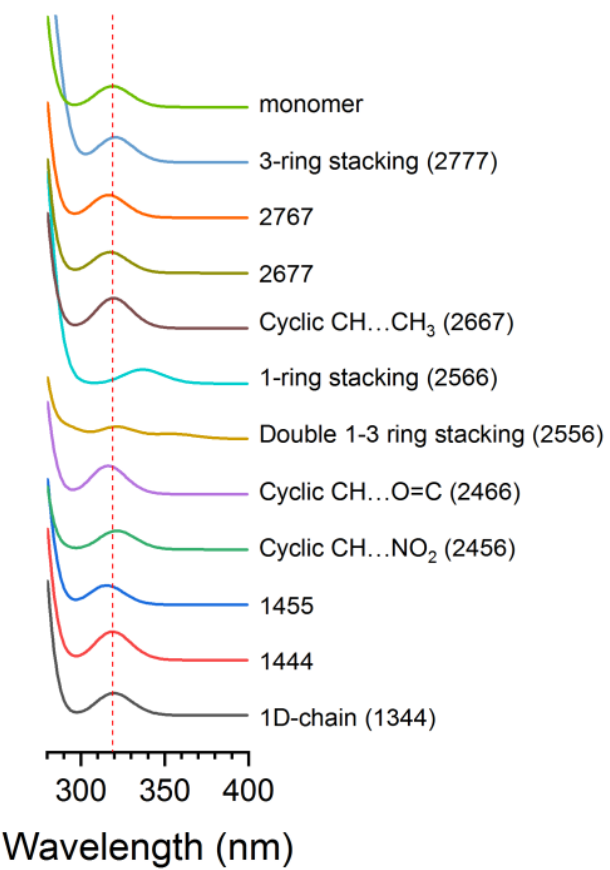

(b)

Figure 40 Absorption spectra of the dimers taken from Gm8m - O PBE-TS optimized structure, simulated using the first 18 excitations calculated by TD-DFT with $\omega B$ 97x. Each dimer is labelled as in Table 23 above using the ARU code for the second molecule and the qualitative description.

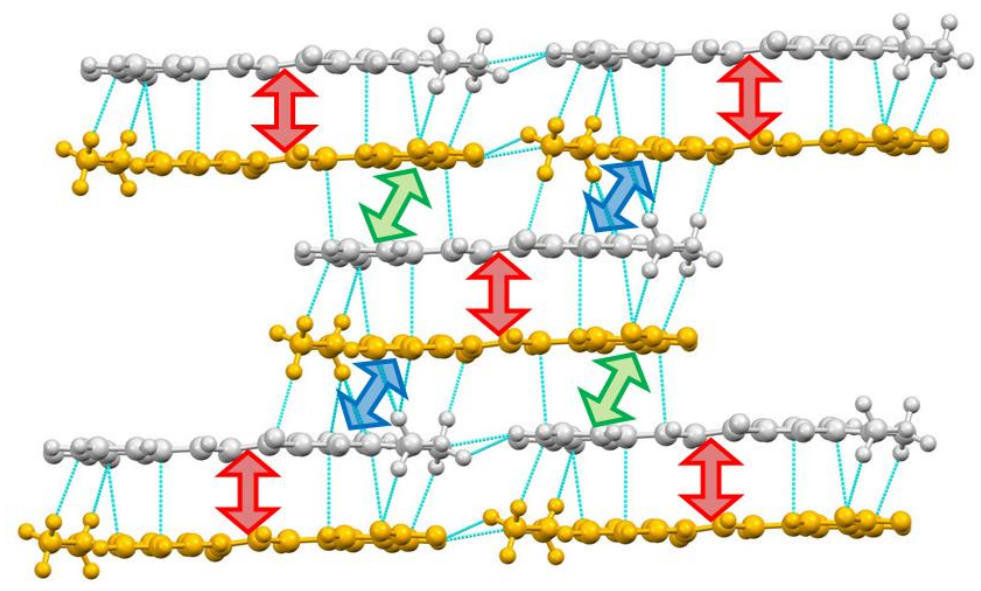

Figure 41 Packing of 1-ring stacking (blue arrow), 3-ring stacking (green arrows) and double 1-3 ring stacking (red arrows) into 2D sheet in $\mathrm{Gm} 8 \mathrm{~m}-0$ crystal structure.

In Gm8m - 0 there exist three dimer motifs: the double 1-3 ring stacking, the 1-ring stacking and the 3ring stacking, which red-shift the strong excitations, thus changing the color from the yellow $\mathrm{Gm} 8 \mathrm{~m}$ solution to the orange $\mathrm{Gm} 8 \mathrm{~m}$ - $\mathrm{O}$ crystal. These dimer motifs in $\mathrm{Gm} 8 \mathrm{~m}$ - $\mathrm{O}$ alternates into a 2D sheet as shown in Figure 41, and then other dimer motifs, e.g. the cyclic $\mathrm{CH} \cdots \mathrm{O}=\mathrm{C}, \mathrm{Cyclic} \mathrm{CH}^{\prime} \cdots \mathrm{NO}_{2}$ and $\mathrm{Cyclic} \mathrm{CH}-\mathrm{CH}_{3}$, help pack these 2D sheets together into 3D structure of $\mathrm{Gm} 8 \mathrm{~m}-\mathrm{O}$ polymorph. 
Gm8p - R

For the Gm8p-R the dimer motifs, most of the first-allowed excitations are red-shifted by less than $4 \mathrm{~nm}$, but the double 1-3 ring stacking motif shifts the first-allowed excitation to the blue end by $7 \mathrm{~nm}$ (SI Table 30). However, the first-allowed excitations have only weak oscillator strengths $<0.003$ for all dimer motifs, thus will not affect the color of the polymorph.

Table 30 TD-DFT calculated first-allowed electronic excitations of the 9 unique dimer motifs of Gm8p - R compared to that of its monomer.

\begin{tabular}{|l|l|l|l|l|}
\hline & & Excitation energy & & \\
\hline Name & $\begin{array}{l}\text { ARU of } \\
\text { the 2 } \\
\text { molecule }\end{array}$ & $\begin{array}{l}\text { To } 1^{\text {st }} \text { excited state in } \\
\text { eV }(\mathrm{nm})\end{array}$ & $\begin{array}{l}\text { To 2 } \\
\text { eV }(\mathrm{nm})\end{array}$ & \\
\hline monomer & & $\mathbf{3 . 4 9}(\mathbf{3 5 5 . 0})$ & & $\begin{array}{l}\text { Shift (nm) } \\
\text { compared to } \\
\text { monomer }\end{array}$ \\
\hline $\begin{array}{l}\text { Short-axis } \\
\text { translation }\end{array}$ & 1455 & $3.51(352.9)$ & & -2.1 \\
\hline 2445 & 2445 & $3.50(354.6)$ & & -0.4 \\
\hline 1-ring T-stack tilted & 2545 & $3.49(355.4)$ & $3.48(356.2)$ & 0.4 \\
\hline Cyclic $\mathrm{NO}_{2} \cdots \mathrm{CH}_{3}$ & 3666 & $3.48(356.3)$ & $3.56(348.0)$ & 1.2 \\
\hline $\begin{array}{l}\text { Double 1-3 ring } \\
\text { stacking }\end{array}$ & 3676 & $3.53(351.0)$ & $3.48(356.3)$ & -7.0 \\
\hline 3-ring stacking & $3766^{*}$ & $3.48(356.4)$ & $3.46(358.4)$ & 1.3 \\
\hline 3776 & 3776 & $3.46(358.4)$ & & 3.4 \\
\hline $\mathrm{NO}_{2} \cdots \mathrm{CH}_{3}$ tilted & 4364 & $3.47(357.4)$ & & 0.1 \\
\hline 4464 & 4464 & $3.49(355.1)$ & & \\
\hline
\end{tabular}

* additional molecule to complete the molecular shell.

Examining the strong absorption features (SI Table 31), a few dimer motifs lead to noticeable red-shifts of the HOMO-LUMO monomer excitation at $324 \mathrm{~nm}$ : the double 1-3 ring stacking red-shifts the peak by 23 $\mathrm{nm}$, the cyclic $\mathrm{NO}_{2} \cdots \mathrm{CH}_{3}$, the 3776 , and the $\mathrm{NO}_{2} \cdots \mathrm{CH}_{3}$ tilted dimer motifs, red-shift by more than $10 \mathrm{~nm}$, and the 1-ring T-stack tilted motif red-shifts by $5 \mathrm{~nm}$, as shown in SI Figure 42 (b). The double 1-3 ring stacking and the $\mathrm{NO}_{2} \cdots \mathrm{CH}_{3}$ tilted motifs also have the strong HOMO-1-LUMO monomer excitation at $288 \mathrm{~nm}$ redshifted by around $5 \mathrm{~nm}$, also noticeable from SI Figure 42 (a) due to the high intensity of the excitation. 
Table 31 Calculated absorption features of every dimer motif in Gm8p - R with oscillator strength $>0.03$ (normalized to one molecule) and wavelength $>250 \mathrm{~nm}$. Highlighted in red are notable shifts of absorptions compared to those in a monomer.

\begin{tabular}{|c|c|c|c|c|c|c|c|c|}
\hline monomer & & $\begin{array}{l}3.83 \\
(323.8) \\
(0.11) \\
\end{array}$ & & & $\begin{array}{l}4.31 \\
(287.8) \\
(1.06) \\
\end{array}$ & & & \\
\hline $\begin{array}{l}\text { Short-axis } \\
\text { translation }\end{array}$ & & $\begin{array}{l}3.87 \\
(320.8) \\
(0.04)\end{array}$ & $\begin{array}{l}3.89 \\
(318.4) \\
(0.07)\end{array}$ & & $\begin{array}{l}4.28 \\
(289.9) \\
(0.99)\end{array}$ & & & \\
\hline 2445 & & $\begin{array}{l}3.86 \\
(321.2) \\
(0.06) \\
\end{array}$ & $\begin{array}{l}3.86 \\
(321.1) \\
(0.06) \\
\end{array}$ & & $\begin{array}{l}4.30 \\
(288.6) \\
(0.95) \\
\end{array}$ & $\begin{array}{l}4.32 \\
(286.9) \\
(0.14) \\
\end{array}$ & & \\
\hline 1-ring T-stack tilted & $\begin{array}{l}3.77 \\
(328.9) \\
(0.06) \\
\end{array}$ & $\begin{array}{l}3.85 \\
(321.9) \\
(0.06) \\
\end{array}$ & & & $\begin{array}{l}4.28 \\
(289.6) \\
(0.94) \\
\end{array}$ & $\begin{array}{l}4.32 \\
(286.6) \\
(0.13) \\
\end{array}$ & & \\
\hline Cyclic $\mathrm{NO}_{2} \cdots \mathrm{CH}_{3}$ & $\begin{array}{l}3.71 \\
(334.1) \\
(0.10)\end{array}$ & & & & $\begin{array}{l}4.32 \\
(286.8) \\
(0.24) \\
\end{array}$ & $\begin{array}{l}4.34 \\
(285.7) \\
(0.05) \\
\end{array}$ & $\begin{array}{l}4.35 \\
(284.9) \\
(0.68) \\
\end{array}$ & $\begin{array}{l}4.72 \\
(262.7) \\
(0.03) \\
\end{array}$ \\
\hline $\begin{array}{l}\text { Double 1-3 ring } \\
\text { stacking }\end{array}$ & $\begin{array}{l}3.57 \\
(346.9) \\
(0.04) \\
\end{array}$ & $\begin{array}{l}3.82 \\
(324.6) \\
(0.05) \\
\end{array}$ & & $\begin{array}{l}4.23 \\
(293.2) \\
(0.78) \\
\end{array}$ & & & & $\begin{array}{l}4.95 \\
(250.7) \\
(0.05) \\
\end{array}$ \\
\hline 3-ring stacking & & $\begin{array}{l}3.80 \\
(326.0) \\
(0.11)\end{array}$ & & & $\begin{array}{l}4.28 \\
(290.0) \\
(1.02)\end{array}$ & & & \\
\hline 3776 & $\begin{array}{l}3.71 \\
(333.9) \\
(0.07) \\
\end{array}$ & & & & $\begin{array}{l}4.33 \\
(286.1) \\
(0.69) \\
\end{array}$ & $\begin{array}{l}4.34 \\
(286.0) \\
(0.38) \\
\end{array}$ & & \\
\hline $\mathrm{NO}_{2} \cdots \mathrm{CH}_{3}$ tilted & $\begin{array}{l}3.69 \\
(335.7) \\
(0.04) \\
\end{array}$ & $\begin{array}{l}3.77 \\
(328.9) \\
(0.06) \\
\end{array}$ & & $\begin{array}{l}4.24 \\
(292.1) \\
(0.94) \\
\end{array}$ & $\begin{array}{l}4.31 \\
(287.3) \\
(0.24) \\
\end{array}$ & & & \\
\hline 4464 & & $\begin{array}{l}3.81 \\
(325.0) \\
(0.07) \\
\end{array}$ & $\begin{array}{l}3.85 \\
(322.3) \\
(0.06) \\
\end{array}$ & & $\begin{array}{l}4.28 \\
(289.5) \\
(0.87) \\
\end{array}$ & $\begin{array}{l}4.30 \\
(288.3) \\
(0.07) \\
\end{array}$ & $\begin{array}{l}4.32 \\
(287.0) \\
(0.14) \\
\end{array}$ & \\
\hline
\end{tabular}




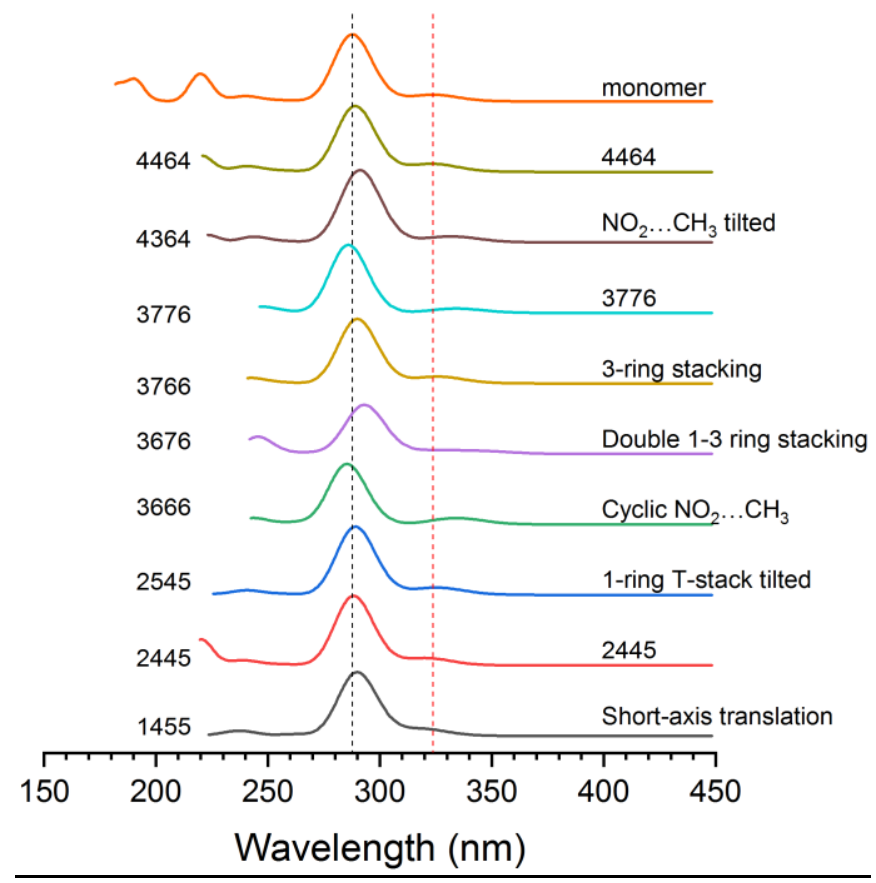

(a)

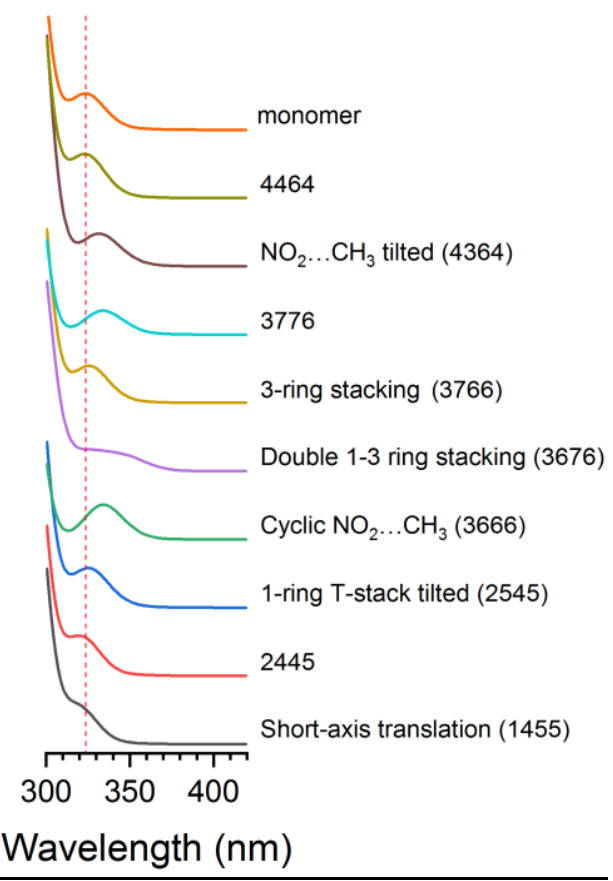

(b)

Figure 42 Absorption spectra of the dimers taken from Gm8p - R PBE-TS optimized structure, simulated using the first 18 excitations calculated by TD-DFT with $\omega$ B97x. Each dimer is labelled as in Table 24 above using the ARU code for the second molecule and the qualitative description.

In $\mathrm{Gm} 8 \mathrm{p}-\mathrm{R}$, the double 1-3 ring stack motif and cyclic $\mathrm{NO}_{2} \cdot \mathrm{CH}_{3}$ motif alternate to pack into 1D steps, which are linked together with the $\mathrm{NO}_{2}{ }^{\prime \cdots} \mathrm{CH}_{3}$ tilted motif into zigzagging $2 \mathrm{D}$ sheets (SI Figure 43). The shortaxis translation, the 3-ring stacking and 1-ring T-stack tilted motifs are involved in linking the 2D sheets into 3D structure of Gm8p - R. 


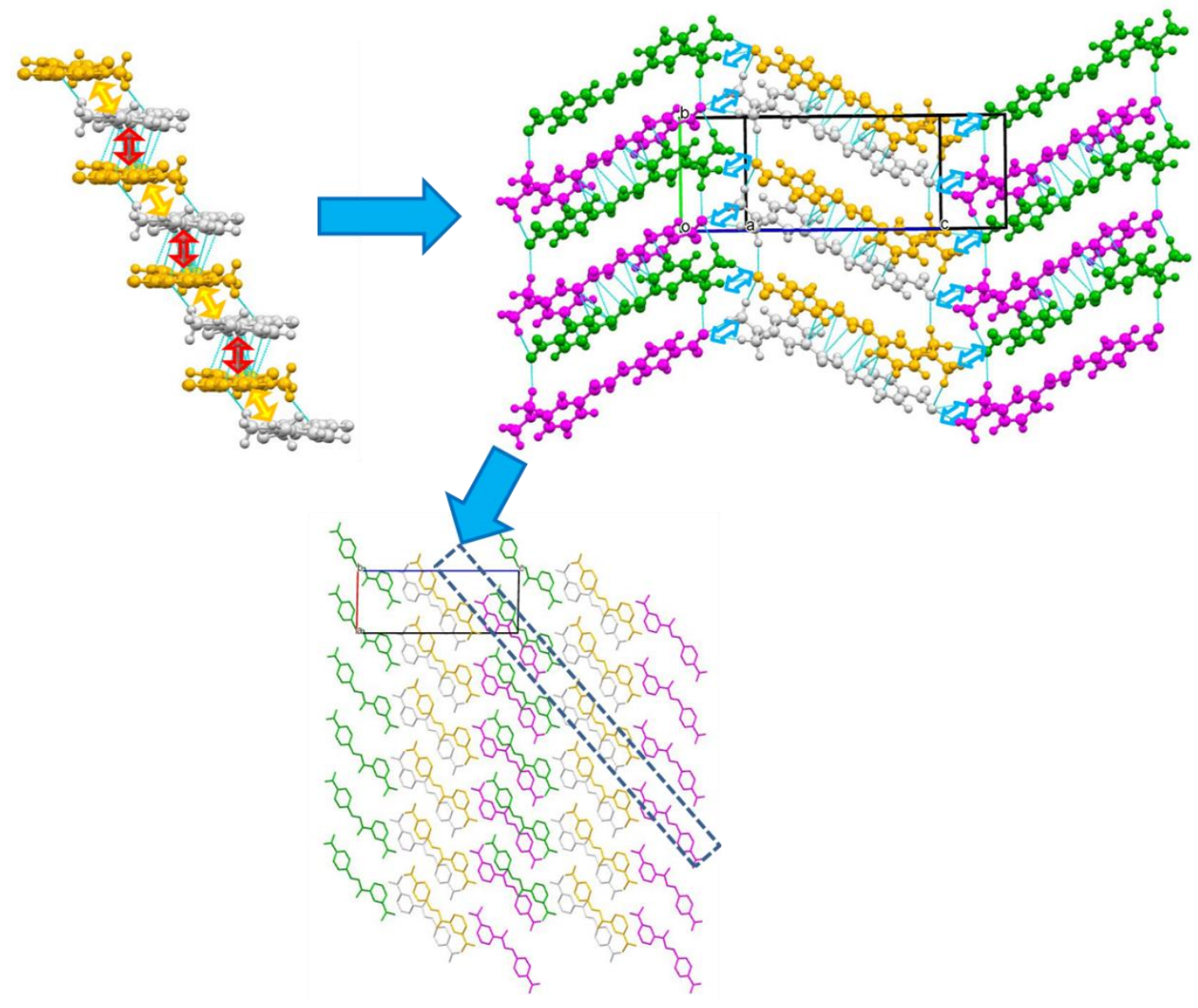

Figure 43 Packing of dimer motifs into 1D, 2D and 3D structure in Gm8p - R. In the 1D steps (top left) are the alternating double 1-3 ring stack motif (red arrows) and cyclic $\mathrm{NO}_{2} \cdots \mathrm{CH}_{3}$ motif (yellow arrows). 1D steps are connected through the $\mathrm{NO}_{2} \cdots \mathrm{CH}_{3}$ tilted motif into zigzagging 2D sheets, which then connect through the remaining motifs into the 3D structure.

Gm8p - B

In nearly all dimers, as in the monomer, the first-allowed excitations are weak with oscillator strength < 0.001 , except for the double 1-3 ring stacking motif, whose first-allowed excitation at $359 \mathrm{~nm}$ has oscillator strength of $\sim 0.05$, and is red-shifted by $6 \mathrm{~nm}$ relative to the monomer (SI Table 32). 
Table 32 TD-DFT calculated first-allowed electronic excitations of the 11 unique dimer motifs of Gm8p - B compared to that of its monomer.

\begin{tabular}{|c|c|c|c|c|}
\hline & & Excitation energy & & \\
\hline Name & $\begin{array}{l}\text { ARU of } \\
\text { the } 2^{\text {nd }} \\
\text { molecule }\end{array}$ & $\begin{array}{l}\text { To } 1^{\text {st }} \text { excited state } \\
\text { in eV }(\mathrm{nm})\end{array}$ & $\begin{array}{l}\text { To } 2^{\text {nd }} \text { excited state } \\
\text { in eV }(\mathrm{nm})\end{array}$ & $\begin{array}{l}\text { Shift }(\mathrm{nm}) \text { compared } \\
\text { to monomer }\end{array}$ \\
\hline monomer & & $3.51(353.0)$ & & \\
\hline $\begin{array}{l}\text { Long-axis } \\
\text { translation }\end{array}$ & 1445 & $3.50(354.6)$ & & 1.6 \\
\hline \multirow[t]{2}{*}{$\mathrm{CH}_{3} \cdots \mathrm{O}=\mathrm{C}$ tilted } & 2645 & 3.51 (353.3) & & 0.3 \\
\hline & 2646 & 3.51 (353.5) & & 0.5 \\
\hline \multirow[t]{2}{*}{$\begin{array}{l}\mathrm{NO}_{2} \cdots \text { backbone } \\
\text { tilted }\end{array}$} & 2746 & $3.49(355.0)$ & & 2.0 \\
\hline & 3556 & $3.51(352.8)$ & $3.51(352.7)$ & -0.3 \\
\hline Double $\mathrm{CH}_{3} \cdots 1$-ring & 3656 & $3.52(352.5)$ & $3.52(352.5)$ & -0.5 \\
\hline $\begin{array}{l}\text { Double 1-3 ring } \\
\text { stacking }\end{array}$ & 3666 & 3.44 (360.9) & $3.45(359.2)$ & 6.3 \\
\hline \multirow[t]{2}{*}{$\begin{array}{l}\text { modified cyclic } \\
\mathrm{NO}_{2} \cdots \mathrm{CH}_{3}\end{array}$} & 3766 & 3.49 (355.7) & 3.49 (355.6) & 2.7 \\
\hline & 4454 & 3.50 (354.7) & & 1.7 \\
\hline $\mathrm{C}=\mathrm{O} \cdots 1$-ring tilted & 4554 & $3.50(353.8)$ & & 0.8 \\
\hline $\mathrm{NO}_{2} \cdots 3$-ring tilted & 4564 & $3.50(354.4)$ & & 1.4 \\
\hline
\end{tabular}

Examining the strong absorption features (SI Table 32), the double 1-3 ring motif has significantly redshifted the HOMO-LUMO transition by more than $30 \mathrm{~nm}$, and the HOMO-1-LUMO transition by $8 \mathrm{~nm}$. The modified cyclic $\mathrm{NO}_{2}-\mathrm{CH}_{3}$ dimer also red- shifts the HOMO-LUMO transition by nearly $14 \mathrm{~nm}$, along with a smaller red-shift of more than $5 \mathrm{~nm}$ by the $\mathrm{NO}_{2}$-backbone motif. 
Table 33 calculated absorption features of every dimer motif in Gm8p - B with oscillator strength > 0.03 (normalized to one molecule) and wavelength $>250 \mathrm{~nm}$. Highlighted in red are those notable shifts of absorptions compared to those in a monomer.

\begin{tabular}{|c|c|c|c|c|c|c|c|c|}
\hline monomer & & $\begin{array}{l}3.78 \\
(327.8) \\
(0.09)\end{array}$ & & & & $\begin{array}{l}4.32 \\
(287.1) \\
(0.08) \\
\end{array}$ & $\begin{array}{l}4.32 \\
(286.9) \\
(1.01)\end{array}$ & \\
\hline $\begin{array}{l}\text { Long-axis } \\
\text { translation }\end{array}$ & $\begin{array}{l}3.74 \\
(332.0) \\
(0.06)\end{array}$ & $\begin{array}{l}3.76 \\
(329.9) \\
(0.05)\end{array}$ & & & & $\begin{array}{l}4.28 \\
(289.9) \\
(1.06)\end{array}$ & $\begin{array}{l}4.33 \\
(286.2) \\
(0.08)\end{array}$ & \\
\hline $\mathrm{CH}_{3} \cdots \mathrm{O}=\mathrm{C}$ tilted & $\begin{array}{l}3.73 \\
(332.5) \\
(0.04) \\
\end{array}$ & $\begin{array}{l}3.73 \\
(332.2) \\
(0.04)\end{array}$ & & & & $\begin{array}{l}4.30 \\
(288.3) \\
(0.36) \\
\end{array}$ & $\begin{array}{l}4.32 \\
(287.0) \\
(0.31)\end{array}$ & $\begin{array}{l}4.32 \\
(286.9) \\
(0.43) \\
\end{array}$ \\
\hline 2646 & & $\begin{array}{l}3.77 \\
(328.9) \\
(0.04)\end{array}$ & $\begin{array}{l}3.82 \\
(324.7) \\
(0.06)\end{array}$ & & & $\begin{array}{l}4.31 \\
(287.7) \\
(0.61)\end{array}$ & $\begin{array}{l}4.31 \\
(287.6) \\
(0.13)\end{array}$ & $\begin{array}{l}4.33 \\
(286.5) \\
(0.32)\end{array}$ \\
\hline $\begin{array}{l}\mathrm{NO}_{2} \text { '.backbone } \\
\text { tilted }\end{array}$ & $\begin{array}{l}3.72 \\
(333.4) \\
(0.04) \\
\end{array}$ & & $\begin{array}{l}3.88 \\
(319.3) \\
(0.07)\end{array}$ & & $\begin{array}{l}4.25 \\
(292.0) \\
(0.67) \\
\end{array}$ & $\begin{array}{l}4.28 \\
(289.6) \\
(0.35) \\
\end{array}$ & & \\
\hline 3556 & & $\begin{array}{l}3.81 \\
(325.7) \\
(0.12) \\
\end{array}$ & & & & $\begin{array}{l}4.31 \\
(287.9) \\
(1.13) \\
\end{array}$ & & \\
\hline Double $\mathrm{CH}_{3}$ 1-ring & & $\begin{array}{l}3.75 \\
(330.5) \\
(0.11) \\
\end{array}$ & & & & $\begin{array}{l}4.29 \\
(289.1) \\
(1.18) \\
\end{array}$ & & \\
\hline $\begin{array}{l}\text { Double 1-3-ring } \\
\text { stacking }\end{array}$ & $\begin{array}{l}3.45 \\
(359.2) \\
(0.05) \\
\end{array}$ & $\begin{array}{l}3.78 \\
(327.7) \\
(0.04)\end{array}$ & & & $\begin{array}{l}4.20 \\
(295.1) \\
(0.75) \\
\end{array}$ & & & $\begin{array}{l}4.67 \\
(265.5) \\
(0.03) \\
\end{array}$ \\
\hline $\begin{array}{l}\text { modified cyclic } \\
\mathrm{NO}_{2} \cdots \mathrm{CH}_{3}\end{array}$ & $\begin{array}{l}3.63 \\
(341.5) \\
(0.07)\end{array}$ & & & $\begin{array}{l}4.13 \\
(300.4) \\
(0.05)\end{array}$ & & & $\begin{array}{l}4.38 \\
(282.9) \\
(0.92)\end{array}$ & \\
\hline 4454 & $\begin{array}{l}3.73 \\
(332.1) \\
(0.04) \\
\end{array}$ & $\begin{array}{l}3.79 \\
(326.8) \\
(0.04) \\
\end{array}$ & & & & $\begin{array}{l}4.31 \\
(287.7) \\
(0.34) \\
\end{array}$ & $\begin{array}{l}4.33 \\
(286.5) \\
(0.73) \\
\end{array}$ & \\
\hline $\mathrm{C}=\mathrm{O} \cdots 1$-ring tilted & $\begin{array}{l}3.73 \\
(332.1) \\
(0.05) \\
\end{array}$ & $\begin{array}{l}3.78 \\
(328.4) \\
(0.05)\end{array}$ & & & & $\begin{array}{l}4.30 \\
(288.3) \\
(0.74) \\
\end{array}$ & $\begin{array}{l}4.33 \\
(286.5) \\
(0.34) \\
\end{array}$ & \\
\hline $\mathrm{NO}_{2}$-3-ring tilted & $\begin{array}{l}3.75 \\
(331.0) \\
(0.04) \\
\end{array}$ & & $\begin{array}{l}3.83 \\
(323.7) \\
(0.06) \\
\end{array}$ & & & $\begin{array}{l}4.28 \\
(289.5) \\
(0.69) \\
\end{array}$ & $\begin{array}{l}4.30 \\
(288.3) \\
(0.39)\end{array}$ & \\
\hline
\end{tabular}

In $\mathrm{Gm} 8 \mathrm{p}-\mathrm{B}$, the double 1-3 ring stack motif and modified cyclic $\mathrm{NO}_{2} \cdots \mathrm{CH}_{3}$ motif alternate to pack into 1D chains, which are linked together with the long-axis translation motif to 2D sheets (SI Figure 45). The $\mathrm{NO}_{2}$ 'backbone tilted motif is involved to link the adjacent 2D sheets in 3D structure of Gm8p - B. 


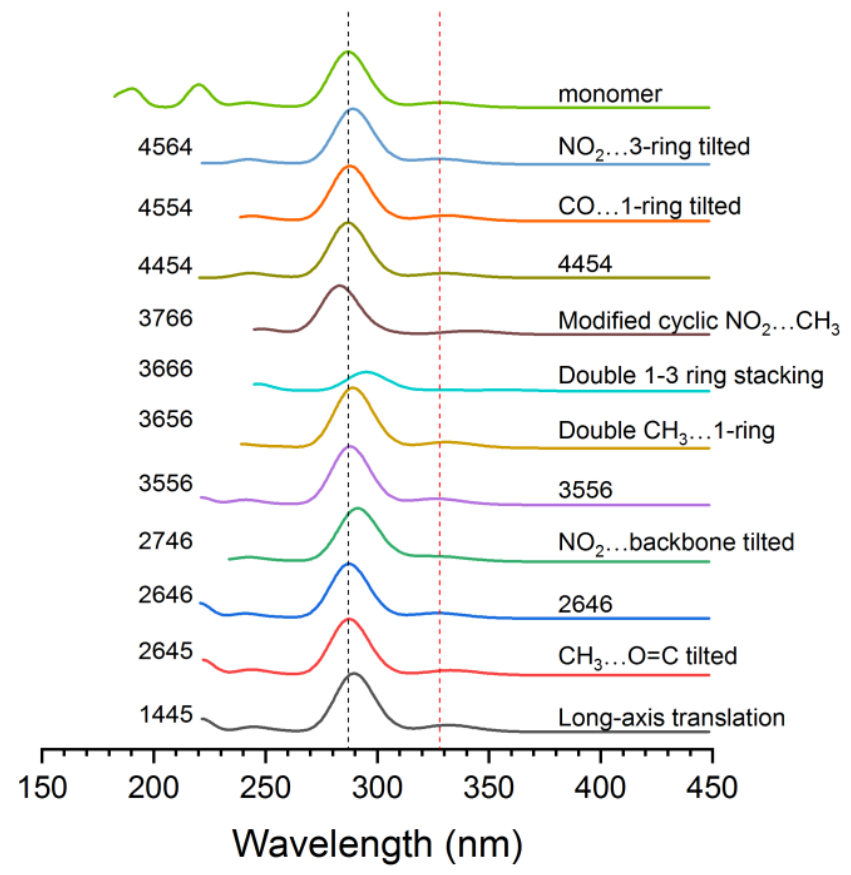

(a)

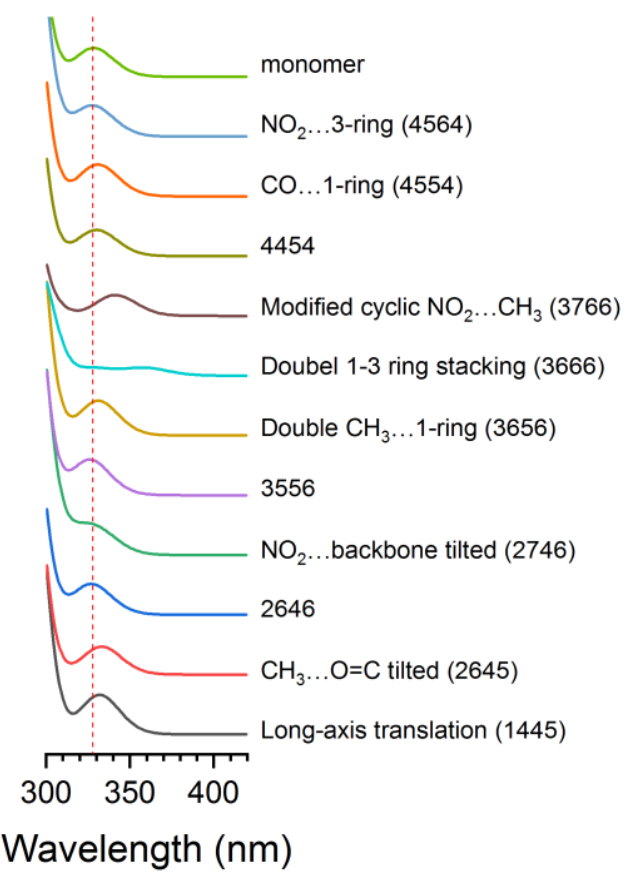

(b)

Figure 44 Absorption spectra of the dimers taken from Gm8p - B PBE-TS optimized structure, simulated using the first 18 excitations calculated by TD-DFT with $\omega B$ 97x. Each dimer is labelled as in Table 25 above using the ARU code for the second molecule and the qualitative description.

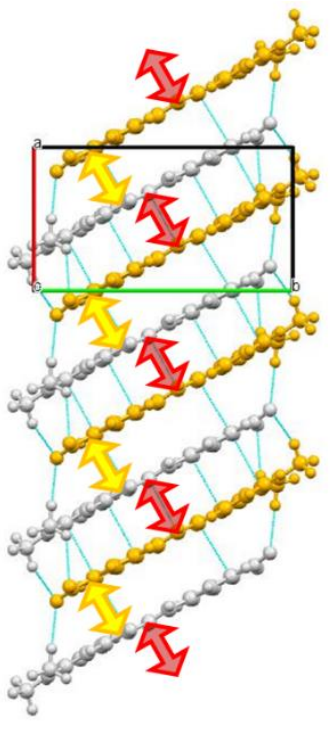

(a)

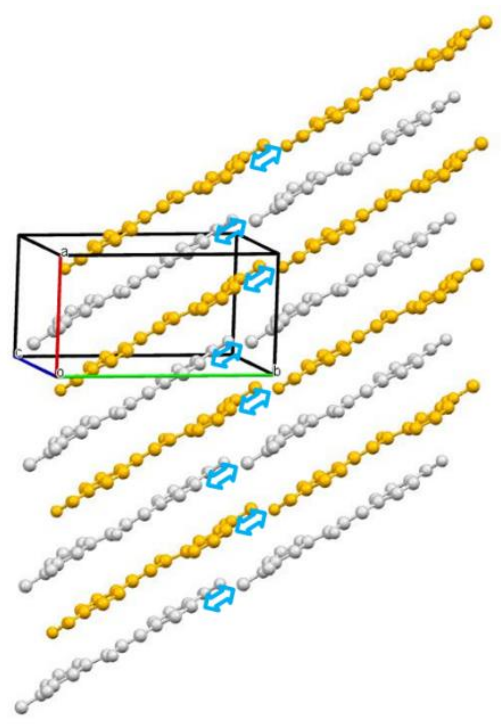

(b)

Figure 45 Packing of the most red-shifting dimer motifs in Gm8p - B:(a) double 1-3 ring stacking (red arrow) and modified cyclic $\mathrm{NO}_{2} \cdots \mathrm{CH}_{3}$ stacking alternate to form 1D stacks of $\mathrm{Gm} 8 \mathrm{p}$ molecules; (b) 1D stacks are linked through the long-axis translation motif into 2D sheets.

\subsubsection{Cumulative effect on UV-Vis spectra of stacks of dimers}

From the results of the set of dimers in Section 2.5.3.4, it is clear that some dimer motifs in the crystal structure of chalcone considerably red-shift the UV-Vis absorption. If the crystal packing has these redshifting dimer motifs close to each other, in a stack, there may be further cumulative effect on the redshifting of the UV-Vis spectra. Hence, TD-DFT calculations were performed on larger oligomer/stacks 
extracted from each crystal structure for the two most red-shifting dimer motifs for the HOMO-LUMO transition selected from SI Table 27, Table 29, Table 31 and Table 33. These two motifs are the nonsymmetry related molecules above and below a common molecule, so they combine to give one stack. This is the most " $\pi$ stacked" motifs for Gm8m - 0 , and the Gm8p polymorphs. The $\pi$ stack seen in Gm8m $-\mathrm{Y}$ is also considered.

\subsubsection{Gm8m - Y stack calculations}

The $\mathrm{NO}_{2}$-opposite and \#3766 dimers are the two most red-shifting motifs in $\mathrm{Gm} 8 \mathrm{~m}-\mathrm{Y}$ (SI Table 27), although both shifts are no more than $5 \mathrm{~nm}$. TD-DFT calculations were performed on the tetramer, hexamer and octamer $\mathrm{NO}_{2}$-opposite-3766 stacks (SI Figure 46 and Figure 47).
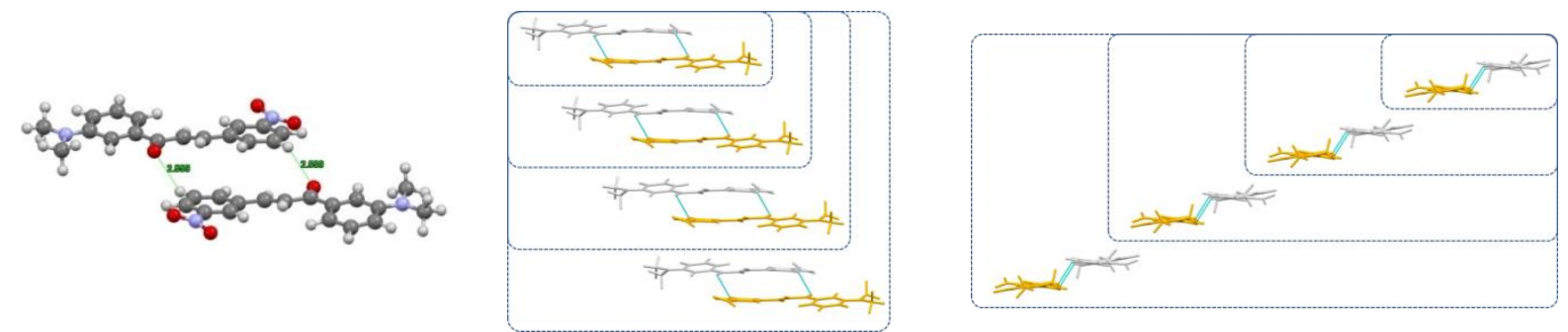

Figure $46 \mathrm{Gm8m}-\mathrm{Y} \mathrm{NO}$-opposite dimer (left), and NO $\mathrm{N}_{2}$-opposite-3766 stack as tetramer, hexamer and octamer (centre and right), shown in different sized rectangles in two views. Each $\mathrm{NO}_{2}$-opposite dimer consists of a white-yellow pair of molecules. Between two adjacent $\mathrm{NO}_{2}$-opposite dimers is the \#3766 motif.

The calculated TD-DFT UV-Vis transitions (SI Table 34) for the $\mathrm{NO}_{2}$-opposite tetramer, hexamer and octamer have two strong absorptions in the red-end of the absorption, one of which at $329 \mathrm{~nm}$, is in addition to those seen in the dimer, with the other one only slightly blue-shifted from the dimer peak at $323.4 \mathrm{~nm}$. Using the FWHM of $0.3 \mathrm{eV}$, the splitting of the peaks is not visible (SI Figure 47), and the oscillator strength average absorption position of the transitions shows a gradual red-shift of the absorption peak position from the dimer (at $323.4 \mathrm{~nm}$ ) to the octamer (at $329.4 \mathrm{~nm}$ ) (SI Table 34). Compared to the $\mathrm{Gm} 8 \mathrm{~m}-\mathrm{Y}$ monomer, the largest red-shift comes from the dimerization ( $+5.0 \mathrm{~nm})$ and gradually reduced when more molecules were added. Between hexamer and octamer, the relative redshift has reduced to $0.6 \mathrm{~nm}$. This indicates only a minor cumulative effect in the UV-Vis spectra of the linear-extending $\mathrm{NO}_{2}$-opposite-3766 oligomers, most possibly due to the weaker intermolecular interaction through the 3766 motif between the $\mathrm{NO}_{2}$-opposite dimers.

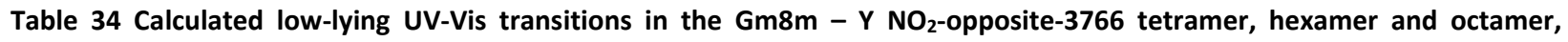
compared to those of the $\mathrm{Gm8m}-\mathrm{Y}$ monomer and the two dimers. *shift relative to the monomer, (+) for red-shift, (-) for blue-shift.

\begin{tabular}{|l|l|l|l|l|l|}
\hline & $\begin{array}{l}\Delta \mathrm{E} / \mathrm{eV}(/ \mathrm{nm}) \\
\text { Peak 1 }\end{array}$ & o.s. & $\begin{array}{l}\Delta \mathrm{E} / \mathrm{eV}(/ \mathrm{nm}) \\
\text { Peak 2 }\end{array}$ & o.s. & $\begin{array}{l}\text { absorption peak position } \\
\text { (shift in nm)* }\end{array}$ \\
\hline monomer & & & $3.89(318.4)$ & 0.0607 & 318.4 \\
\hline 3766 dimer & & & $3.83(323.4)$ & 0.0635 & $323.4(+5.0)$ \\
\hline NO$_{2}$-opposite dimer & & & $3.83(323.4)$ & 0.0811 & $323.4(+5.0)$ \\
\hline tetramer & $3.77(329.1)$ & 0.0467 & $3.84(322.7)$ & 0.0382 & $326.2(+7.8)$ \\
\hline hexamer & $3.77(329.2)$ & 0.0559 & $3.84(322.7)$ & 0.0255 & $327.2(+8.8)$ \\
\hline octamer & $3.76(329.4)$ & 0.0622 & $3.84(322.6)$ & 0.0191 & $327.8(+9.4)$ \\
\hline
\end{tabular}




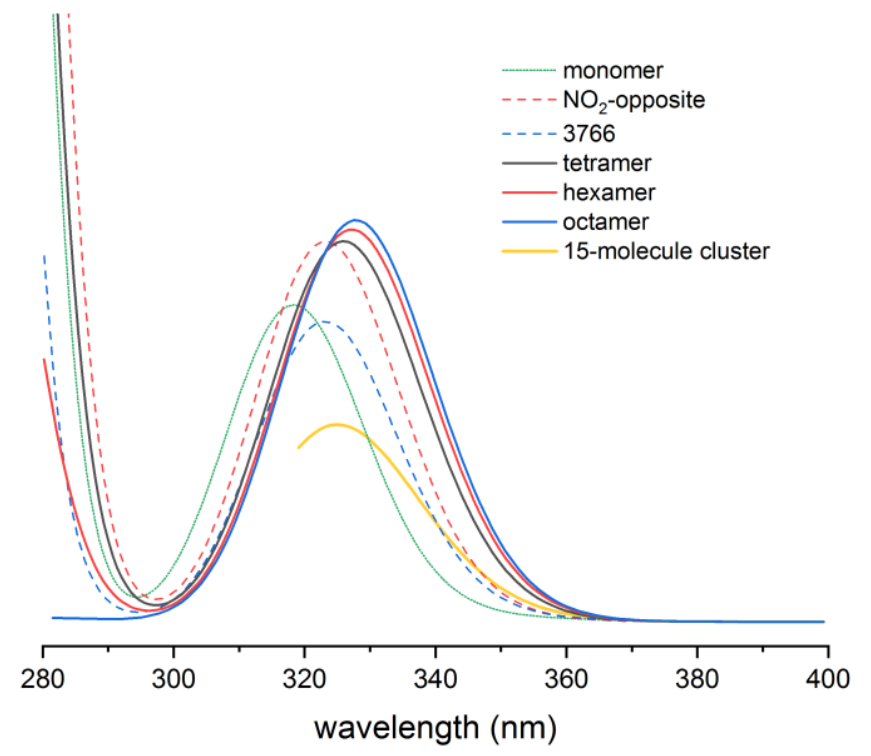

Figure 47 Calculated UV-Vis spectra of $\mathrm{NO}_{2}$-opposite-3766 oligomers, compared to that of the monomer, of the $\mathrm{NO}_{2}$-opposite dimer, of the \#3766 dimer and of a 15-molecule cluster of Gm8m - Y.

The only dimer motif involving an obvious $\pi-\pi$ stacking in $\mathrm{Gm} 8 \mathrm{~m}-\mathrm{Y}$, the half-stacking motif (Figure 39b), leads to the blue-shift of the HOMO-LUMO transition (Table 27), a trend that is maintained by extending the stack (Figure 48, Table 35).

Table 35 Calculated low-lying transitions in the $\mathrm{Gm} 8 \mathrm{~m}-\mathrm{Y}$ half-stacking dimer, tetramer, hexamer and octamer, compared to that of the $\mathrm{Gm8m}-\mathrm{Y}$ monomer. *shift relative to the monomer, (+) for red-shift, (-) for blue-shift.

\begin{tabular}{|l|l|l|l|l|l|l|l|}
\hline & $\begin{array}{l}\Delta \mathrm{E} / \mathrm{eV} \\
(/ \mathrm{nm})\end{array}$ & o.s. & $\begin{array}{l}\Delta \mathrm{E} / \mathrm{eV} \\
(/ \mathrm{nm})\end{array}$ & $\mathbf{0 . s .}$ & $\begin{array}{l}\Delta \mathrm{E} / \mathrm{eV} \\
(/ \mathrm{nm})\end{array}$ & o.s. & $\begin{array}{l}\text { absorption peak } \\
\text { position (shift in } \mathrm{nm} \text { * }\end{array}$ \\
\hline monomer & & & $\begin{array}{l}3.89 \\
(318.4)\end{array}$ & 0.0607 & & & 318.4 \\
\hline $\begin{array}{l}\text { Half-stacking } \\
\text { dimer }\end{array}$ & $\begin{array}{l}3.85 \\
(322.1)\end{array}$ & 0.0190 & & & $\begin{array}{l}3.96 \\
(313.0)\end{array}$ & 0.0358 & $316.2(-2.2)$ \\
\hline tetramer & $\begin{array}{l}3.84 \\
(322.9)\end{array}$ & 0.0088 & $\begin{array}{l}3.92 \\
(316.7)\end{array}$ & 0.0175 & $\begin{array}{l}3.96 \\
(313.2)\end{array}$ & 0.0217 & $316.3(-2.1)$ \\
\hline hexamer & 3.84 & 0.0058 & $\begin{array}{l}3.92 \\
(316.7)\end{array}$ & 0.0240 & $\begin{array}{l}3.96 \\
(313.4)\end{array}$ & 0.0147 & $316.5(-1.9)$ \\
\hline octamer & $(323.2)$ & & $\begin{array}{l}3.91 \\
(316.8)\end{array}$ & 0.0271 & $\begin{array}{l}3.96 \\
(313.5)\end{array}$ & 0.0110 & $316.6(-1.8)$ \\
\hline
\end{tabular}




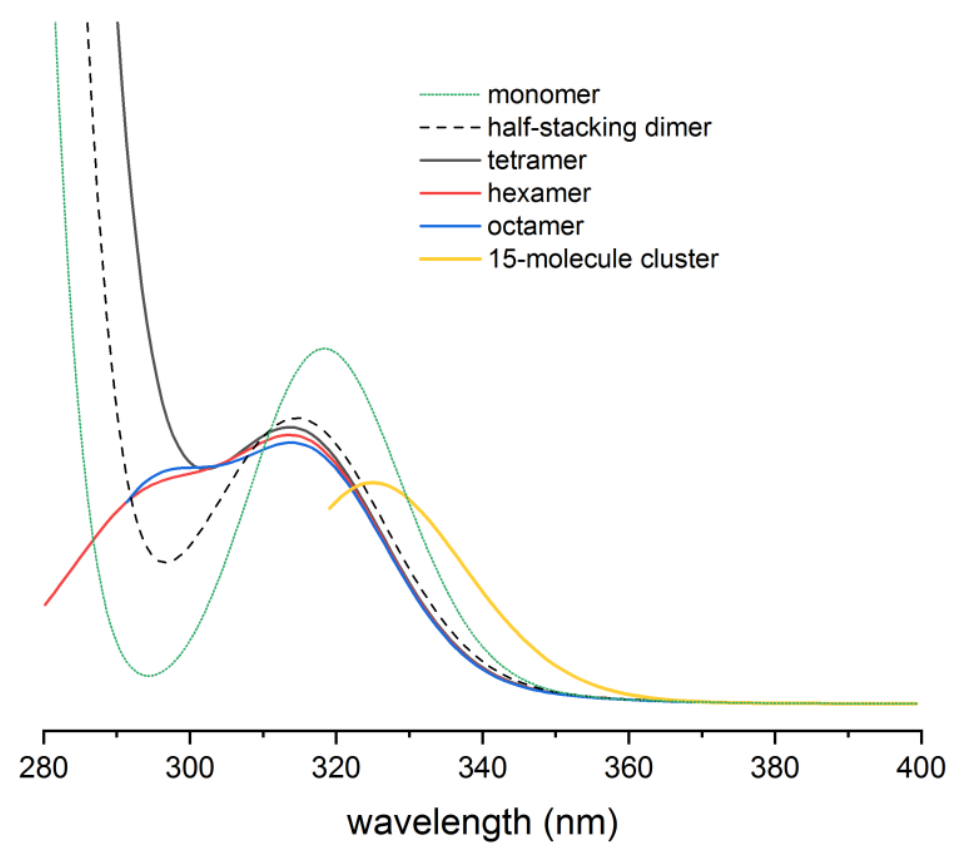

Figure 48 Calculated UV-Vis spectra of half-stacking oligomers, compared to that of the monomer, of the half-stacking dimer, and of a 15-molecule cluster of Gm8m - Y.

Hence stacks of $\mathrm{NO}_{2}$-opposite dimers, interlinked by 3766 motif, have slightly further red-shifted UV-Vis absorption (by $4.4 \mathrm{~nm}$ in peak position) than the dimers alone, which also only modestly red-shifted compared to the $\mathrm{Gm} 8 \mathrm{~m}-\mathrm{Y}$ monomer (by $5 \mathrm{~nm}$ ). Comparison with the excitations of a 15-molecule cluster, which includes all the dimer motifs in $\mathrm{Gm} 8 \mathrm{~m}-\mathrm{Y}$, but does not extend the stack, confirms that the extended stack is indeed necessary for the additional red-shift.

\subsubsection{Gm8m - 0 stack calculations}

Using the strongest red-shifting $\pi$ dimers of $\mathrm{Gm8m}-\mathrm{O}$ (SI Table 29), a tetramer, a hexamer and an octamer of the double 1-3 ring stacking dimer, combined with the 1-ring stacking motif, were constructed (Figure 49) and the TD-DFT UV-Vis spectra calculated (SI Table 36, Figure 50).
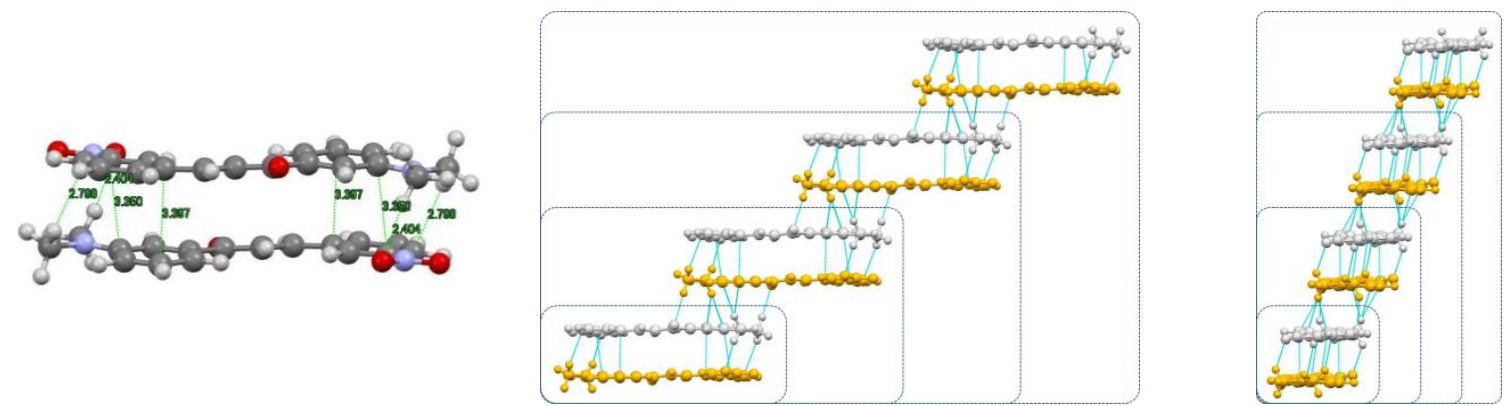

Figure 49 the double 1-3 ring stacking dimer in $\mathrm{Gm8m}-\mathrm{O}$ (left), and a stack of these dimers used to construct the tetramer, hexamer and octamer, shown in rectangles of increasing size, in two views (center and right). Between every two adjacent double 1-3 ring stacking dimers is the 1-ring stacking motif.

The two dimer components of this $\pi$ stack (SI Table 29), produces a red-shift of nearly $18 \mathrm{~nm}$ from the monomer HOMO-LUMO excitation at $319 \mathrm{~nm}$ from the 1-ring stacking dimer while the double 1-3 ring stacking motif splits the absorption into two peaks with one peak at $355 \mathrm{~nm}$, a red-shift of $37 \mathrm{~nm}$. When 
more dimers are added to the stack, as shown in SI Figure 50, there is a further red shift of the leading edge of the absorption which plateaus around $360 \mathrm{~nm}$ with a long absorption tail extending up to $400 \mathrm{~nm}$. These stacks produce a significant red-shift in absorbance relative to the 15-molecule cluster (SI Figure 35).

Table 36 Calculated low-lying transitions in the Gm8m - 0 double 1-3 ring stacking dimer, tetramer, hexamer and octamer, compared to that of the $\mathrm{Gm} 8 \mathrm{~m}-\mathrm{O}$ monomer.

\begin{tabular}{|l|l|l|l|l|}
\hline & $\begin{array}{l}\Delta \mathrm{E} / \mathrm{eV} \\
(/ \mathrm{nm})\end{array}$ & o.s. & $\begin{array}{l}\Delta \mathrm{E} / \mathrm{eV} \\
(/ \mathrm{nm})\end{array}$ & o.s. \\
\hline monomer & & & $3.89(318.9)$ & 0.0769 \\
\hline $\begin{array}{l}\text { 1-ring stacking } \\
\text { dimer }\end{array}$ & $3.68(336.6)$ & 0.0506 & & \\
\hline $\begin{array}{l}\text { Double 1-3 ring } \\
\text { stacking dimer }\end{array}$ & $3.49(355.4)$ & 0.0174 & $3.86(321.5)$ & 0.0434 \\
\hline tetramer & $3.39(365.5)$ & 0.0106 & $3.85(322.2)$ & 0.0108 \\
& $3.47(357.6)$ & 0.0089 & & 0.0231 \\
& $3.64(340.5)$ & & & 0.0119 \\
\hline hexamer & $3.38(367.3)$ & 0.0090 & $3.68(337.4)$ & 0.0153 \\
& $3.40(365.0)$ & 0.0056 & $3.85(322.3)$ & \\
\hline octamer & $3.47(357.7)$ & 0.0059 & & 0.0152 \\
& $3.63(341.6)$ & 0.0040 & & 0.0115 \\
& $3.38(367.3)$ & 0.0121 & $3.68(336.9)$ & \\
\hline
\end{tabular}

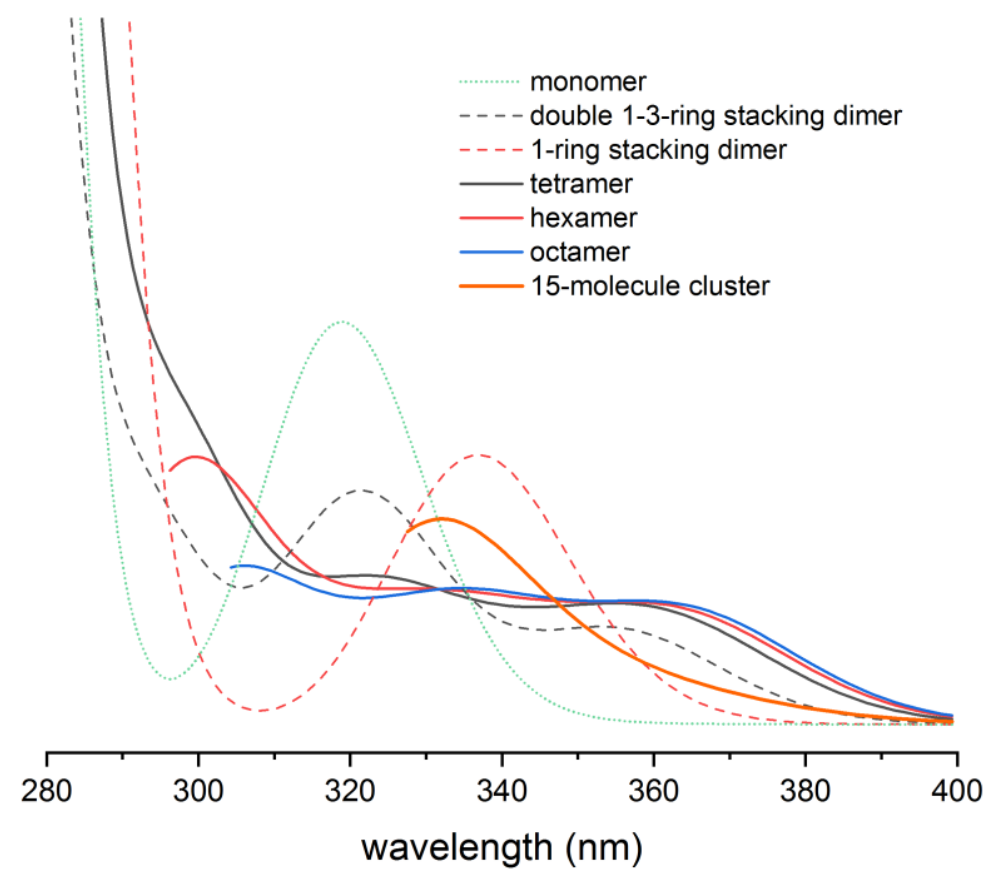

Figure 50 Calculated UV-Vis spectra of the double 1-3 ring stacking oligomers in Gm8m - 0, compared to that of the monomer, of the $\mathrm{NO}_{2}$-opposite dimer, of the \#3766 dimer and of a 15-molecule cluster of $\mathrm{Gm8m}-0$. 


\subsubsection{Comparison of TD-DFT calculations for 15-molecular clusters in Gm8m}

Focusing on the red-end spectral region, the calculated UV-Vis spectra for the 15-molecule clusters (SI Figure 34 and Figure 35) of Gm8m - Y and Gm8m - O polymorphs, shown in SI Figure 51, clearly showed a shift to the red for the 15-molecule cluster of the $\mathrm{Gm} 8 \mathrm{~m}$ - 0 polymorph, whose peak absorption is redshifted by $7 \mathrm{~nm}$ compared to that of $\mathrm{Gm} 8 \mathrm{~m}-\mathrm{Y}$, and has a more extended tail towards the red end.

By comparing the UV-Vis spectra calculated using the complete molecular shell of a central molecule, with those calculated pairwise as separate dimers, shown in Figure 52, we can see clearly that for the Gm8m 0 , the long absorption tail to the red-end of the spectrum can be attributed to the double 1-3 ring stacking and the 1-ring stacking dimer motifs, while no contribution from the dimers in $\mathrm{Gm} 8 \mathrm{~m}-\mathrm{Y}$ can red-shift the absorptions in a similar way. This justifies the choice of stacks of dimers in Section 2.5.4.2.

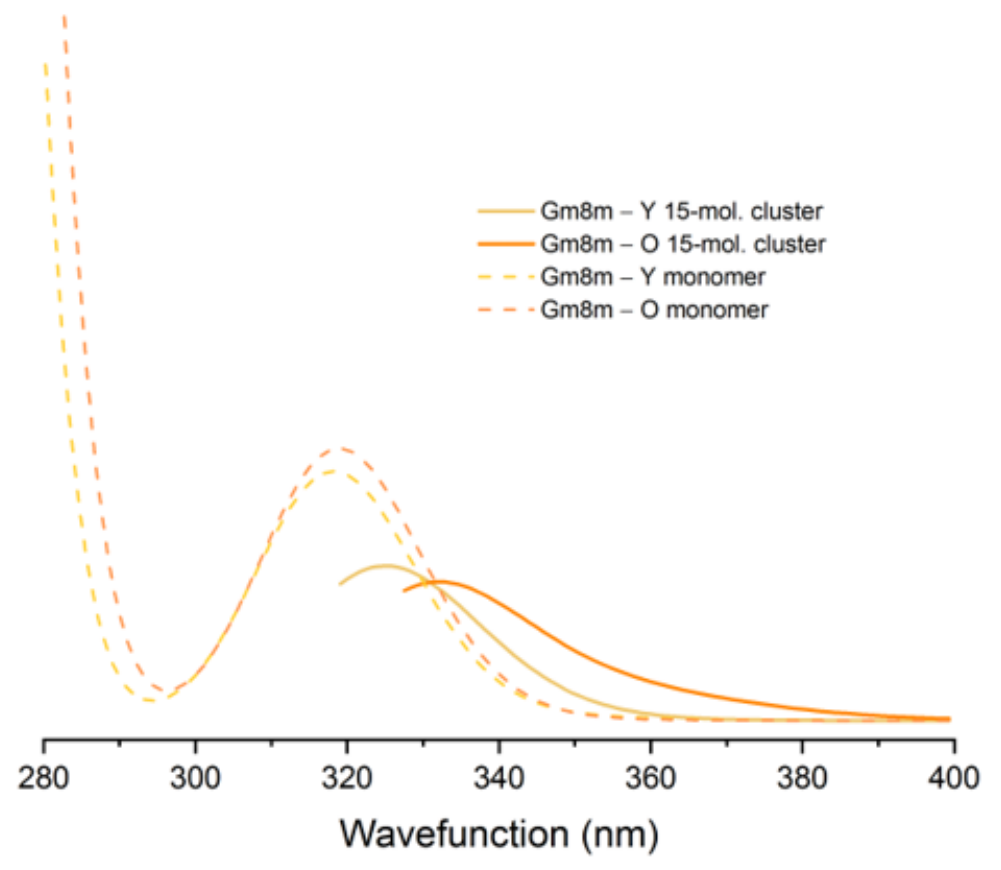

Figure 51 Calculated UV-Vis spectra from the lowest 30 electronic excitations using Turbomole RI-TD-DFT with the electronic excitations of 15-moelcule clusters of $\mathrm{Gm8m}-\mathrm{Y}$ and $\mathrm{Gm8m}-\mathrm{O}$ polymorphs, as shown in SI Figure 34 and Figure 35 . Also shown are calculated UV-Vis spectra (in dashed lines) of monomers as in Gm8m - Y and Gm8m - O polymorphs. 


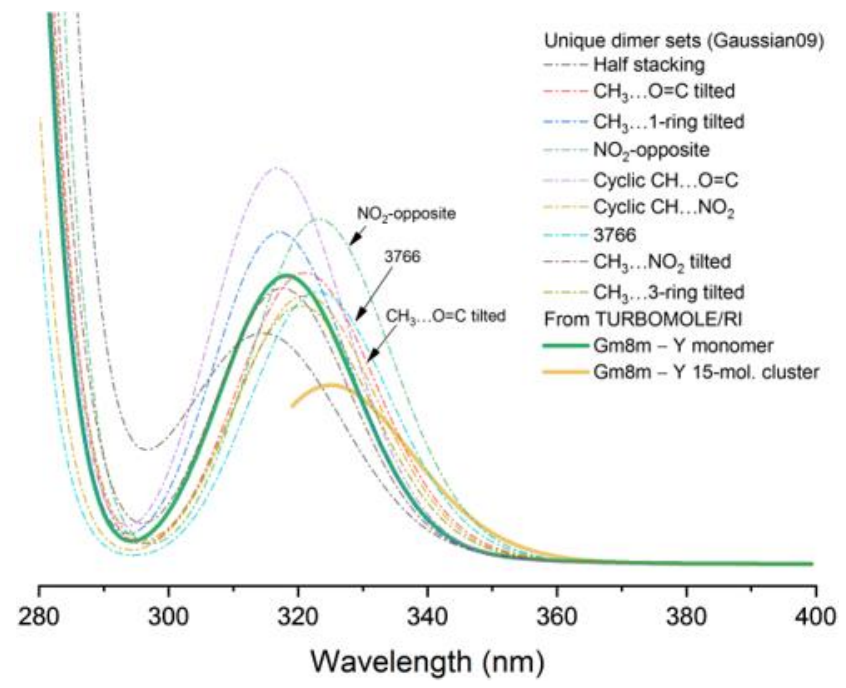

(a)

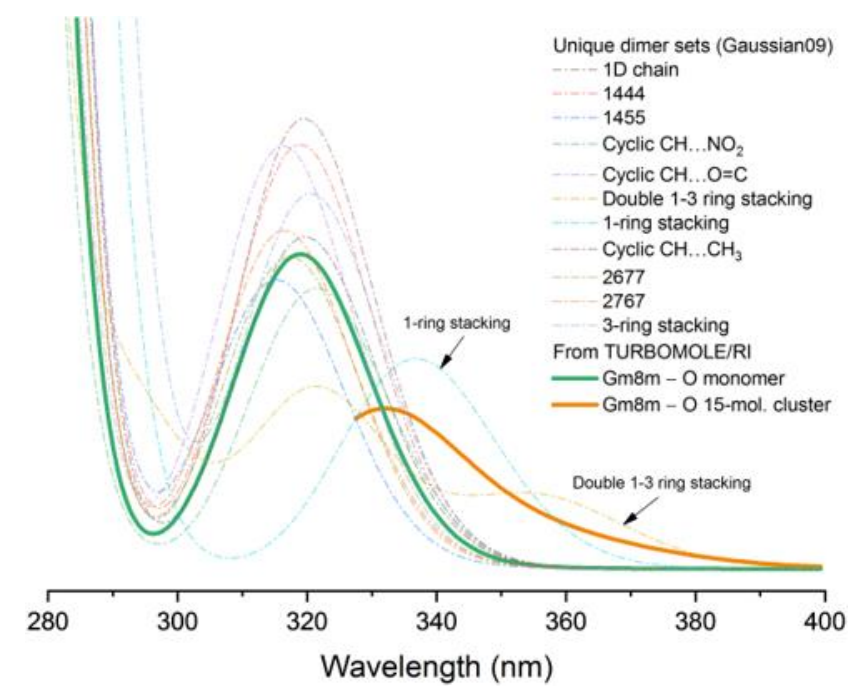

(b)

Figure 52 Calculated UV-Vis spectra from the lowest 30 electronic excitations using Turbomole RI-TD-DFT with the electronic excitations of 15-molecule clusters of $\mathrm{Gm} 8 \mathrm{~m}-\mathrm{Y}$ and $\mathrm{Gm} 8 \mathrm{~m}-\mathrm{O}$ polymorphs, as shown in SI Figure 34 and Figure 35, compared to the full set of dimer motifs in Gm8m - Y and Gm8m - 0 polymorphs.

\subsubsection{Causes of color differences between $\mathrm{Gm8m}$ polymorphs}

Contrasting the calculated UV-Vis spectra of: 1) $\mathrm{Gm} 8 \mathrm{~m}-\mathrm{Y}$ and $\mathrm{Gm} 8 \mathrm{~m}-\mathrm{O}$ monomers; 2) the 15-molecule cluster of $\mathrm{Gm} 8 \mathrm{~m}-\mathrm{Y}$ and $\mathrm{Gm8m}-0$; 3) the NO2-opposite dimer in $\mathrm{Gm} 8 \mathrm{~m}-\mathrm{Y}$ and the double 1-3 ring stacking dimer in $\mathrm{Gm8m}-\mathrm{O}$; and 4) stacks of most red-shifting dimers together (SI Figure 53), it becomes clear that the most significant contribution to the color difference between the two polymorphs, comes from the double 1-3 ring stacked dimers in $\mathrm{Gm} 8 \mathrm{~m}-0$, which is able to red-shift by nearly $40 \mathrm{~nm}$ of the onset of UV-Vis absorption. Their effective stacking in $\mathrm{Gm} 8 \mathrm{~m}-\mathrm{O}$ red-shifts the absorption further by 13 $\mathrm{nm}$, more than doubling the stacking effect in $\mathrm{Gm} 8 \mathrm{~m}-\mathrm{Y}$ stacks for the $\mathrm{NO}_{2}$-opposite dimers. This contributes to the color of the $\mathrm{Gm8m}-\mathrm{O}$ polymorph. All in all, the stronger color of $\mathrm{Gm} 8 \mathrm{~m}-\mathrm{O}$ is mostly the result of a more chromophoric dimer motif, enhanced by their effective stacking.

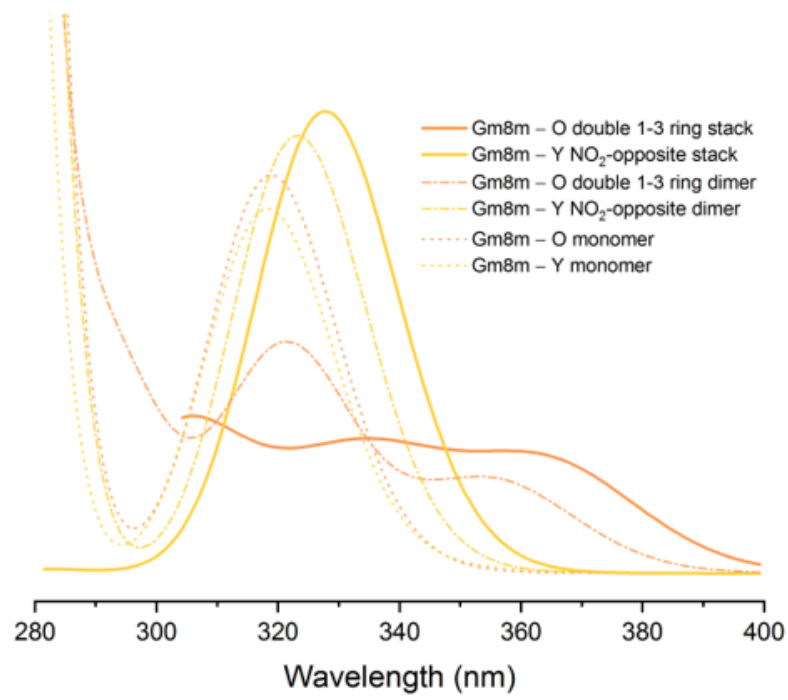

Figure 53 Comparing the UV-Vis spectra of Gm8m - Y and Gm8m - O: molecular conformation (dotted lines), dimerization (dash-dotted lines), 15-molecular clusters (dashed lines) and stacks of strongest red-shifting dimer motifs (solid lines). 


\subsubsection{Gm8p - R stack calculations}

Gm8p-R has many dimer motifs which red-shift the absorption relative to the monomer (SI Table 31). As the cyclic $\mathrm{NO}_{2} \cdots \mathrm{CH}_{3}$ motif shows a considerable red-shift with a high oscillator strength (SI Figure 42b), its combination with the most red-shifting motif, the double 1-3 ring stacking dimer, were extracted from the crystal structure to give tetramer, hexamer and octamer stacks (Figure 49) for TD-DFT calculations (SI Table 37 and Figure 55). This produced only a small additional red-shift no more than $5 \mathrm{~nm}$ for the octamer despite the close contacts.
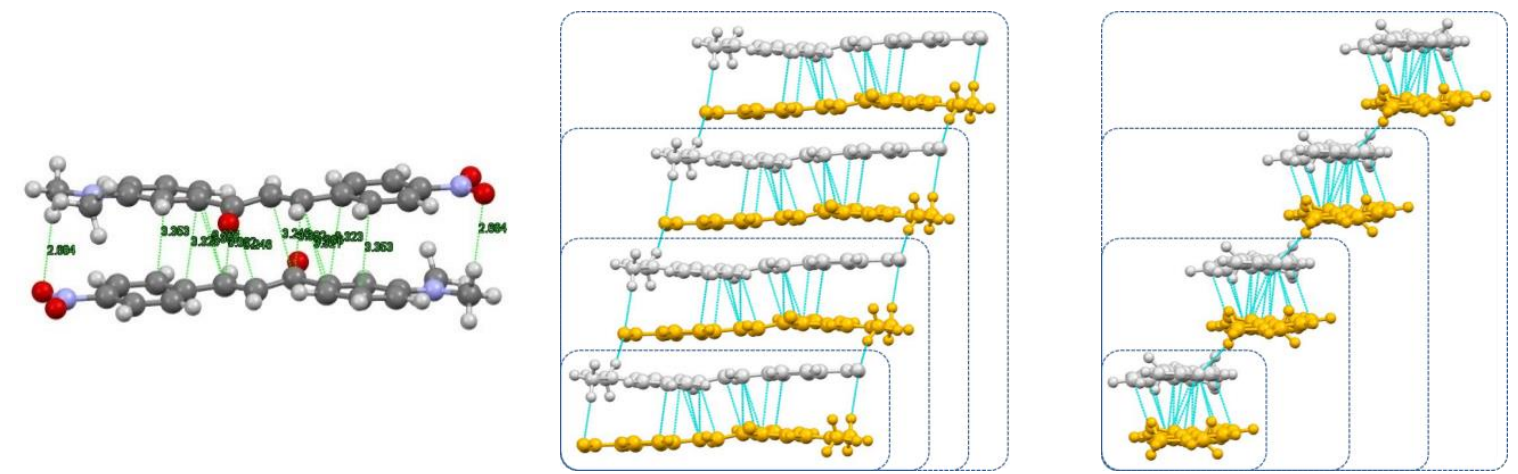

Figure 54 The double 1-3 ring stacking dimer in Gm8p - R (left), and a stack of these dimers used to construct the tetramer, hexamer and octamer, shown in rectangles of increasing size, in two views (center and right). Between every two adjacent double 1-3 ring stacking dimers is the cyclic $\mathrm{NO}_{2} \cdots \mathrm{CH}_{3}$ motif.

Table 37 Calculated low-lying transitions in the Gm8p - R double 1-3 ring stacking dimer, tetramer, hexamer and octamer, compared to that of the Gm8p - R monomer.

\begin{tabular}{|l|l|l|l|l|l|l|}
\hline & $\Delta \mathrm{E} / \mathrm{eV}(\mathrm{nm})$ & $\mathbf{0 . s .}$ & $\Delta \mathrm{E} / \mathrm{eV}(\mathrm{nm})$ & $\mathbf{0 . s .}$ & $\Delta \mathrm{E} / \mathrm{eV}(\mathrm{nm})$ & 0.s. \\
\hline monomer & & & & & $3.83(323.8)$ & 0.1066 \\
\hline${\text { Cyclic } \mathrm{NO}_{2}-\mathrm{CH}_{3} \text { dimer }}_{\text {Double 1-3 ring }}$ & & & $3.71(334.1)$ & 0.1020 & & \\
\hline ttacking dimer & $3.57(346.9)$ & 0.0400 & & & $3.82(324.6)$ & 0.0533 \\
\hline tetramer & $3.55(349.6)$ & 0.0285 & $3.73(332.3)$ & 0.0298 & $3.83(324.1)$ & 0.0240 \\
\hline hexamer & $3.51(353.6)$ & 0.0097 & $3.73(332.4)$ & 0.0300 & $3.83(324.0)$ & 0.0162 \\
& $3.54(349.9)$ & 0.0207 & $3.74(331.5)$ & 0.0082 & & \\
\hline & $3.51(353.7)$ & 0.0155 & $3.73(332.6)$ & 0.0108 & & \\
& $3.54(349.9)$ & 0.0148 & $3.73(332.2)$ & 0.0244 & & \\
& & & $3.74(331.3)$ & 0.0077 & & \\
\hline
\end{tabular}




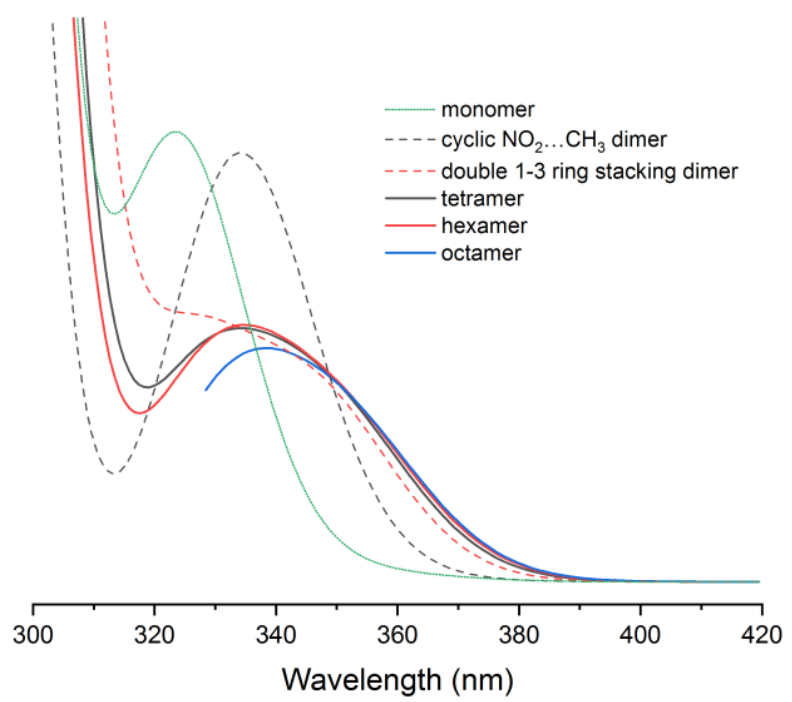

Figure 55 Calculated UV-Vis spectra of the double 1-3 ring stacking dimer, tetramer, hexamer and octamer in Gm8p - R , compared to that of the $\mathrm{Gm} 8 \mathrm{p}-\mathrm{R}$ monomer, of the cyclic $\mathrm{NO}_{2} \cdots \mathrm{CH}_{3}$ dimer.

\subsubsection{Gm8p - B stack calculations}

The two most red-shifting dimers for Gm8p - B (SI Table 33), the double 1-3-ring stacking dimer and the modified cyclic $\mathrm{NO}_{2} \cdots \mathrm{CH}_{3}$ motif, combine to form the oligomeric stacks in SI Figure 56 . There is a further red-shift and increase in intensity from the Gm8p - B tetramer (SI Table 38 and Figure 57), though the spectra of larger stacks are very similar.
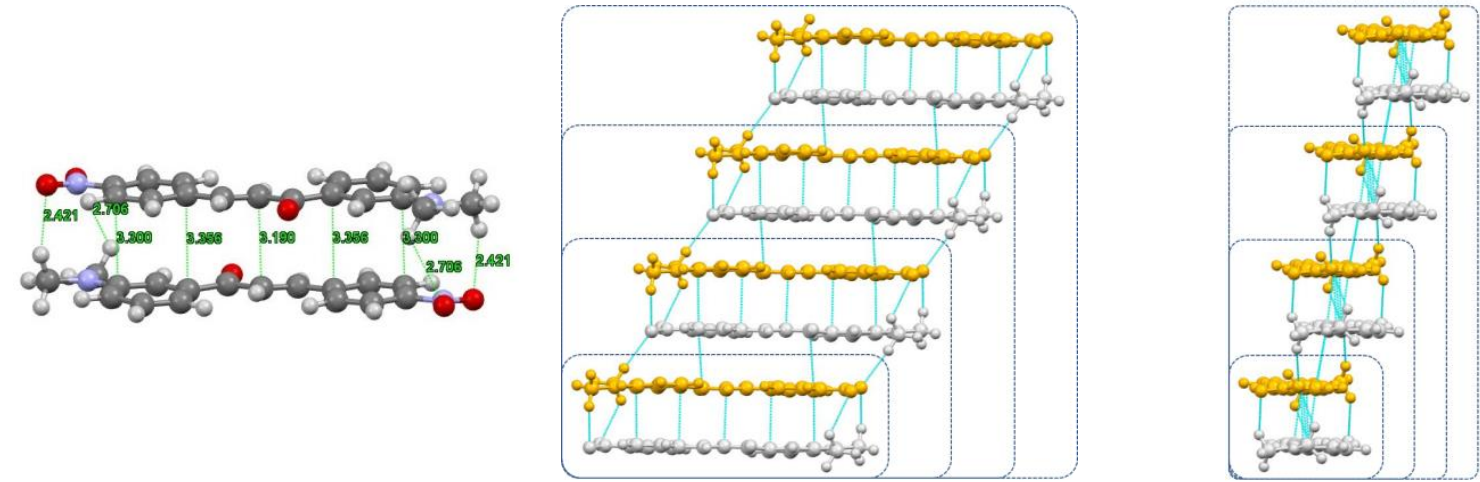

Figure 56 The double 1-3 ring stacking dimer in Gm8p - B (left), and a stack of these dimers used to construct the tetramer, hexamer and octamer, shown in rectangles of increasing size, in two views (center and right). Between every two adjacent double 1-3 ring stacking dimers is the modified cyclic $\mathrm{NO}_{2} \cdots \mathrm{CH}_{3}$ motif. 
Table 38 Calculated low-lying transitions in the Gm8p - B double 1-3 ring stacking dimer, tetramer, hexamer and octamer, compared to that of the Gm8p - B monomer.

\begin{tabular}{|c|c|c|c|c|c|c|}
\hline & $\begin{array}{l}\Delta \mathrm{E} / \mathrm{eV} \\
(/ \mathrm{nm})\end{array}$ & o.s. & $\Delta \mathrm{E} / \mathrm{eV}(/ \mathrm{nm})$ & o.s. & $\Delta \mathrm{E} / \mathrm{eV}(/ \mathrm{nm})$ & o.s. \\
\hline monomer & & & & & $3.78(327.8)$ & 0.0917 \\
\hline $\begin{array}{l}\text { modified cyclic } \\
\mathrm{NO}_{2} \cdot \mathrm{CH}_{3} \text { dimer }\end{array}$ & & & $3.63(341.5)$ & 0.0660 & & \\
\hline $\begin{array}{l}\text { Double 1-3 ring } \\
\text { stacking dimer }\end{array}$ & 3.45 (359.2) & 0.0513 & $3.73(332.7)$ & 0.0101 & 3.78 (327.7) & 0.0413 \\
\hline tetramer & $\begin{array}{l}3.39 \text { (365.6) } \\
3.43(361.6)\end{array}$ & $\begin{array}{l}0.0138 \\
0.0331\end{array}$ & 3.66 (338.7) & 0.0135 & 3.78 (328.0) & 0.0233 \\
\hline hexamer & $\begin{array}{l}3.38(367.2) \\
3.39(366.3) \\
3.43(361.5)\end{array}$ & $\begin{array}{l}0.0079 \\
0.0155 \\
0.0227 \\
\end{array}$ & $\begin{array}{l}3.66(339.2) \\
3.68(336.9)\end{array}$ & $\begin{array}{l}0.0069 \\
0.0144\end{array}$ & 3.78 (328.0) & 0.0154 \\
\hline octamer* & $\begin{array}{l}3.38 \text { (366.9) } \\
3.38 \text { (366.4) } \\
3.43 \text { (361.4) }\end{array}$ & $\begin{array}{l}0.0087 \\
0.0183 \\
0.0163\end{array}$ & $3.68(336.8)$ & 0.0198 & & \\
\hline
\end{tabular}

* with 30 excitations included, the highest excitation energy calculated is $3.73 \mathrm{eV}(332.3 \mathrm{~nm})$.

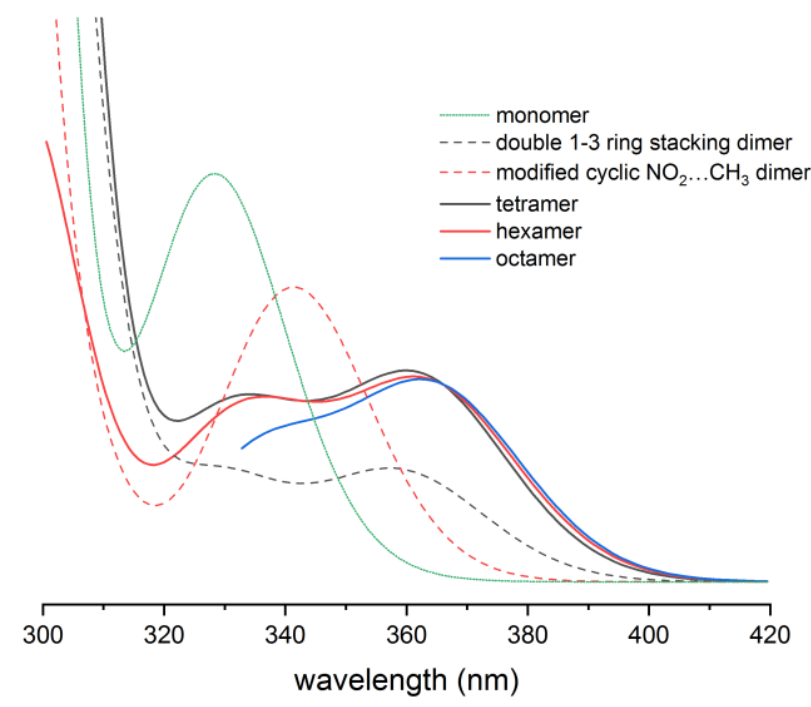

Figure 57 Calculated UV-Vis spectra of the double 1-3 ring stacking dimer, tetramer, hexamer and octamer in Gm8p - B, compared to that of the $\mathrm{Gm} 8 \mathrm{p}-\mathrm{B}$ monomer, of the modified cyclic $\mathrm{NO}_{2} \cdots \mathrm{CH}_{3}$ dimer.

\subsubsection{Causes of color differences between Gm8p polymorphs}

A dominating contribution to the difference in the color of the two $\mathrm{Gm} 8 \mathrm{p}$ polymorphs is the more effective dimer stacking in Gm8p - B. This becomes clear when the calculated UV-Vis spectra of Gm8p - B and Gm8p - R monomers, the double 1-3 ring stacked dimers, and stacks of the dimers in both polymorphs are compared in Figure 58. The monomer absorption for the conformers in the two polymorphs differs by only $4 \mathrm{~nm}$, but the packing in Gm8p - B red-shifts its onset absorption considerably. 


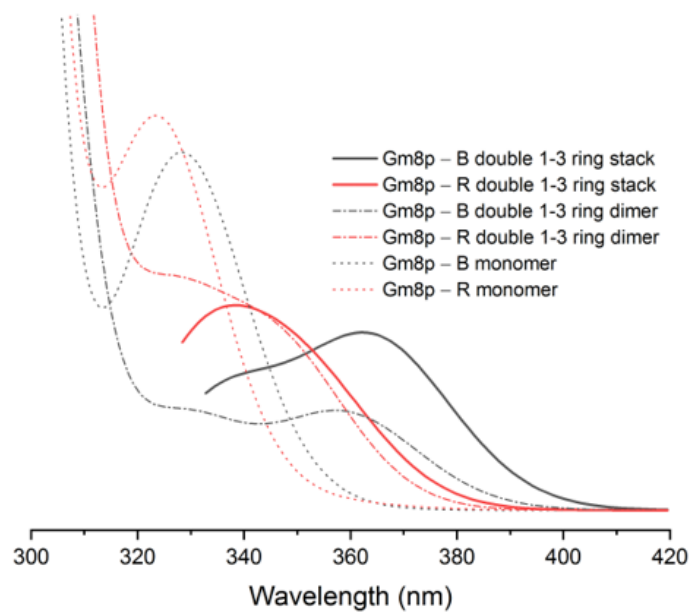

Figure 58 Comparing the UV-Vis spectra of Gm8p-B and Gm8p-R : molecular conformation (dotted lines), dimerization (dashdotted lines) and stacks of strongest red-shifting dimer motifs (solid lines).

\subsubsection{Equivalence of optical transitions calculated with Gaussian 09 and Turbomole}

The equivalence of Gaussian09 and Turbomole calculations was established by examining the excitation energies and oscillator strengths of electronic excitations of Gm8m monomers (SI Table 39), showing those calculated with TURBOMOLE/RI method are nearly identical to those calculated with Gaussian09/TD-DFT, apart from a minor reranking of the HOMO-LUMO transition as the 3rd excitation, which is because there is a very small difference in energy between the $2 \mathrm{nd}$ and the $3 \mathrm{rd}$ excitations.

Table 39 the first 6 electronic excitations of Gm8m monomers calculated with Gaussian TD-DFT and with TURBOMOLE/RI method. In parentheses are the calculated oscillator strengths (o.s.) for any excitation with 0.5 . $>0.01$.

\begin{tabular}{|l|l|l|l|}
\hline \multicolumn{2}{|c|}{ Gm8m - Y monomer (PBE-TS opt.) } & \multicolumn{2}{c|}{ Gm8m - O monomer (PBE-TS opt.) } \\
\hline Gaussian TDDFT & TURBOMOLE/RI & Gaussian TDDFT & TURBOMOLE/RI \\
\hline 349.4 & 350.7 & 349.5 & 350.5 \\
\hline $318.4(0.06)$ & 318.6 & 322.0 & 322.7 \\
\hline 317.9 & $318.2(0.06)$ & $318.9(0.08)$ & $319.0(0.08)$ \\
\hline 280.8 & 281.2 & 282.1 & 282.5 \\
\hline $266.4(0.92)$ & $266.4(0.92)$ & $269.0(0.90)$ & $268.9(0.91)$ \\
\hline 260.7 & 260.5 & 264.7 & 264.5 \\
\hline
\end{tabular}

\subsection{Calculation of diamagnetic susceptibility tensors}

The diamagnetic susceptibility is another crystal property that is dominated by the packing of the $\pi$ systems, though unlike color, it can be well approximated by the tensorial addition of the molecular diamagnetic susceptibility tensors. Hence it is a property that reflects the differences in orientations of the functional groups, such as conjugated systems, that have a very anisotropic magnetics response, rather than the interactions between the $\pi$ systems.

The diamagnetic susceptibility of the polymorphs of Gm8m and Gm8p were calculated at the PBE-TS optimized structures with CASTEP using PBE and the same cut-off energies and k-point grids as used in structure optimization. More details of the method can be found in ref 20 . The calculated eigenvalues of 
diamagnetic susceptibility tensors (SI Table 40) show that there is only a small variation in the isotropic and smallest components of the tensor between all four crystals. However, $\chi_{\max }^{\text {cryst }}$ is significantly larger for the forms which have a larger red-shift in their optical spectrum (Gm8m - O and Gm8p-B) and Gm8m - $O$ has a particularly small $\chi_{\text {mid }}^{\text {cryst }}$ similar to $\chi_{\min }^{\text {cryst }}$. The orientation of the diamagnetic susceptibility tensor to the crystal packing and estimated morphology is in SI Figure 59 for Gm8m and Figure 60 for Gm8p.

Table 40 Calculated crystal diamagnetic susceptibilities (in cgs-ppm) of Gm8m and Gm8p polymorphs.

\begin{tabular}{|l|l|l|l|l|l|l|}
\hline polymorphs & \multicolumn{1}{|c|}{$\chi_{\min }^{\text {cryst }}$} & \multicolumn{1}{|c|}{$\chi_{\text {mid }}^{\text {cryst }}$} & $\chi_{\max }^{\text {cryst }}$ & \multicolumn{1}{|c|}{$\chi_{\text {iso }}^{\text {cryst }}$} & $\Delta \chi_{\text {an }}^{\text {cryst }}$ & alignment \\
\hline Gm8m & & & & & & \\
\hline $\mathrm{Gm} 8 m-Y$ & -109.5 & -138.7 & -222.1 & -156.8 & -112.6 & $\chi_{\text {mid }}^{\text {cryst }}$ along $b$ \\
\hline $\mathrm{Gm} 8 m-0$ & -100.2 & -108.1 & -258.3 & -155.5 & -158.2 & None \\
\hline Gm8p & & & & & & \\
\hline$G m 8 p-R$ & -104.7 & -168.9 & -196.3 & -156.6 & -91.6 & $\chi_{\max }^{\text {cryst }}$ along $b$ \\
\hline$G m 8 p-B$ & -110.7 & -148.4 & -232.8 & -164.0 & -122.2 & $\chi_{\text {mid }}^{\text {cryst }}$ along $b$ \\
\hline
\end{tabular}
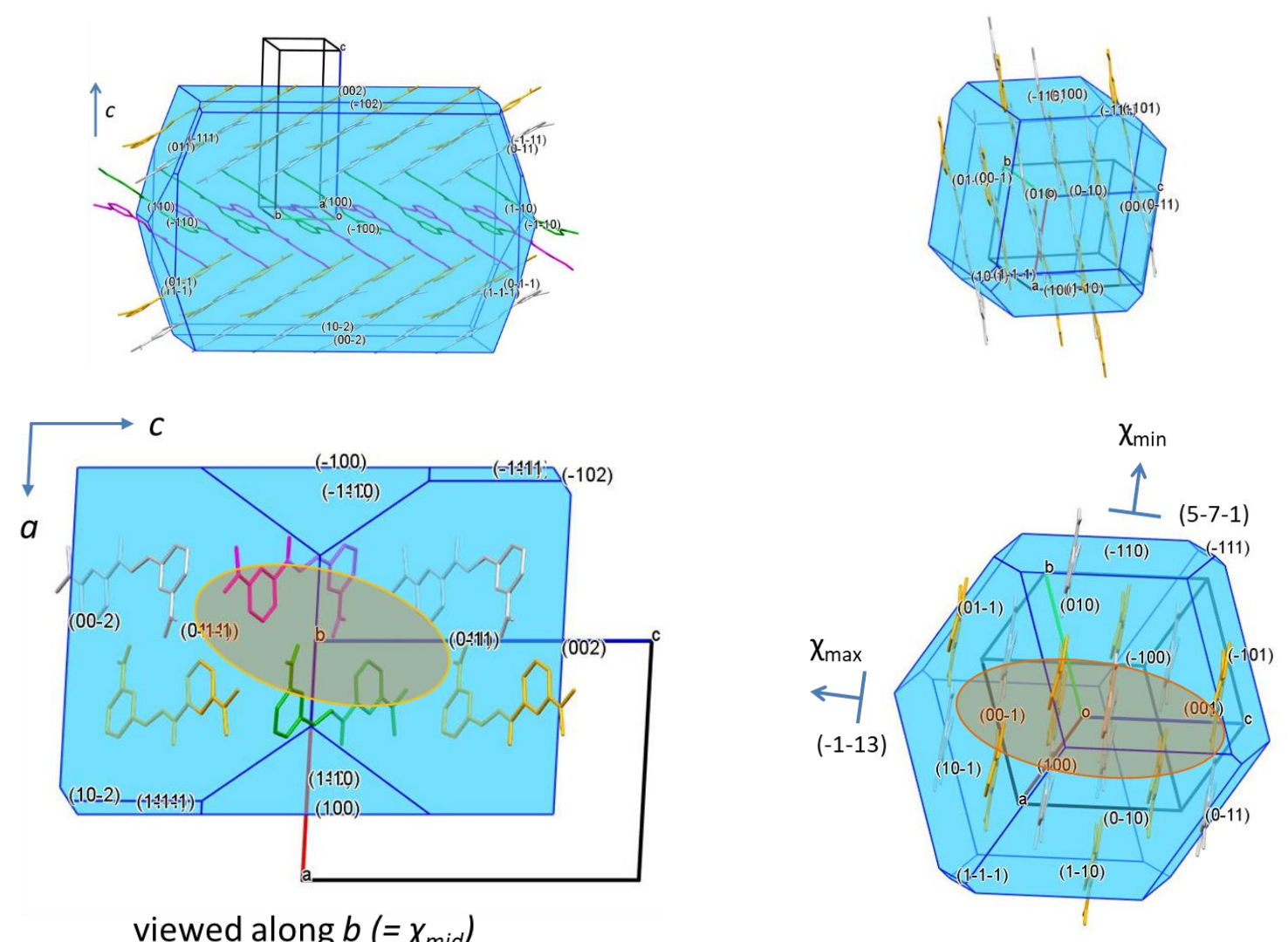

viewed along $b\left(=\chi_{\text {mid }}\right)$

\section{Gm8m - Y}

Gm8m - 0

Figure 59 Crystal structure and unit cell overlaid on BFDH morphologies of Gm8m - Y and Gm8m - 0, with the approximate direction of $\chi_{\max }$ shown for $\mathrm{Gm} 8 \mathrm{~m}-Y$ (top row). Calculated diamagnetic susceptibility $(\chi)$ ellipsoid overlaid on the crystal structure of $\mathrm{Gm} 8 \mathrm{~m}-Y$ and $\mathrm{Gm} 8 \mathrm{~m}-\mathrm{O}$ (bottom row), with the eigenvalues of $\chi$ plotted to the same scale. The BDFH morphology, which is estimated from the lattice spacing, and the crystal packing were calculated using Mercury. 

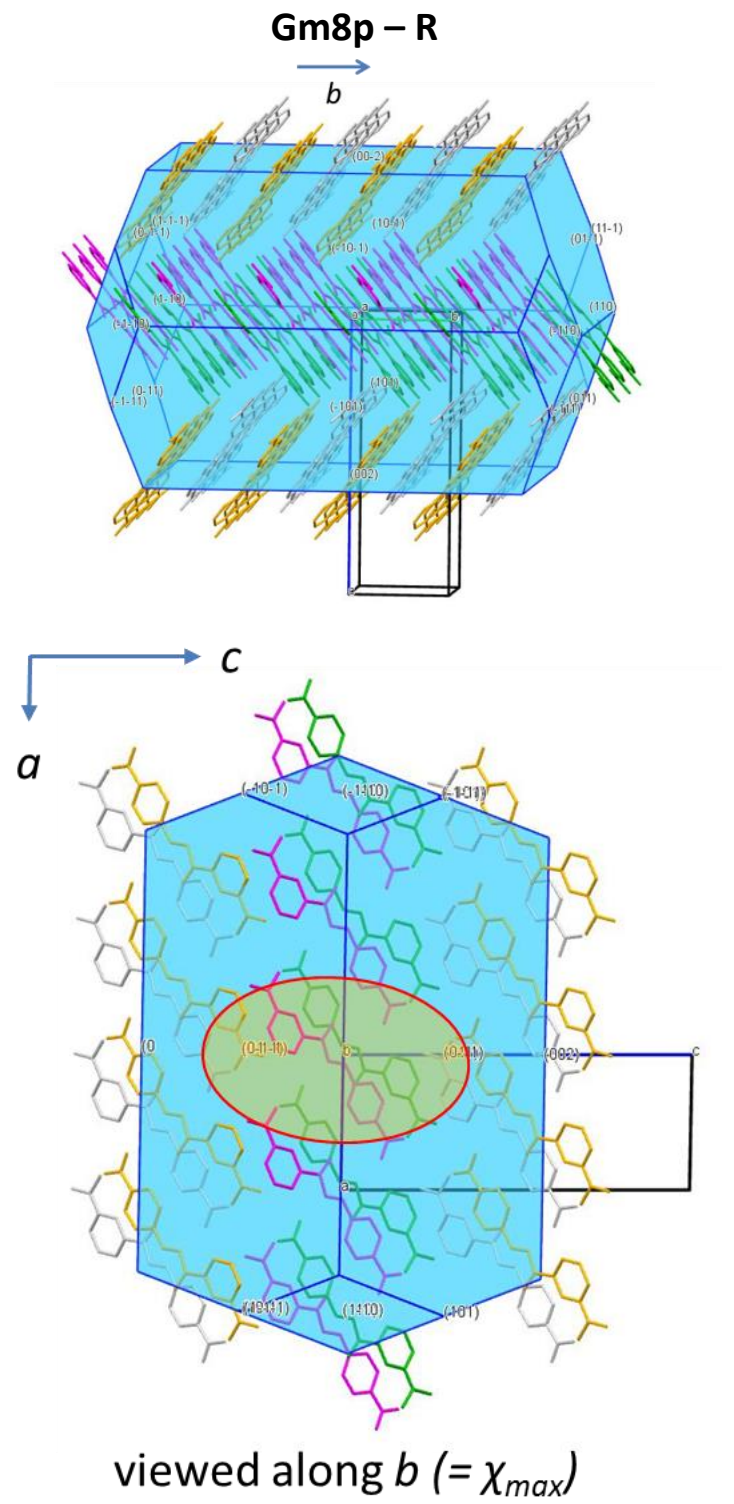

Gm8p - B
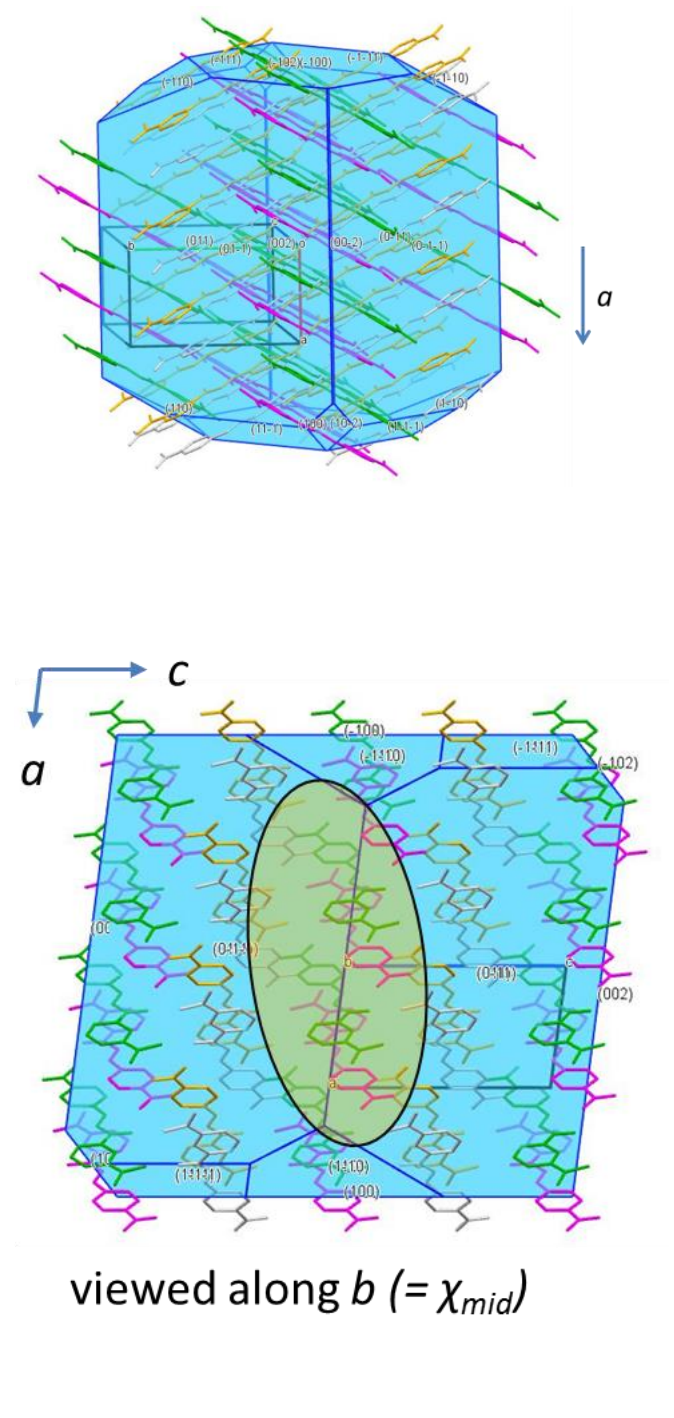

Figure 60 Crystal structure and unit cell overlaid on BFDH morphologies of Gm8p - R and Gm8p - B, with the approximate direction of $\chi \max$ shown (top row). Calculated diamagnetic susceptibility $(\chi)$ ellipsoid overlaid on the crystal structure of $\mathrm{Gm} 8 \mathrm{p}$ $-R$ and $\mathrm{Gm} 8 \mathrm{~m}-\mathrm{B}$ (bottom row), with the eigenvalues of $\chi$ plotted to the same scale. The BDFH morphology, which is estimated from the lattice spacing, and the crystal packing were calculated using Mercury. 


\section{References}

1. Doebelin, N.; Kleeberg, R., Profex: a graphical user interface for the Rietveld refinement program BGMN. Journal of Applied Crystallography 2015, 48, 1573-1580.

2. Georgieva, D.; Jansen, J.; Sikharulidze, I.; Jiang, L.; Zandbergen, H.; Abrahams, J., Evaluation of Medipix2 detector for recording electron diffraction data in low dose conditions. J. Instrum. 2011, 6, C01033.

3. Palatinus, L.; Brazda, P.; Jelinek, M.; Hrda, J.; Steciuk, G.; Klementova, M., Specifics of the data processing of precession electron diffraction tomography data and their implementation in the program PETS2.0. Acta Cryst. Sec. B., Struc. Sci. Cryst. Eng. Mat. 2019, 75, 512-522.

4. Vasileiadis, M.; Pantelides, C. C.; Adjiman, C. S., Prediction of the crystal structures of axitinib, a polymorphic pharmaceutical molecule. Chem, Eng. Sci. 2015, 121, 60-76.

5. Pantelides, C. C.; Adjiman, C. S.; Kazantsev, A. V., General Computational Algorithms for Ab Initio Crystal Structure Prediction for Organic Molecules. Top. Curr. Chem. 2014, 345, 25-58.

6. Habgood, M.; Sugden, I. J.; Kazantsev, A. V.; Adjiman, C. S.; Pantelides, C., Efficient Handling of Molecular Flexibility in Ab Initio Generation of Crystal Structures. J. Chem. Theory Comp. 2015, 11, 19571969.

7. $\quad$ Price, S. L.; Leslie, M.; Welch, G. W. A.; Habgood, M.; Price, L. S.; Karamertzanis, P. G.; Day, G. M., Modelling Organic Crystal Structures using Distributed Multipole and Polarizability-Based Model Intermolecular Potentials. Phys. Chem. Chem. Phys. 2010, 12, 8478-8490.

8. Abdullahi, S. S.; Güner, S.; Koseoglu, Y.; Musa, I. M.; I., A. B.; Abdulhamid, M. I., Sımple Method for the Determınatıon of Band Gap of a Nanopowdered Sample Usıng Kubelka Munk Theory. J. Niger. Ass. Math. Phys. 2016, 35, 241-246.

9. Clark, S. J.; Segall, M. D.; Pickard, C. J.; Hasnip, P. J.; Probert, M. J.; Refson, K.; Payne, M. C., First principles methods using CASTEP. Z. Kristallogr. Cryst. Mater. 2005, 220, 567-570.

10. Tkatchenko, A.; Scheffler, M., Accurate Molecular Van Der Waals Interactions from Ground-State Electron Density and Free-Atom Reference Data. Phys. Rev. Lett. 2009, 102, 073005.

11. Grimme, S., Accurate description of van der Waals complexes by density functional theory including empirical corrections. J. Comp. Chem. 2004, 25, 1463-1473.

12. Ambrosetti, A.; Reilly, A. M.; DiStasio, R. A.; Tkatchenko, A., Long-range correlation energy calculated from coupled atomic response functions. J Chem. Phys. 2014, 140, 18A508.

13. Hinuma, Y.; Pizzi, G.; Kumagai, Y.; Oba, F.; Tanaka, I., Band structure diagram paths based on crystallography. Comp. Mater. Sci. 2017, 128, 140-184.

14. Frisch, M. J.; Trucks, G. W.; Schlegel, H. B.; Scuseria, G. E.; Robb, M. A.; Cheeseman, J. R.; Scalmani, G.; Barone, V.; Mennucci, B.; Petersson, G. A.; Nakatsuji, H.; Caricato, M.; Li, X.; Hratchian, H. P.; Izmaylov, A. F.; Bloino, J.; Zheng, G.; Sonnenberg, J. L.; Hada, M.; Ehara, M.; Toyota, K.; Fukuda, R.; Hasegawa, J.; Ishida, M.; Nakajima, T.; Honda, Y.; Kitao, O.; Nakai, H.; Vreven, T.; Montgomery, J. A., Jr; Peralta, J. E.; Ogliaro, F.; Bearpark, M.; Heyd, J. J.; Brothers, E.; Kudin, K. N.; Staroverov, V. N.; Kobayashi, R.; Normand, J.; Raghavachari, K.; Rendell, A.; Burant, J. C.; Iyengar, S. S.; Tomasi, J.; Cossi, M.; Rega, N.; Millam, J. M.; Klene, M.; Knox, J. E.; Cross, J. B.; Bakken, V.; Adamo, C.; Jaramillo, J.; Gomperts, R.; Stratmann, R. E.; Yazyev, O.; Austin, A. J.; Cammi, R.; Pomelli, C.; Ochterski, J. W.; Martin, R. L.; Morokuma, K.; Zakrzewski, V. G.; Voth, G. A.; Salvador, P.; Dannenberg, J. J.; Dapprich, S.; Daniels, A. D.; Farkas, Ö.; Foresman, J. B.; Ortiz, J. V.; Cioslowski, J.; Fox, D. J. Gaussian 09, Revision D.01, 2009.

15. Peach, M. J. G.; Benfield, P.; Helgaker, T.; Tozer, D. J., Excitation energies in density functional theory: An evaluation and a diagnostic test. J. Chem. Phys. 2008, 128, 44118-44118.

16. Jacquemin, D.; Moore, B.; Planchat, A.; Adamo, C.; Autschbach, J., Performance of an Optimally Tuned Range-Separated Hybrid Functional for 0-0 Electronic Excitation Energies. J. Chem. Theory Comput. 2014, 10, 1677-1685. 
17. Spek, A. L., Structure validation in chemical crystallography. Acta Cryst. Sec. D 2009, 65, 148-155.

18. Gelbrich, T.; Hursthouse, M. B., A versatile procedure for the identification, description and quantification of structural similarity in molecular crystals. CrystEngComm 2005, 7, 324-336.

19. Holden, J. R.; Du, Z. Y.; Ammon, H. L., Prediction of Possible Crystal-Structures For C-, H-, N-, Oand F-Containing Organic Compounds. J. Comput. Chem. 1993, 14, 422-437.

20. Guo, R.; Uddin, M. N.; Price, L. S.; Price, S. L., Calculation of Diamagnetic Susceptibility Tensors of Organic Crystals: From Coronene to Pharmaceutical Polymorphs. J. Phys. Chem. A 2020, 124, 1409-1420. 